Aus dem Institut für Neuro- und Sinnesphysiologie

(Prof. Dr. rer. nat. S. O. Rizzoli)

im Zentrum Physiologie und Pathophysiologie

der Medizinischen Fakultät der Universität Göttingen

\title{
Evaluierung einer oralen Antioxidantien- Therapie in einem Mausmodell für das Rett-Syndrom
}

\author{
INAUGURAL-DISSERTATION \\ zur Erlangung des Doktorgrades \\ für Zahnmedizin \\ der Medizinischen Fakultät der \\ Georg-August-Universität zu Göttingen
}

vorgelegt von

Lena Rinne

aus

Hildesheim

Göttingen 2021 
Dekan:

\section{Betreuungsausschuss}

Betreuer/in:

Ko-Betreuer/in:

\section{Prüfungskommission}

Referent/in:

Ko-Referent/in:

Drittreferent/in:

Datum der mündlichen Prüfung: $\quad$ 07.09.2021
Prof. Dr. rer. nat. M. Müller

Prof. Dr. rer. nat. T. Dresbach

Prof. Dr. rer. nat. M. Müller

Prof. Dr. rer. nat. T. Dresbach

Prof. Dr. med. N. Miosge 
Hiermit erkläre ich, die Dissertation mit dem Titel „Evaluierung einer oralen Antioxidantien-Therapie in einem Mausmodell für das Rett-Syndrom“ eigenständig angefertigt und keine anderen als die von mir angegebenen Quellen und Hilfsmittel verwendet zu haben.

Göttingen, den 12.03.2021

(Unterschrift) 
Die Daten, auf denen die vorliegende Arbeit basiert, wurden teilweise publiziert:

Can K, Menzfeld C, Rinne L, Rehling P, Kügler S, Golubiani G, Dudek J, Müller M (2019): Neuronal redox-imbalance in Rett syndrome affects mitochondria as well as cytosol, and is accompanied by intensified mitochondrial $\mathrm{O}_{2}$ consumption and ROS release. Front Physiol 10, 479 


\section{Inhaltsverzeichnis}

Abbildungsverzeichnis.............................................................................................III

Tabellenverzeichnis ....................................................................................................... IV

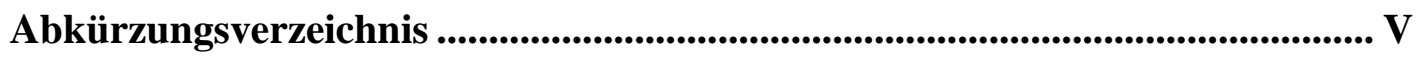

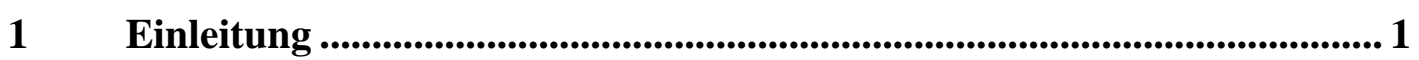

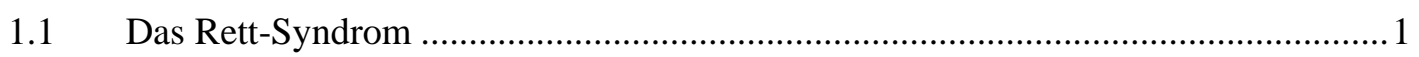

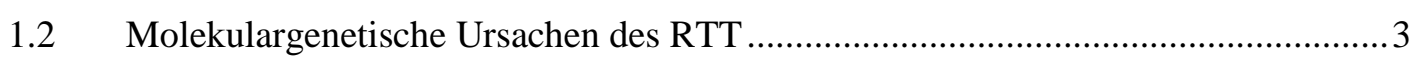

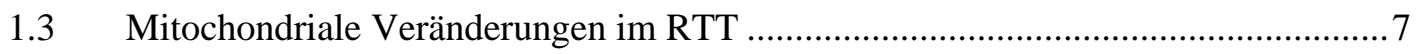

1.4 Reaktive Sauerstoffspezies und oxidativer Stress.................................................... 9

1.5 Oxidativer Stress im RTT und assoziierte Therapieansätze …................................12

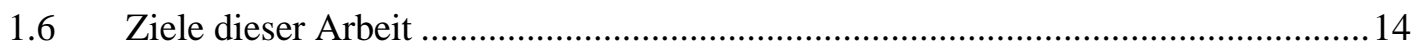

2 Material und Methoden ........................................................................... 15

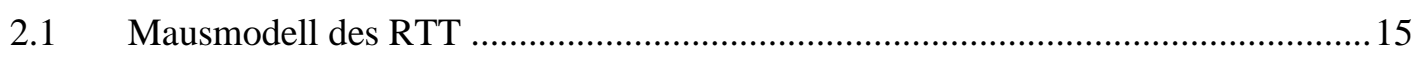

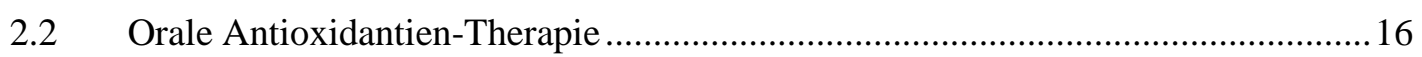

2.3 Herstellung und Auswertung Nissl-gefärbter Hirnschnitte...................................... 18

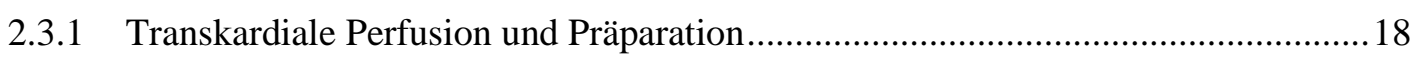

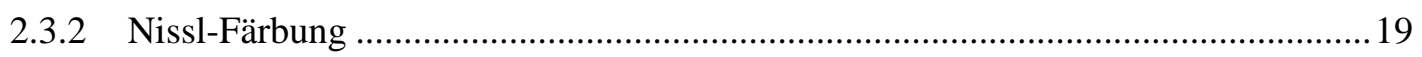

2.3.3 Auswertung der nach Nissl gefärbten Hirnschnitte …….........................................20

2.4 Messung der $\mathrm{H}_{2} \mathrm{O}_{2}$-Produktion isolierter Mitochondrien........................................22

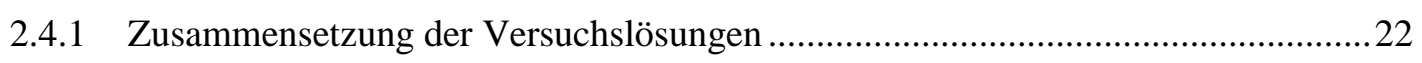

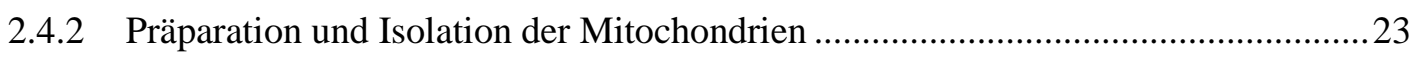

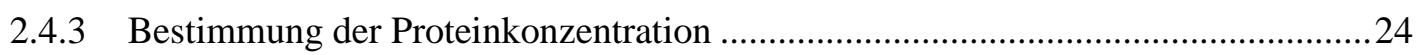

2.4.4 Messung der $\mathrm{H}_{2} \mathrm{O}_{2}$-Produktion mit Amplex UltraRed..........................................24

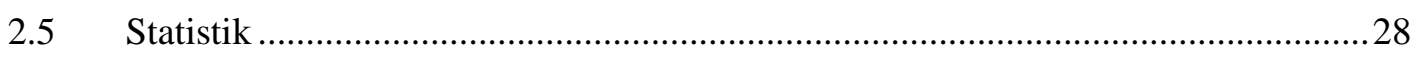

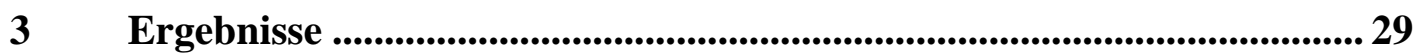

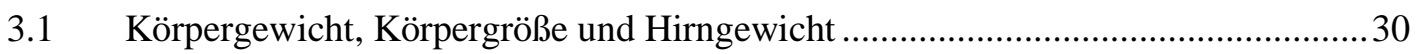

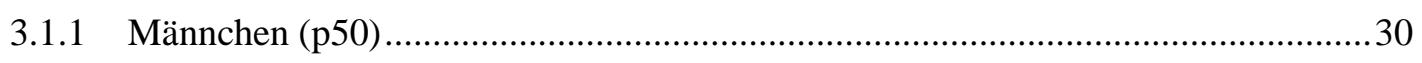

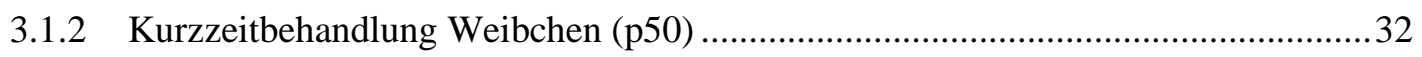

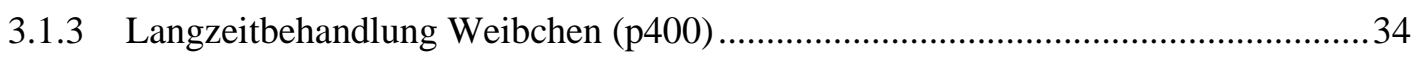

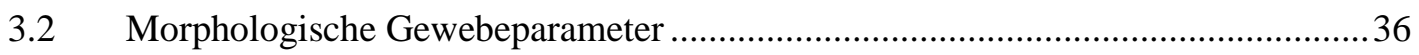

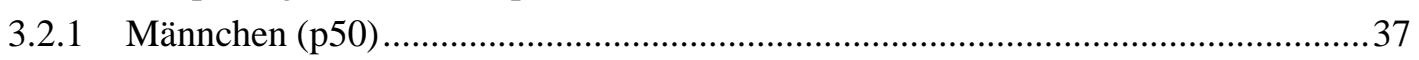

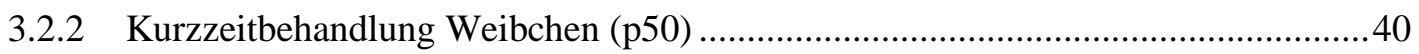

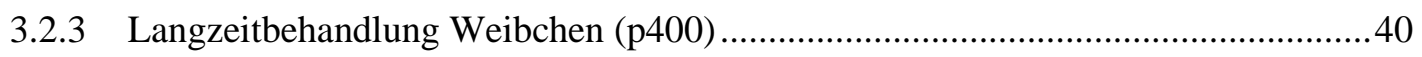

$3.3 \quad \mathrm{H}_{2} \mathrm{O}_{2}$-Produktion isolierter Mitochondrien ............................................................ 46 


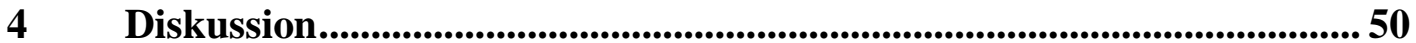

4.1 Einfluss der Antioxidantien-Therapie auf Körpergröße, Körpergewicht und

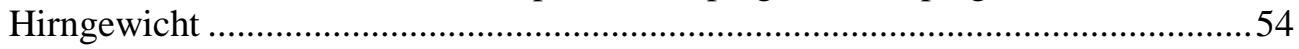

4.2 Antioxidantien-Therapie verbessert morphologische Gewebeparameter .................55

4.3 Ausmaß der mitochondrialen $\mathrm{H}_{2} \mathrm{O}_{2}$-Produktion unter Antioxidantien-Therapie......57

4.4 Limitationen des Studiendesigns und Ausblick .......................................................59

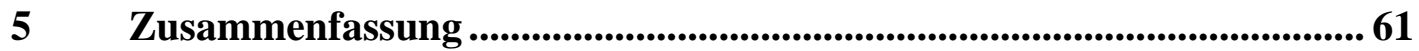

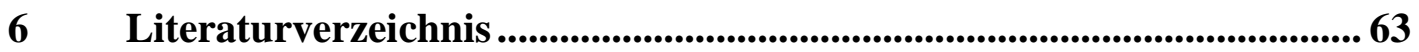




\section{Abbildungsverzeichnis}

Abbildung 1: $M E C P 2-G e n s t r u k t u r$. .5

Abbildung 2: Schematische Darstellung des humanen Methyl-CpG-Bindeprotein 2. .........6

Abbildung 3: Entstehung von ROS im Rahmen der mitochondrialen Atmungskette.......... 10

Abbildung 4: Kreislauf der vermehrten Entstehung von oxidativem Stress im RTT. ......... 12

Abbildung 5: Anfertigung von Hirnschnitten. ......................................................... 19

Abbildung 6: Durchführung der Nissl-Färbung..................................................... 20

Abbildung 7: Beurteilung morphologischer Gewebeparameter........................................2 21

Abbildung 8: Spektrofluorometer SAFAS Flx-Xenius....................................................25

Abbildung 9: Reaktion von Amplex Red zu Resorufin. ...............................................26

Abbildung 10: Schematischer Versuchsaufbau der Fluoreszenzspektroskopie. ................ 27

Abbildung 11: Körpergewicht, Körpergröße und Hirngewicht männlicher Mäuse (p50). ..31

Abbildung 12: Körpergröße und Hirngewicht weiblicher Versuchsgruppen (p50)............33

Abbildung 13: Körpergewicht und Hirngewicht weiblicher Versuchsgruppen (p400)......35

Abbildung 14: Morphometrische Analyse histologischer Schnittbilder. ...........................37

Abbildung 15: Darstellung morphologischer Gewebeparameter männlicher Mäuse (p50). 39

Abbildung 16: Darstellung morphologischer Gewebeparameter weiblicher Mäuse (p50)..42

Abbildung 17: Morphologische Gewebeparameter weiblicher Mäuse (p400) - I.............44

Abbildung 18: Morphologische Gewebeparameter weiblicher Mäuse (p400) - II.............45

Abbildung 19: $\mathrm{H}_{2} \mathrm{O}_{2}$-Produktion isolierter kortikaler Mitochondrien...............................47

Abbildung 20: Überschießende $\mathrm{H}_{2} \mathrm{O}_{2}$-Produktion isolierter Mitochondrien in Mecp $2^{-/ y}$ 


\section{Tabellenverzeichnis}

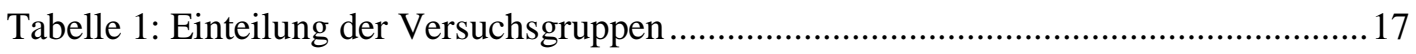

Tabelle 2: Einstellungsparameter Spektroflurometer SAFA Flx-Xenius............................27

Tabelle 3: Körpergewicht, Körpergröße und Hirngewicht männlicher Mäuse (p50) ...........30

Tabelle 4: Körpergewicht, Körpergröße und Hirngewicht weiblicher Mäuse (p50) ............32

Tabelle 5: Körpergewicht, Körpergröße und Hirngewicht weiblicher Mäuse (p400) ..........34

Tabelle 6: Morphologische Gewebeparameter männlicher Mäuse (p50) ….......................... 38

Tabelle 7: Morphologische Gewebeparameter weiblicher Mäuse (p50) .............................. 41

Tabelle 8: Morphologische Gewebeparameter weiblicher Mäuse (p400) ...........................43

Tabelle 9: Relative Fluoreszenzintensität (Kortex) ...........................................................49 


\section{Abkürzungsverzeichnis}

AOF

ATP

BSA

CA

CDKL5

CDKL5

$\mathrm{CpG}$

DMSF

DNA

GSH

GPx

$\mathrm{H}_{2}$ DCFDA

HRP

MiRO5

Mecp2

$M E C P 2$

$\mathrm{MeCP} 2$

$\mathrm{Mecp}^{+1-}$

$\operatorname{Mecp}^{-/ y}$

MBD

NLS

$\mathrm{NF}$

- $\mathrm{O}_{2}{ }^{-}$

$\cdot \mathrm{OH}$

PBS

PMSF

ROS

RTT

$\operatorname{Sin} 3 \mathrm{a}$

SOD

TRD

$\mathrm{TrxS}_{2}$

WT
Antioxidantien-Futter

Adenosintriphosphat

bovine serum albumine, bovines Serumalbumin

cornu ammonis, Ammonshorn des Hippokampus

cyclin-dependent kinase-like 5 (humanes Gen)

cyclin-dependent kinase-like 5 (exprimiertes Protein)

Cytosin-phosphatidyl-Guanin

Dimethylsulfoxid

desoxyribonucleic acid, Desoxyribonukleinsäure

Glutathion

Glutathionperoxidase

$2^{6}, 7^{6}$-Dichlordihydrofluorescein-Diacetat

horseradish peroxidase, Meerrettich-Peroxidase

mitochondrial respiration medium 05 , mitochondriales

Atmungsmedium

methyl-CpG-binding protein 2 (nicht-humanes Gen)

methyl-CpG-binding protein 2 (humanes Gen)

methyl-CpG-binding protein 2 (exprimiertes Protein)

Mausmodell des Rett-Syndroms (heterozygotes weibliches Tier)

Mausmodell des Rett-Syndroms (hemizygotes männliches Tier)

Methyl-CpG-bindende Domäne

Kernlokalisationssignale

Normalfutter

Superoxidanion

Hydroxylradikal

phosphate-buffered saline, phosphat-gepufferte Salzlösung

Phenylmethylsulfonylfluorid

reactive oxygen species, reaktive Sauerstoffspezies

Rett-Syndrom

Corepressor (gepaartes amphiphatisches Helixprotein)

Superoxiddismutase

Transkription-Repressor-Domäne

Thioredoxin

Wildtyp 


\section{$1 \quad$ Einleitung}

\subsection{Das Rett-Syndrom}

Beim Rett-Syndrom (RTT, MIM312750) handelt es sich um eine 1966 erstmalig in Österreich beschriebene neurologische Entwicklungsstörung, von der hauptsächlich weibliche Individuen betroffen sind (Rett 1966). Mit einer Inzidenz von 1:10000 bis 1:15000 (Hagberg 1985) ist das RTT nach dem Krankheitsbild der Trisomie 21 die zweithäufigste genetische Ursache für eine schwere geistige Behinderung bei Mädchen (Hagberg 1995). Durch Publikationen des schwedischen Neurologen Dr. Bengt Hagberg in englischer Sprache rückte das RTT erstmals auch in den internationalen Fokus. Bevor genetische Ursachen bekannt wurden, konnte die Diagnose nur anhand klinischer Kriterien gestellt werden. So zeichnet sich die klassische Variante des RTT zunächst dadurch aus, dass prä- und perinatal sowie in den ersten 6 bis 18 Lebensmonaten keine Auffälligkeiten registriert werden können und sich die Patientinnen psychomotorisch scheinbar der Norm entsprechend entwickeln (Hagberg et al. 1985). Manche Patientinnen erlernen sogar das Laufen und erste Worte (Chahrour und Zoghbi 2007). Anfängliche Hauptsymptome ab dem sechsten Lebensmonat sind das eingeschränkte Kopf- und damit Hirnwachstum sowie der Verlust zielgerichteter Handbewegungen, die sich zu stereotypen Handwaschbewegungen ausbilden (Weaving et al. 2005). Es kommt außerdem zum Verlust erlernter sprachlicher Fähigkeiten, die mit einer gestörten Kommunikation und sozialer Distanzierung einhergehen. Auch motorische und kognitive Beeinträchtigungen gehören zum klinischen Bild des RTT, die sich vor allem durch Apraxie und Ataxie ab dem ersten Lebensjahr abbilden (Hagberg et al. 1985).

Neben den genannten Hauptmerkmalen können zusätzliche Symptome auftreten. So werden Unregelmäßigkeiten der Atmung im wachen Zustand in Form von Apnoe, Hyperventilation, Aerophagie und forcierter Ausatmung beschrieben, die während des Schlafes in der Regel keine Rolle spielen (Julu et al. 2001; Weaving et al. 2005). Des Weiteren zeigen sich teilweise veränderte EEG-Verläufe mit epileptiformen Mustern und verlangsamter Hintergrundaktivität (Hagberg et al. 1983; Weaving et al. 2005). Aktuelleren Studien zufolge leiden etwa 81 bis $94 \%$ der Patientinnen an Epilepsie (Steffenburg et al. 
2001; Jian et al. 2006). Auch allgemeine Wachstumsstörungen, Dystonien und Muskelhypotonien sowie Skoliosen prägen das klinische Bild des RTT. Zusätzlich wird von vasomotorischen Störungen, Bruxismus und Schlafstörungen berichtet (Chahrour und Zoghbi 2007). Aufgrund von Schluckbeschwerden und Kauproblemen kommt es häufig zu Verdauungsstörungen und damit zur Unterernährung der Patientinnen (Weaving et al. 2005; Chahrour und Zoghbi 2007).

Der Gesamtverlauf lässt sich in vier Stadien einteilen (Hagberg und Witt-Engerström 1986). Stadium I ist das Stadium der Stagnation, das den frühkindlichen Entwicklungsstillstand beschreibt. Dieses Stadium beginnt mit 6 bis 18 Monaten und dauert mehrere Monate an. Die Entwicklung stagniert, verzögertes Schädel- und Körperwachstum sowie die typischen Handbewegungen setzen ein und die Kommunikation verschlechtert sich. Eltern registrieren häufig unspezifische Persönlichkeitsänderungen ihrer betroffenen Kinder sowie deren Interessenverlust an äußeren Einflüssen. Das Stadium II beginnt im Alter von ein bis drei Jahren und dauert mehrere Wochen bis Monate. Es nennt sich auch Stadium der Regression und ist geprägt von einem schnellen und destruktiven Charakter. Die Entwicklung verschlechtert sich zunehmend, autistische Züge manifestieren sich und es kommt immer mehr zu deutlichen Mobilitätseinschränkungen. Erstmalig können auch Atemstörungen registriert werden (Hagberg und Witt-Engerström 1986). Das Stadium III, bekannt als Plateau- oder pseudostationäre Phase, beginnt im Alter von zwei bis zehn Jahren und dauert mehrere Jahre. Hier stabilisiert sich der Zustand der Patientinnen erstmalig. Trotz deutlicher geistiger Behinderung sind emotionaler Kontakt und leichte Kommunikation wieder zu einem gewissen Grad möglich. Die autistischen Züge mildern sich. Demgegenüber verstärken sich Ataxie und Apraxie und es kann zum Auftreten epileptischer Anfälle kommen. Das Stadium IV, auch bekannt als Phase der motorischen Verschlechterung, beginnt ab dem zehnten Lebensjahr. Während sich der emotionale Kontakt zu Mitmenschen zunehmend verbessert, verschlechtert sich die Mobilität der Patientinnen nochmals. Häufig sind diese deswegen an einen Rollstuhl oder andere Gehhilfen gebunden (Chahrour und Zoghbi 2007). Die Pubertät läuft trotz der allgemeinen Wachstumsstörungen weitestgehend normal ab. Des Weiteren können sich Skoliosen oder Kyphosen manifestieren. Die Schwere der Epilepsie verringert sich in dieser Phase, was durch eine geringere Anfallsfrequenz und mildere Anfälle deutlich wird (Steffenburg et al. 2001). 
Auf der Grundlage einer aktuellen australischen Kohortenstudie geht man von einer Überlebensrate der Patientinnen von 77,6\% bis zum Alter von 20 Jahren, 71,5\% bis 25 Jahre und 59,8\% bis 37 Jahre aus (Anderson et al. 2014). Rett-Patientinnen sind aufgrund der Atemstörungen und damit verbundenen kardialen Belastung gefährdet, einem spontanen Tod zu erliegen. Trotz der schwerwiegenden Symptomatik der Erkrankung erreichen einige Patientinnen unter dauerhafter Unterstuitzung ein Alter von über 70 Jahren (Chahrour und Zoghbi 2007). Neben dem klassischen RTT gibt es außerdem atypische Varianten, die zum Beispiel durch mildere Verlaufsformen, verspätet auftretende Symptome oder einen direkten Beginn der Symptomatik nach der Geburt ausgezeichnet sind. Zudem gibt es die seltene Variante des männlichen RTT (Hagberg und Skjeldal 1994).

\subsection{Molekulargenetische Ursachen des RTT}

In 95\% der Fälle liegt dem RTT eine Mutation des MECP2-Gens zugrunde, das für das methyl-CpG-binding protein $2(\mathrm{MeCP} 2)$ kodiert und sich auf Position 28 des langen Arms des X-Chromosoms (Xq28) befindet (Amir et al. 1999). Mit einer Wahrscheinlichkeit von $99,5 \%$ handelt es sich dabei um De-novo-Mutationen in der väterlichen Keimbahn (Trappe et al. 2001) und meist um eine Transition von Cytosin zu Thymin an Cytosinphosphatidyl-Guanin-Dinukleotiden (CpG-Dinukleotiden). Ethnie und Alter der Eltern scheinen keinen Einfluss auf die Entstehung einer Mutation des MECP2-Gens zu haben (Huppke et al. 2000; Trappe et al. 2001). Da in paternalen Keimzellen ein hohes Level an methylierten CpG-Einheiten herrscht, kann durch spontane Desaminierung von 5-Methyl-Cytosin die Nukleinbase Thymin entstehen (Wan et al. 1999). Dieser Prozess ist in der maternalen Keimbahn kaum zu beobachten, denn das Genom weiblicher Oozyten ist nahezu unmethyliert (Monk et al. 1987). Da der Mann sein X-Chromosom ausschließlich an weibliche Nachkommen vererben kann, sind Jungen natürlicherweise vor dieser Art der Entstehung des RTT geschützt. So erklärt sich, warum fast ausschließlich das weibliche Geschlecht von der Erkrankung betroffen ist (Girard et al. 2001; Trappe et al. 2001).

Trotzdem sind einige Fälle von männlichen Patienten mit RTT bekannt, auch wenn diese nur einen sehr geringen Anteil ausmachen (Christen und Hanefeld 1995; Jan et al. 1999; Masuyama et al. 2005). Die Ursache bei ihnen ist selten spontan, sondern hauptsächlich durch familiäre Weitergabe des Gendefekts durch eine Trägermutter bedingt. Liegt bei 
den betroffenen männlichen Patienten eine MECP2-Mutation vor, die bei Mädchen das klassische RTT auslösen würde, führt dies zu neonataler Enzephalopathie und sie versterben meist innerhalb des ersten Lebensjahres (Villard 2007). Ein milderer Phänotyp kann auftreten, wenn die Jungen zusätzlich normal exprimierende Zellen aufweisen. Dies ist beim seltenen Klinefelter-Syndrom der Fall, bei dem die Patienten ein zusätzliches X-Chromosom (XXY) besitzen (Schwartzman et al. 2001), oder kann im Rahmen eines somatischen Mosaizismus zum Tragen kommen (Villard 2007). Demgegenüber stehen Fälle des männlichen RTT, die auf Mutationen des MECP2-Gens beruhen, die bei Mädchen bisher nicht mit dem RTT in Verbindung gebracht werden konnten. In diesen Fällen werden bei den Jungen meist milde bis schwere unspezifische geistige Behinderungen registriert, die aber größtenteils mit dem Leben vereinbar sind (Villard 2007). Auffällig ist, dass Mütter, die in familiären Fällen eine klassische Mutation an ihre Nachkommen weitergeben, selbst häufig keine Symptome oder nur einen sehr milden Phänotyp zeigen. Eine solch milde Ausprägung ist aufgrund von X-ChromosomInaktivierung möglich (Zoghbi et al. 1990). Nach der Lyon-Hypothese wird bei Mädchen während der Embryonalentwicklung zufällig jeweils pro Zelle das paternale oder das maternale X-Chromosom inaktiviert, sodass bei X-chromosomal vererbten Merkmalen und heterozygoten weiblichen Individuen Mosaikphänotypen entstehen (Lyon 1961). Bei der auffälligen Symptomfreiheit einiger Rett-Konduktorinnen kann allerdings von einer Art Selektion gegen das Rett-Allel ausgegangen werden, die mit einer nicht zufälligen X-Chromosom-Inaktivierung verknüpft ist. Durch die damit entstandene erhöhte Expression des gesunden Allels sinkt die Manifestation des Rett-Phänotyps (Zoghbi et al. 1990; Young und Zoghbi 2004).

Die Funktionen von MeCP2 sind vielfältig. Das MECP2-Gen selbst besteht aus vier Exons (Abbildung 1), aus denen durch alternatives Spleißen zwei verschiedene Isoformen des Proteins gebildet werden können (Chahrour und Zoghbi 2007). MeCP2 wird in fast allen Geweben exprimiert und kann besonders häufig im neuronalen Gewebe nachgewiesen werden (Jung et al. 2003). Zunächst ging man davon aus, dass das Protein ausschließlich als Transkriptionshemmer dient. Neuere Erkenntnisse zeigen, dass MeCP2 neben der Repression der Transkription auch bei der Regulierung des Spleißens eine Rolle spielt sowie in manchen Geweben außerdem aktivierend auf die Transkription wirken kann (Buschdorf und Strätling 2004; Young et al. 2005; Chahrour et al. 2008). 


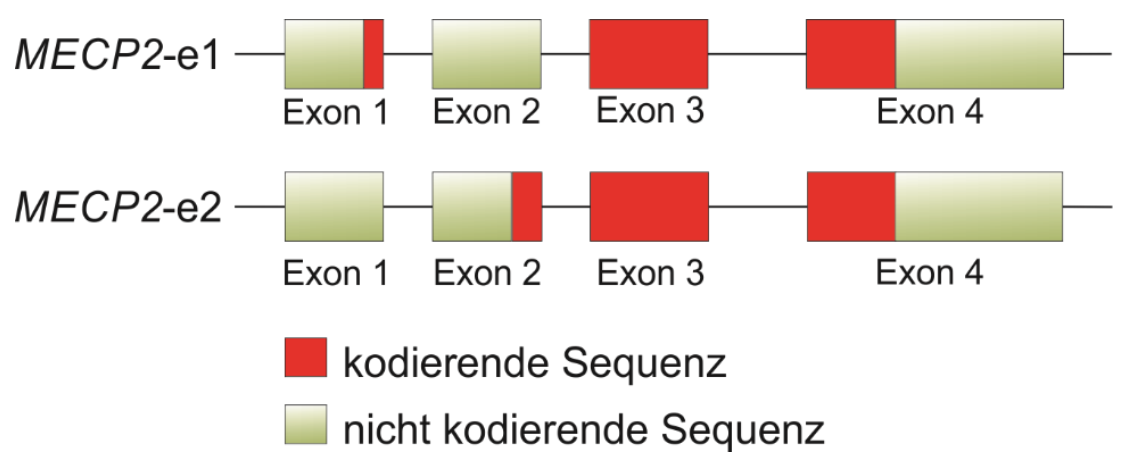

Abbildung 1: $\boldsymbol{M E C P 2 - G e n s t r u k t u r . ~ D u r c h ~ a l t e r n a t i v e s ~ S p l e i ß e n ~ e n t s t e h e n ~ n a c h ~ E n t f e r n u n g ~}$ entsprechender Exons die Isoformen $M E C P 2-\mathrm{e} 1$, bestehend aus Teilen von Exon 1, 3 und 4, und MECP2-e2, bestehend aus Teilen von Exon 2, 3 und 4 (basierend auf Chahrour und Zoghbi 2007).

Generell muss zunächst hervorgehoben werden, dass eine Hemmung der Transkription vor allem durch Methylierung der DNA an CpG-Inseln innerhalb von Promotoren hervorgerufen wird. Einerseits führt die Methylierung dazu, dass die sequenzspezifische Bindung von Transkriptionsfaktoren unterbunden wird, andererseits verursacht die Bindung von Methyl-CpG-Bindeproteinen an methylierte DNA eine Änderung der Chromatinstruktur, sodass keine Transkription mehr stattfinden kann (Lewis et al. 1992). Für die Interaktion mit der DNA hat MeCP2 drei funktionelle Domänen (Abbildung 2), die Methyl-CpG-bindende Domäne (MBD), die Transkription-Repressor-Domäne (TRD) und die C-terminale Domäne. Zusätzlich gibt es zwei Kernlokalisationssignale (NLS) (Chahrour und Zoghbi 2007). Mithilfe der MBD kann MeCP2 an ein methyliertes CpGDinukleotid in der Promotorregion eines Gens binden. Die TRD kann daraufhin HistonDeacetylasen und Corepressoren wie Sin3a rekrutieren. Es kommt zur Deacetylierung von Kernhistonen und damit zur Kompaktion der DNA, was letztlich die Transkriptionshemmung bedingt (Lewis et al. 1992; Jones et al. 1998; Nan et al. 1998). Der C-Terminus vereinfacht die Bindung zur DNA und ermöglicht die Interaktion mit Spleißfaktoren (Buschdorf und Strätling 2004). Allgemein wird außerdem angenommen, dass MeCP2 die Expression neuronaler Gene als Antwort auf elektrische Signale und damit die Entstehung neuer synaptischer Verbindungen reguliert. Somit spielt es vermutlich eine Rolle bei der Modellierung von Aktivität und Plastizität von Neuronen, was den neuronal geprägten Phänotyp der Erkrankung erklären könnte (Weaving et al. 2005; Chahrour und Zoghbi 2007). 


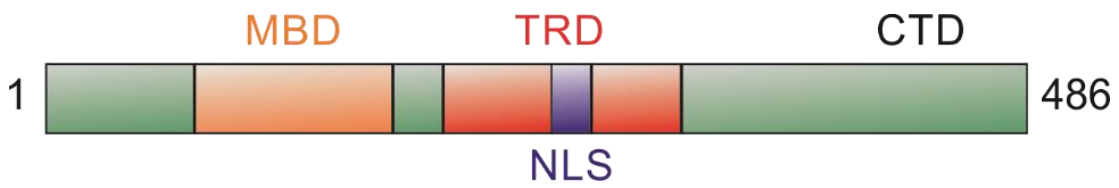

Abbildung 2: Schematische Darstellung des humanen Methyl-CpG-Bindeprotein 2. Das humane MECP2 ist charakterisiert durch die funktionellen Domänen MBD, TRD sowie CTD und besitzt außerdem NLS (basierend auf Guy et al. 2001).

Das Spektrum der Mutationen umfasst verschiedenste Missense-, Nonsense- und Frameshift-Mutationen bis hin zu Deletionen ganzer Exons (Wan et al. 1999; Archer et al. 2006). Mögliche Folgen sind die Entstehung eines verkürzten Proteins oder gar die vollständige Absenz von MeCP2 durch verfrühte Beendigung der Transkription aufgrund eines neuen Stoppcodons. Außerdem können Veränderungen und damit Funktionsstörungen der funktionellen Domänen des Proteins ausgelöst werden (Wan et al. 1999). Betrifft eine Mutation die MBD, kommt es zu Störungen der Methyl-CpG-Bindung, ist die TRD betroffen, hat dies eine Störung der Proteinfaltung und Interaktion mit Hilfskomplexen zur Folge (Wan et al. 1999). In welcher Art und Weise verkürzte MeCP2Proteine in ihrer Funktionsweise gestört sind, bleibt offen (Wan et al. 1999). Insgesamt wird das RTT also hauptsächlich durch partiellen oder vollständigen Funktionsverlust von MeCP2 hervorgerufen (Amir et al. 1999). Patientinnen mit identischen Mutationen zeigen trotzdem teilweise sehr unterschiedliche Phänotypen, sodass davon ausgegangen werden muss, dass neben der Art und Position einer Mutation des MECP2-Gens weitere Faktoren in der Entwicklung des Phänotyps eine Rolle spielen (Huppke et al. 2000). Es wird vermutet, dass auch in diesem Zusammenhang die Schwere des Phänotyps mit dem Grad der Inaktivierung des mutierten X-Chromosoms korreliert (Zoghbi et al. 1990; Young und Zoghbi 2004).

Neben der Mutation des MECP2-Gens führen in 5\% der Fälle andere Ursachen zur Entstehung von Rett-Varianten (Weaving et al. 2005). So lösen Mutationen des CDKL5Gens einen Rett-ähnlichen Phänotyp aus. Das Gen codiert für die cyclin-dependent kinase-like 5 (CDKL5) und befindet sich auf dem kurzen Arm des X-Chromosoms (Xp22) (Tao et al. 2004; Weaving et al. 2004). Eine Mutation von CDKL5 ruft eine seltene Form des RTT hervor, die durch ein frühes Auftreten von Anfällen charakterisiert ist (Scala et al. 2005). Das Protein steht im Zusammenhang mit der Phosphorylierung von MeCP2, sodass von einem gemeinsamen Signalweg der Proteine ausgegangen wird 
(Bertani et al. 2006). Auf der anderen Seite wird aktuell diskutiert, ob es sich bei CDKL5Mutationen nicht doch um ein eigenständiges Krankheitsbild handelt (Fehr et al. 2013). Eine weitere seltene Ursache des RTT ist eine Mutation im Forkhead-box-1-Gen (FOXG1) (Ariani et al. 2008).

Seit 1999 kann die Diagnostik des RTT mithilfe von Gentests durchgeführt werden (Amir et al. 1999; Buyse et al. 2000). Da jedoch bei manchen Patientinnen mit phänotypischen Rett-Merkmalen keine genetischen Mutationen festgestellt werden können und andere Patientinnen mit Mutationen von $M E C P 2$ wiederum keine klassischen Rett-Symptome aufweisen, wird der klinischen Diagnose nach wie vor ein hoher Stellenwert zugeschrieben (Suter et al. 2014).

\subsection{Mitochondriale Veränderungen im RTT}

Zunächst ging man davon aus, dass das RTT eine Stoffwechselerkrankung sei (Matsuishi et al. 1994). Auch wenn man mittlerweile weiß, dass die Erkrankung genetischen Ursprungs ist, hat die Pathogenese eine bedeutende metabolische Komponente, bei der vor allem Mitochondrien eine tragende Rolle spielen. Wesentliche Hauptaufgabe von Mitochondrien ist die Generierung des Energieträgers Adenosintriphosphat (ATP) unter Verbrauch von molekularem Sauerstoff $\left(\mathrm{O}_{2}\right)$. Im Gehirn entstehen während der oxidativen Phosphorylierung an der inneren Mitochondrienmembran etwa 95\% des insgesamt produzierten ATPs. Der ATP-Ertrag durch die im Zytoplasma stattfindende Glykolyse hat im Gegensatz dazu nur einen Anteil von 1 bis 5\% (Erecinska und Silver 1989). Neben der Energiegewinnung erfüllen Mitochondrien außerdem Funktionen im Zusammenhang mit der zellulären Kalziumhomöostase, pH-Regulierung und Induktion von Apoptose und anderen Signalwegen. Während der Zellatmung entsteht in den Mitochondrien zudem ein Großteil der reaktiven Sauerstoffspezies (reactive oxygen species, ROS). Auch mit der Kontrolle neuronaler Erregbarkeit und synaptischer Funktionen stehen Mitochondrien in Zusammenhang (Boveris und Chance 1973; Foster et al. 2006). Neurone sind demnach besonders anfällig für metabolische Unregelmäßigkeiten. So gibt es eine Vielzahl an neurodegenerativen Erkrankungen, die mit mitochondrialen Dysfunktionen verknüpft sind (Moreira et al. 2010), auch wenn es sich beim RTT nicht um eine solche handelt (Armstrong et al. 1995). Beispielhaft zu nennen sind an dieser Stelle Morbus Parkinson (Schulz und Beal 1994), Morbus Alzheimer (Behl und Moosmann 
2002), Chorea Huntington (Tabrizi et al. 2000), das Leigh-Syndrom (Dahl 1998) und die amyotrophe Lateralsklerose (Kong und Xu 1998).

Erste Indizien für eine Beteiligung von Mitochondrien im RTT gaben Muskel- und Frontallappenbiopsien von Rett-Patientinnen, anhand derer man mitochondriale Veränderungen im Vergleich zu gesunden Kontrollgruppen registrieren konnte. So zeigen sich Mitochondrien von Rett-Patientinnen morphologisch in einer ungewöhnlich hantelförmigen und geschwollenen Gestalt (Eeg-Olofsson et al. 1988) mit Vakuolisierungen und granulären Einschlüssen (Ruch et al. 1989; Cornford et al. 1994). Auch Veränderungen in der Membranstruktur und der Anordnung der cristae sind festzustellen (Eeg-Olofsson et al. 1990). Ähnliche Strukturauffälligkeiten lassen sich ebenfalls im Mausmodell nachweisen (Belichenko et al. 2009). Neben den morphologischen Veränderungen ergaben weiterführende Untersuchungen biochemische Alterationen, die zu Störungen des allgemeinen Energiemetabolismus führen. So sind die Enzymaktivitäten aller vier Hauptkomplexe der Atmungskette im RTT beeinflusst (Coker und Melnyk 1991; Dotti et al. 1993; Gibson et al. 2010). Im Mausmodell konnte beispielsweise ein direkter Zusammenhang zwischen der Überexpression der Untereinheit ubiquinol-cytochrome c reductase core protein 1 (Uqcrc1) der Cytochromc-Oxidoreduktase (Komplex III) und der fehlenden Interaktion von MeCP2 mit der entsprechenden Promotorregion aufgezeigt werden. Dies hat eine erhöhte Aktivität des Komplexes III mit einem Leckstrom an Protonen über die innere Mitochondrienmembran in die Matrix zur Folge, was durch eine gesteigerte Atmungskette kompensiert wird (Kriaucionis et al. 2006). Auch in der Arbeitsgruppe um Prof. M. Müller konnte eine gesteigerte basale Respirationsrate mit erhöhtem Sauerstoffverbrauch nachgewiesen werden (Großer et al. 2012; Can et al. 2019). Die mitochondriale Respiration erscheint demnach weniger effizient. Da das Symptom der Atemstörung im RTT eine Unterversorgung an Sauerstoff mit sich bringen kann, hätte dies einen direkten Einfluss auf die Funktion der Mitochondrien und den Energiemetabolismus. Dennoch konnte die Arbeitsgruppe kein reduziertes ATP-Level im Hippokampus MeCP2-defizienter Mäuse registrieren (Fischer et al. 2009), während andere Studien sehr wohl auf ein zerebrales ATP-Defizit hinweisen (Saywell et al. 2006).

In einer Studie an Lymphozyten betroffener Patientinnen wurden zahlreiche weitere Änderungen in Genexpressionsmustern nachgewiesen, die neben der Beeinflussung mitochondrialer Funktionen auch mit der Ubiquitinierung sowie der Chromatinfaltung in 
Verbindung stehen (Pecorelli et al. 2013). Die fehlende Expression des $\mathrm{MeCP} 2$-Gens hat insgesamt also vielfältige Auswirkungen, die nach wie vor nicht vollständig geklärt sind.

\subsection{Reaktive Sauerstoffspezies und oxidativer Stress}

Allgemein handelt es sich bei reaktiven Sauerstoffspezies (ROS) um Moleküle oder freie Radikale, die sich vom molekularen Sauerstoff ableiten. Radikale sind wiederum Strukturen mit mindestens einem ungepaarten Valenzelektron, das ihnen eine erhöhte Reaktivität verleiht (Turrens 2003). Grundsätzlich haben ROS vielfältige physiologische Funktionen. Sie sind beteiligt an Zellkommunikationsprozessen und Signalwegen, spielen eine funktionelle Rolle bei der Abwehr von Krankheitserregern sowie der Reaktion auf Noxen und können die Mitose beeinflussen (Valko et al. 2007). Gleichzeitig sind ROS aber auch potenziell zellschädigend. Sie entstehen zu $85 \%$ während der oxidativen Phosphorylierung in den Mitochondrien. Ein weitaus geringerer Anteil wird durch zytosolische Oxidasen produziert. Demnach kann davon ausgegangen werden, dass die Gesamtmenge der ROS-Produktion mit der Stoffwechselaktivität korreliert (Boveris und Chance 1973). Im Rahmen der Zellatmung entweichen während der Elektronentransportkette zwischen den Komplexen I bis IV grundsätzlich geringe Mengen Elektronen in die Mitochondrienmatrix oder seltener auch in den Intermembranraum. Dort reagieren sie mit $\mathrm{O}_{2}$ zu Superoxidanionen $\left(\bullet \mathrm{O}_{2}^{-}\right)$, die als Vorstufe weiterer ROS gelten. Hauptverantwortlich dafür sind vor allem die Komplexe I und III der Atmungskette (Boveris et al. 1976; Turrens und Boveris 1980; Kushnareva et al. 2002).

Superoxidmoleküle können aufgrund ihrer Ladung die innere Mitochondrienmembran nicht passieren (Valko et al. 2007), sind aber in der Lage mit weiteren Molekülen zu reagieren und direkt oder enzymkatalysiert sekundäre ROS zu erzeugen (Valko et al. 2007). In der Matrix reagieren sie umgehend, vermittelt durch eine mitochondriale Isoform der Superoxiddismutase (SOD2, MnSOD), zu dem weniger reaktionsfreudigen Wasserstoffperoxid $\left(\mathrm{H}_{2} \mathrm{O}_{2}\right)$. Außerhalb der Matrix ist dafür die SOD1 (CuZnSOD) verantwortlich (Weisiger und Fridovich 1973; Lenaz et al. 2006; Brand 2010). Das entstandene $\mathrm{H}_{2} \mathrm{O}_{2}$ kann Membranen passieren und Signalfunktionen erfüllen oder in Anwesenheit von Eisen $\left(\mathrm{Fe}^{2+}\right)$ in der Fenton-Reaktion zu einem Hydroxylradikal $(\cdot \mathrm{OH})$ reagieren, das als reaktivstes natürliches Oxidationsmittel gilt (Dean et al. 1997). Da Hydroxylradikale nur eine kurze Halbwertszeit von $10^{-9} \mathrm{~s}$ besitzen, wirken sie meist 
unmittelbar an ihrem Entstehungsort (Valko et al. 2007). Neben den Superoxiddismutasen gibt es weitere enzymatische Antioxidantien zum Erhalt einer zellulären Redoxbalance (Abbildung 3). So kann $\mathrm{H}_{2} \mathrm{O}_{2}$ von der Katalase, der Glutathionperoxidase (GPx) unter Oxidation des Glutathions (Bai und Cederbaum 2001) und von Peroxiredoxin unter Oxidation von Thioredoxin $\left(\operatorname{TrxS}_{2}\right)($ Chae et al. 1999) eliminiert werden. Als nichtenzymatische Antioxidantien gelten Ascorbinsäure (Vitamin C), $\alpha$-Tocopherol (Vitamin E) (Buettner 1993; Brigelius-Flohé und Traber 1999), Karotinoide und Flavonoide (Valko et al. 2007).

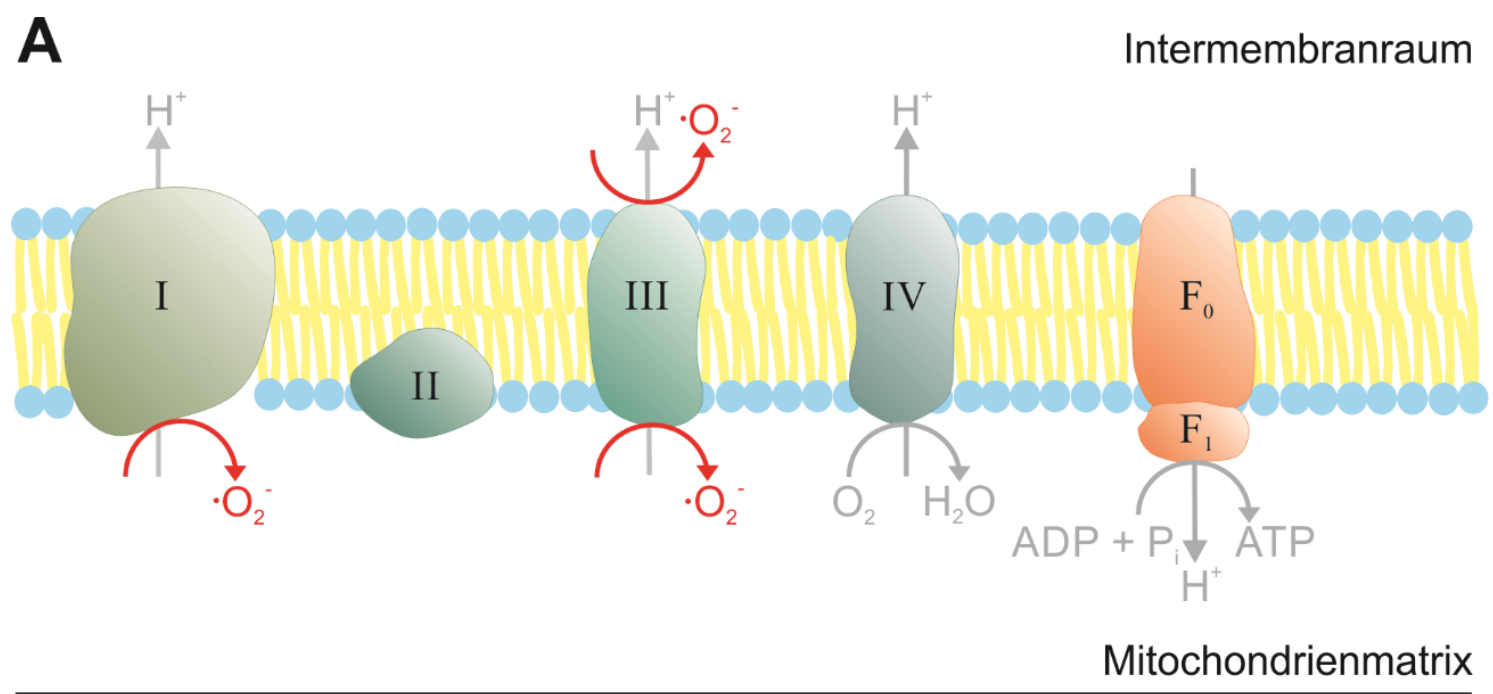

B

$$
\begin{array}{ll}
\mathrm{O}_{2}^{-}+1 \mathrm{e}^{-}+2 \mathrm{H}^{+} \longrightarrow \mathrm{H}_{2} \mathrm{O}_{2} & \text { Superoxidlismutase } \\
\mathrm{H}_{2} \mathrm{O}_{2} \longrightarrow \mathrm{H}_{2} \mathrm{O}+\mathrm{O}_{2} & \text { Katalase } \\
2 \mathrm{GSH}+\mathrm{H}_{2} \mathrm{O}_{2} \longrightarrow \mathrm{GSSG}+\mathrm{H}_{2} \mathrm{O} & \text { Glutathionperoxidase } \\
\mathrm{TrxS}_{2}+\mathrm{H}_{2} \mathrm{O}_{2} \longrightarrow \operatorname{Trx}(\mathrm{SH})_{2}+\mathrm{H}_{2} \mathrm{O} & \text { Peroxiredoxin }
\end{array}
$$

Abbildung 3: Entstehung von ROS im Rahmen der mitochondrialen Atmungskette. A) Allgemein dient die Atmungskette dem Aufbau eines Protonengradienten zwischen Intermembranraum und Mitochondrienmatrix. Dabei werden schrittweise Elektronen über die Komplexe I, II und III an Komplex IV weitergeleitet, der die Elektronen unter Entstehung von $\mathrm{H}_{2} \mathrm{O}$ auf $\mathrm{O}_{2}$ überträgt. Durch den Rückfluss von Protonen in die Matrix wird Energie frei, die von der $F_{1}$-Untereinheit der ATP-Synthase zur Synthese von ATP verwendet wird. Hauptentstehungsort von ROS in Form von Superoxidanionen $\left(\bullet \mathrm{O}_{2}{ }^{-}\right)$sind in diesem Prozess die Komplexe I und III. B) Es gibt verschiedene antioxidativ wirksame Enzyme. Die SOD katalysiert die Entstehung von $\mathrm{H}_{2} \mathrm{O}_{2}$ aus Superoxidanionen. Die Katalase, GPx und Peroxiredoxin machen $\mathrm{H}_{2} \mathrm{O}_{2}$ unschädlich (basierend auf Balaban et al. 2005). 
Gerät die Balance zwischen Produktion und Regulation von ROS aus dem Gleichgewicht, entsteht oxidativer Stress (Turrens 1997; Avshalumov und Rice 2002). Ein solches Ungleichgewicht wird entweder durch die Überproduktion von ROS, ein Defizit an enzymatischen und nicht-enzymatischen Schutzmechanismen oder eine Kombination aus beidem hervorgerufen. Allgemein führt oxidativer Stress zur Schädigung von Lipiden, Proteinen und Nukleinsäuren (Chan 1996; Gilgun-Sherki et al. 2004). Dadurch können Schäden der Zellarchitektur sowie Störungen zellulärer Signalfunktionen entstehen (Foster et al. 2006). So führt eine vermehrte Oxidation von Proteinen zu ihrem Funktionsverlust und steigert ihren Abbau durch Proteinasen (Dean et al. 1997). Neurone sind besonders anfällig für oxidativen Stress, da sie einen hohen metabolischen Umsatz zur Energiegewinnung aufweisen und hierbei entsprechend große Mengen an ROS entstehen (De Felice et al. 2012). Werden Membranlipide oxidiert, kann dies die Aktivität von Ionenkanälen beeinträchtigen (Kron und Müller 2010) und das Membranpotenzial beeinflussen (Pellmar 1995; Chan 2006). Dies scheint eine Hypererregbarkeit der Neurone auszulösen (Zhang et al. 2008) und Störungen der synaptischen Plastizität und Transmission hervorzurufen (Avshalumov und Rice 2002; Asaka et al. 2006). Zusätzlich bestätigte die Arbeitsgruppe um Prof. M. Müller eine verringerte Hypoxietoleranz von hippokampalen Neuronen der Region cornu ammonis 1 (CA1) MeCP2-defizienter Mäuse und vermutet eine beeinträchtigte Kalziumhomöostase sowie eine Funktionsstörung von Kaliumkanälen als Ursache (Fischer et al. 2009; Kron und Müller 2010).

Gleichzeitig sind mitochondriale Strukturen stark betroffen. Akkumulationen von Mutationen der mitochondrialen DNA durch ROS stehen im Zusammenhang mit der Entstehung weiterer Defekte in der Atmungskette (Lenaz 1998; Lenaz et al. 1999) und können den Kreislauf der Entstehung von oxidativem Stress zusätzlich verstärken (Abbildung 4) (Reeve et al. 2008). Diese Annahme passt zu dem progressiven Charakter der Erkrankung. Die vielfältig ausgelösten Beeinträchtigungen beeinflussen neben den bereits erwähnten neurodegenerativen Erkrankungen auch die Zellalterung (Dean et al. 1997), die Pathogenese einiger weiterer chronischer Krankheitsbilder, wie z. B. arteriosklerotische Vorgänge, und die Karzinogenese (Valko et al. 2007). Viele Organismen weisen während der Alterung eine Änderung des mitochondrialen Metabolismus, eine Steigerung der ROS-Generierung und eine verschlechterte Resistenz gegen oxidativen Stress auf (Balaban et al. 2005; Lenaz et al. 2006). Unter Umständen kann oxidativer Stress außerdem den Zelltod durch Apoptose oder Nekrose hervorrufen (Turrens 1997). 


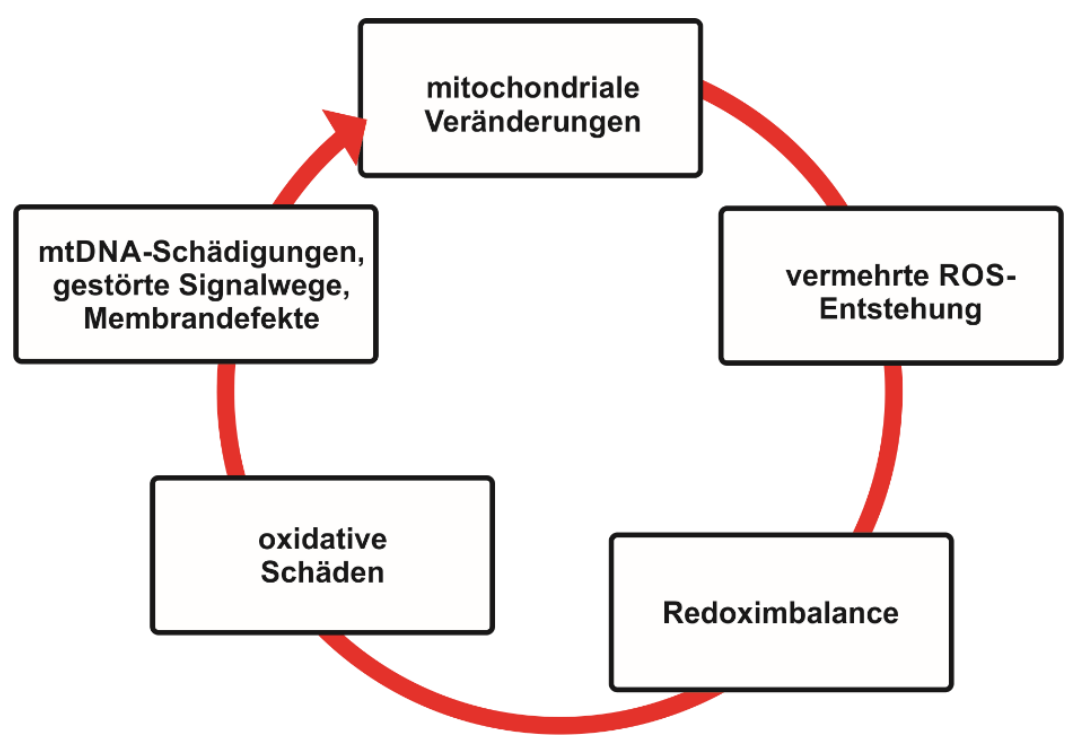

Abbildung 4: Kreislauf der vermehrten Entstehung von oxidativem Stress im RTT. Durch mitochondriale Veränderungen entsteht eine gesteigerte ROS-Produktion, die eine Redoximbalance erzeugt. Resultierende oxidative Schäden betreffen mitunter mtDNA, Signalwege und Membranstrukturen und bedingen ihrerseits weitere mitochondriale Veränderungen.

\subsection{Oxidativer Stress im RTT und assoziierte Therapieansätze}

Insgesamt kann auch im RTT ein veränderter Redoxstatus festgestellt werden. So zeigte die Arbeitsgruppe um Prof. M. Müller im Mausmodell ein erhöhtes Oxidationslevel an hippokampalen Zell- und Schnittkulturen und eine gesteigerte Anfälligkeit dieser für oxidativen Stress (Großer et al. 2012; Bebensee et al. 2017; Can et al. 2019). Zudem ergaben Untersuchungen an Rett-Patientinnen signifikant erhöhte Marker für oxidative Belastung (freies Eisen, $F_{2}$-Isoprostane, Malondialdehyde, Proteincarbonyle) in Plasma und Erythrozyten (Sierra et al. 2001; De Felice et al. 2009). Gleichzeitig zeigte sich eine Korrelation zwischen den erhöhten Stressmarkern und einem reduzierten peripheren und arteriellen Sauerstofflevel. Da die respiratorischen Störungen im RTT eine Sauerstoffunterversorgung bedingen können, scheint dies mitunter eine Ursache für oxidativen Stress zu sein (De Felice et al. 2009). Weitere Auffälligkeiten ergeben sich bei der Betrachtung der Radikalfänger und Antioxidantien. So sind sowohl das Serumlevel von Vitamin E (Formichi et al. 1998) als auch die Aktivität der SOD (Sierra et al. 2001) signifikant verringert. Zusätzlich registrierte man in post mortem untersuchtem Hirngewebe einer Rett-Patientin verringerte Mengen an Ascorbinsäure und Glutathion (Sofic et al. 1987). Andere Studien zeigten wiederum eine gesteigerte Synthese von Isoformen der SOD, des Peroxiredoxins und der Katalase in Lymphozyten betroffener Rett- 
Patientinnen (Pecorelli et al. 2013). Dementsprechend konnte auch im Mausmodell eine vermehrte Expression der SOD1 bestätigt werden (Großer et al. 2012). Diesen gegensätzlichen Ergebnissen wird dabei ein kompensatorisches Geschehen zugesprochen. Die Gesamtheit dieser Resultate unterstützt die Annahme einer erhöhten Redoximbalance im RTT und einer Verbindung zwischen Mutationen im MeCP2-Gen und der Entstehung von oxidativem Stress. Auch konnten durch postnatale Reaktivierung der MeCP2Expression die allgemeine Rett-Symptomatik und oxidative Schäden im Mausmodell reduziert werden (Guy et al. 2007; De Felice et al. 2014). Trotzdem ist noch nicht abschließend geklärt, ob eine gesteigerte basale Respirationsrate der Mitochondrien, ein allgemein gestörter Metabolismus oder eingeschränkte Schutzmechanismen gegen oxidativen Stress eine solche Imbalance im RTT entstehen lassen.

Ein vielversprechender Therapieansatz ist demnach die Wiederherstellung und Stabilisierung der Redoxbalance. Möglicherweise umsetzbar ist dieses Ziel durch die Senkung der allgemeinen ROS-Produktion, die Stimulation der Generierung zelleigener Radikalfänger oder die externe Zufuhr von Antioxidantien (Müller und Can 2014). Eine Studie an 20 Rett-Patientinnen, die sechs Monate einer Diät folgten, welche reich an antioxidativ wirksamen ungesättigten $\omega-3$-Fettsäuren war, löste signifikante Verbesserungen klinischer Symptome und die Verringerung oxidativer Stressmarker aus (De Felice et al. 2012). In einer weiteren Studie an 24 Rett-Patientinnen wurde beobachtet, dass Probandinnen, die das Vitamin-E-Derivat EPI-743 erhielten, einen größeren Kopfumfang entwickelten. Patientinnen mit einer besonders deutlichen Erhöhung des Kopfumfangs zeigten in diesem Zusammenhang zusätzlich eine Verbesserung der funktionellen Handbewegungen, Sauerstoffsättigung und Stressmarker (Enns und Cohen 2017). Außerdem zeigte die Fütterung von Kurkumin an heterozygote weibliche Mäuse einen positiven Effekt auf die Produktion von Superoxidanionen (Panighini et al. 2013). In der Arbeitsgruppe um Prof. M. Müller konnten ebenfalls positive Effekte im Zusammenhang mit der Wirkung von Antioxidantien belegt werden. So verbesserte die Inkubation akuter hippokampaler Hirnschnitte MeCP2-defizienter Mäuse mit dem wasserlöslichen Vitamin-EDerivat Trolox (6-Hydroxy-2,5,7,8-tetramethylchroman-2-carbonsäure) die zelluläre Redoxbalance (Großer et al. 2012), die synaptische Plastizität sowie die allgemeine Hypoxietoleranz der Neurone und reduzierte die neuronale Hypererregbarkeit (Janc und Müller 2014). 


\subsection{Ziele dieser Arbeit}

Aufgrund vielversprechender Ergebnisse von In-vitro-Behandlungen mit Trolox (Großer et al. 2012; Janc und Müller 2014) wurde daraufhin die systemische Wirksamkeit des Vitamin-E-Derivats im Mausmodell durch regelmäßige intraperitoneale Injektionen des Wirkstoffes erprobt. Zwar konnten auch hier positive Effekte auf die synaptische Plastizität, Hypoxietoleranz und das Oxidationslevel der Zellen registriert werden, jedoch zeigten sich keine Verbesserungen der allgemeinen phänotypischen Rett-Symptomatik. Unter anderem wird vermutet, dass die invasive Applikationsart des Vitamin-E-Derivats und die häufige Handhabung der Mäuse in der beschriebenen In-vivo-Studie einen negativen Effekt auf die Ergebnisse hatten (Janc et al. 2016).

Die vorliegende Dissertation soll an genannte Resultate anknüpfen und dient der Evaluierung einer oralen Antioxidantien-Therapie im Mausmodell basierend auf den Voruntersuchungen der Arbeitsgruppe. Dabei wurde in dieser Dissertation eine Kombinationstherapie der antioxidativ und synergistisch wirksamen Substanzen Vitamin E, $\alpha$-Liponsäure und N-Acetylcystein angewendet. Neben männlichen Mäusen wurden zusätzlich weibliche Mäuse berücksichtigt. Bei den Weibchen wurden außerdem verschiedene Altersgruppen betrachtet, um neben den Kurzzeitfolgen auch langfristige Auswirkungen der Medikamente zu untersuchen. Als Darreichungsform der Wirkstoffe diente ein speziell für diese Zwecke angefertigtes Futter, das eine Kombination der drei Substanzen enthielt. Die Antioxidantien wurden in diesem Fall also wenig invasiv über die Fütterung verabreicht und im Sinne einer präklinischen Studie zur Ermittlung eines potenziell kurativen Ansatzes für Rett-Patientinnen beurteilt.

Vergangene morphologische Untersuchungen ergaben, dass die Größe neuronaler Zellen bei Rett-Patientinnen verkleinert und die Packungsdichte dieser erhöht ist (Bauman et al. 1995). Die Arbeitsgruppe um Prof. M. Müller bestätigte diese Annahme im Mausmodell für die CA1-Region des Hippokampus (Fischer et al. 2009). Daran anknüpfend wurden in dieser Dissertation die Auswirkungen der Antioxidantien-Therapie insbesondere auf morphologische Parameter hippokampaler Strukturen sowie der kortikalen Schichtdicke betrachtet und zusätzlich Effekte auf die $\mathrm{H}_{2} \mathrm{O}_{2}$-Produktion isolierter Mitochondrien zur Beurteilung des Redoxstatus neuronalen Gewebes bewertet. 


\section{Material und Methoden}

Alle Versuche dieser Arbeit fanden an isoliertem murinen Gewebe statt und sind im Rahmen des breiter angelegten, umfassenden Projekts „Fütterung eines AntioxidantienCocktails als Therapieansatz in einem Maus Modell für das Rett Syndrom“ unter dem Aktenzeichen G17/2544 von der Tierschutzkommission der Universitätsmedizin Göttingen registriert und vom Niedersächsischen Landesamt für Verbraucherschutz und Lebensmittelsicherheit (LAVES) genehmigt worden.

Insofern nicht anders angegeben, stammen alle in den Experimenten verwendeten Chemikalien von der Firma Sigma-Aldrich.

\subsection{Mausmodell des RTT}

Mittlerweile wurden für das RTT verschiedenste Mausmodelle generiert. Diesen Modellen liegen Mecp2-Alterationen zugrunde, die teilweise den Veränderungen im menschlichen Genom ähneln oder neu entworfen wurden. Einerseits gibt es die Kategorie der Knockin-Mäuse mit Missense- (Jentarra et al. 2010) oder Nonsense-Mutationen (Shahbazian et al. 2002) des Mecp2-Gens. Letztere rufen die Entstehung eines verfrühten Stoppcodons hervor und führen dadurch zur Expression eines verkürzten MeCP2Proteins (Lawson-Yuen et al. 2007; Wegener et al. 2014). Andere Modelle bewirken wiederum eine verminderte Expressionsrate von MeCP2 (Samaco et al. 2008). Im Rahmen dieser Dissertation wurde das Mausmodell der Zuchtlinie B6.129P2(C)Mecp $2^{\text {tm-1-1Bird }}$ verwendet. Hierbei handelt es sich um Knockout-Mäuse der Bird-Linie, die durch das Cre-loxP-Verfahren hergestellt wurden und bei denen die Exons drei und vier des Mecp2-Gens fehlen (Guy et al. 2001). In der Zucht wurden heterozygote Weibchen dieser Linie mit männlichen C57BL/6J-Mäusen verpaart. Mögliche Nachkommen sind hierbei heterozygote Weibchen $\left(\right.$ Mecp $\left.^{+/-}\right)$, hemizygote Männchen $\left(\right.$ Mecp $\left.^{-/ y}\right)$ und Wildtypen (WT) beider Geschlechter.

Männliche $M е с p 2^{-/ y}$-Mäuse zeigen aufgrund der vollständigen Penetranz der X-chromosomalen Aberration einen deutlichen Phänotyp mit charakteristischer Rett-Symptomatik wie vermindertes Körpergewicht, Mikrozephalie, reduzierte Aktivität, verkleinerte Neurone und Atemunregelmäßigkeiten (Chen et al. 2001; Guy et al. 2001). Weibliche

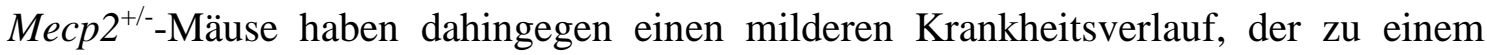
späteren Zeitpunkt auffällig wird und eine deutlich höhere Variabilität aufweist. Diese 
Unterschiede sind mit der zufälligen X-Chromosom-Inaktivierung bei heterozygoten Weibchen zu begründen, die bei Männchen nicht zum Tragen kommt (Shahbazian et al. 2002). Aufgrund des homogeneren Phänotyps wurden in der Vergangenheit Untersuchungen häufig nur an männlichen Mäusen vorgenommen. Da es sich bei den klinisch beschriebenen Fällen des RTT allerdings meist um weibliche Patientinnen handelt, wurden in dieser Arbeit neben männlichen $M e c p 2^{-/ y}$-Mäusen auch weibliche $M e c p 2^{+/-}$Mäuse und entsprechende Wildtypen betrachtet.

Alle Mäuse für die Versuche stammen aus der eigenen Zucht. Durch zusätzliche Neukäufe bei The Jackson Laboratory (Bar Harbour, ME) wurden die Zuchtpaare regelmäßig aufgefrischt. Gehalten wurden sie in der zentralen tierexperimentellen Einrichtung der Universitätsmedizin Göttingen. Die Genotypisierung anhand von Schwanzbiopsie und Polymerase-Kettenreaktion erfolgte durch die technische Assistentin der Arbeitsgruppe.

\subsection{Orale Antioxidantien-Therapie}

Das verwendete Gewebe dieser Arbeit stammt von Mäusen, die eine AntioxidantienTherapie erhalten haben und entsprechend normal gefütterten Vergleichsgruppen. Nachdem die Arbeitsgruppe um Prof. M. Müller zuvor im Rahmen mehrfacher In-vitround In-vivo-Untersuchungen einen positiven Effekt des wasserlöslichen Vitamin-EDerivats Trolox auf Zellkulturen sowie akute Hirnschnitte bestätigen konnte (Janc und Müller 2014; Janc et al. 2016), wurde in dieser Arbeit nun die Wirksamkeit eines oral verabreichten Antioxidantien-Cocktails erprobt. Dafür erhielten die Mäuse speziell angefertigtes Futter, das ihnen pro Tag und pro kg Körpergewicht die Aufnahme von 40 mg Vitamin E, $40 \mathrm{mg} \alpha$-Liponsäure und $400 \mathrm{mg}$ N-Acetylcystein ermöglichte. Die Dosierung erfolgte auf der Grundlage von Durchschnittswerten der täglichen Nahrungsaufnahme einer Maus (Wolfensohn und Lloyd 2013).

Allgemein verhindert Vitamin E die Lipidperoxidation und schützt so vor allem Membranstrukturen vor oxidativen Schäden (Burton und Ingold 1981). Die Substanz $\alpha$-Liponsäure und ihre reduzierte Form Dihydroliponsäure haben neben ihrer Hauptaufgabe als Coenzym der oxidativen Decarboxylierung zusätzlich vielfältige antioxidative Funktionen. Einerseits sind sie an der Eliminierung von Superoxidanionen und Hydroxylradikalen beteiligt, andererseits bilden sie Chelatkomplexe mit Metallen wie Eisen und Kupfer, sodass diese nicht mehr prooxidativ wirken können. Zusätzlich 
scheinen sie an der Regeneration von Vitamin C und reduziertem Glutathion (GSH) und damit indirekt auch an der Wiedergewinnung von Vitamin $\mathrm{E}$ beteiligt zu sein (Packer et al. 1995). Der dritte Wirkstoff des Futters, N-Acetylcystein, ist ein Vorläufer von Cystein, das in der Synthese von GSH benötigt wird und dabei einen limitierenden Faktor der GSH-Produktion darstellt (Aldini et al. 2018). Insgesamt wird anhand vorangegangener Studien vermutet, dass die Komposition dieser drei Substanzen eine potenzierte antioxidative Wirksamkeit durch synergistische Effekte hervorruft (López-Erauskin et al. 2011). Das Futter wurde eigens für die Arbeitsgruppe angefertigt und bezogen von Ssniff Spezialdiäten GmbH. Begonnen wurde mit der Fütterung von Normal- oder Antioxidantien-Futter unmittelbar nach dem Absetzen der Jungtiere um den postnatalen Tag p20. Die Einteilung der Mäuse erfolgte demnach anhand des Geschlechts, des Genotyps, des verabreichten Futters sowie anhand des Alters zur Beurteilung der Kurzund Langzeitfolgen (Tabelle 1).

Tabelle 1: Einteilung der Versuchsgruppen

\begin{tabular}{|c|c|c|c|}
\hline Alter [Tage] & Genotyp & Normalfutter (NF) & Antioxidantien-Futter (AOF) \\
\hline \multirow[t]{2}{*}{ p50 } & Wildtyp $\sigma^{\lambda}$ & & \\
\hline & $\operatorname{Mecp}^{2 / \mathrm{y}}$ & & \\
\hline \multirow[t]{2}{*}{$\mathrm{p} 50$} & Wildtyp & & \\
\hline & Mecp2 $2^{+/}$ & & \\
\hline \multirow[t]{2}{*}{$\mathrm{p} 400$} & Wildtyp & & \\
\hline & $\operatorname{Mecp}^{+/-}$ & & \\
\hline
\end{tabular}

Die Mäuse wurden jeweils abhängig vom Alter und Geschlecht aufgeteilt in WT und hemizygote Männchen bzw. heterozygote Weibchen, die entweder normales Futter oder Antioxidantien-Futter erhielten. Im weiteren Verlauf werden die entsprechenden Gruppen mithilfe der dargestellten Farbmarkierung gekennzeichnet. Da Mecp2-/y-Männchen kurz nach Erreichen des Alters p50 versterben, konnten im Rahmen dieser Dissertation keine älteren Männchen untersucht werden. 


\subsection{Herstellung und Auswertung Nissl-gefärbter Hirnschnitte}

\subsubsection{Transkardiale Perfusion und Präparation}

Die Gewinnung des Probenmaterials für die Herstellung histologischer Schnittbilder zur Auswertung der Morphologie nach Nissl-Färbung erfolgte mittels Gewebefixierung durch transkardiale Perfusion. Diese wurde von Mitgliedern der Arbeitsgruppe mit entsprechender Erfahrung und Berechtigung durchgeführt. Vor der eigentlichen Perfusion wurden Körpergewicht und Körpergröße der Mäuse bestimmt. Dabei gab es je eine Versuchsgruppe mit männlichen und weiblichen Mäusen im Alter von 50 Tagen (p50) sowie eine weitere Gruppe mit Weibchen im Alter von 400 Tagen (p400). Aufgrund der geringen Lebenserwartung männlicher Rett-Mäuse war es nicht möglich eine p400Gruppe der Rett-Männchen zu generieren. Nach der Perfusion des Gewebes wurde das fixierte Gehirn entnommen und zunächst in $4 \%$ Paraformaldehyd (PFA) überführt, welches nach 48 h gegen phosphatgepufferte Salzlösung (PBS) ausgetauscht wurde. Anschließend konnte das Hirngewicht bestimmt werden. Die verwendete PBS setzte sich aus $137 \mathrm{mM} \mathrm{NaCl}, 2,7 \mathrm{mM} \mathrm{KCl}$ und $12 \mathrm{mM}$ Phosphatpuffer $\left(\mathrm{HPO}_{4}{ }^{2-}\right.$ und $\left.\mathrm{H}_{2} \mathrm{PO}_{4}{ }^{-}\right)$ zusammen und wurde mit $1 \mathrm{M}$ Natronlauge auf einen $\mathrm{pH}-$ Wert von 7,4 eingestellt.

Zur Herstellung der Hirnschnitte diente das Vibratom Leica VT1200S. Als Vorbereitung wurde das Hirngewebe mit PBS umspült. Danach wurden das Kleinhirn und der Frontalkortex mit einer scharfen Klinge orthogonal entfernt. Nun konnte das vorbereitete Gewebe mittels Sekundenkleber (Roti coll 1, Roth) mit der dorsalen Fläche auf der Trägerplatte des Vibratoms befestigt werden. Nach Trocknung des Sekundenklebers wurde das leicht feuchte Gewebe mithilfe einer Pipette vorsichtig in Agar eingebettet, um dem Gewebe mehr Stabilität während des Schneidevorgangs zu verleihen. Nach Entfernung der Überschüsse des Agars wurde die Trägerplatte in den Halter des Vibratoms gesetzt und mit PBS umgeben. Mit einem Klingenvorschub von 0,7 mm/s und einer Amplitude von 1,2 mm konnten nun $30 \mu \mathrm{m}$ dicke koronale Hirnschnitte im Bereich des Hippokampus angefertigt werden (Abbildung 5). Die genannten Einstellungen zeigten sich als optimal gewebeschonend. Anschließend wurden die so entstandenen Schnitte mithilfe eines feinen Pinsels auf Superfrost Plus Objektträger (Thermo Fisher Scientific) aufgezogen und 30-60 min in staubfreier Umgebung getrocknet. 

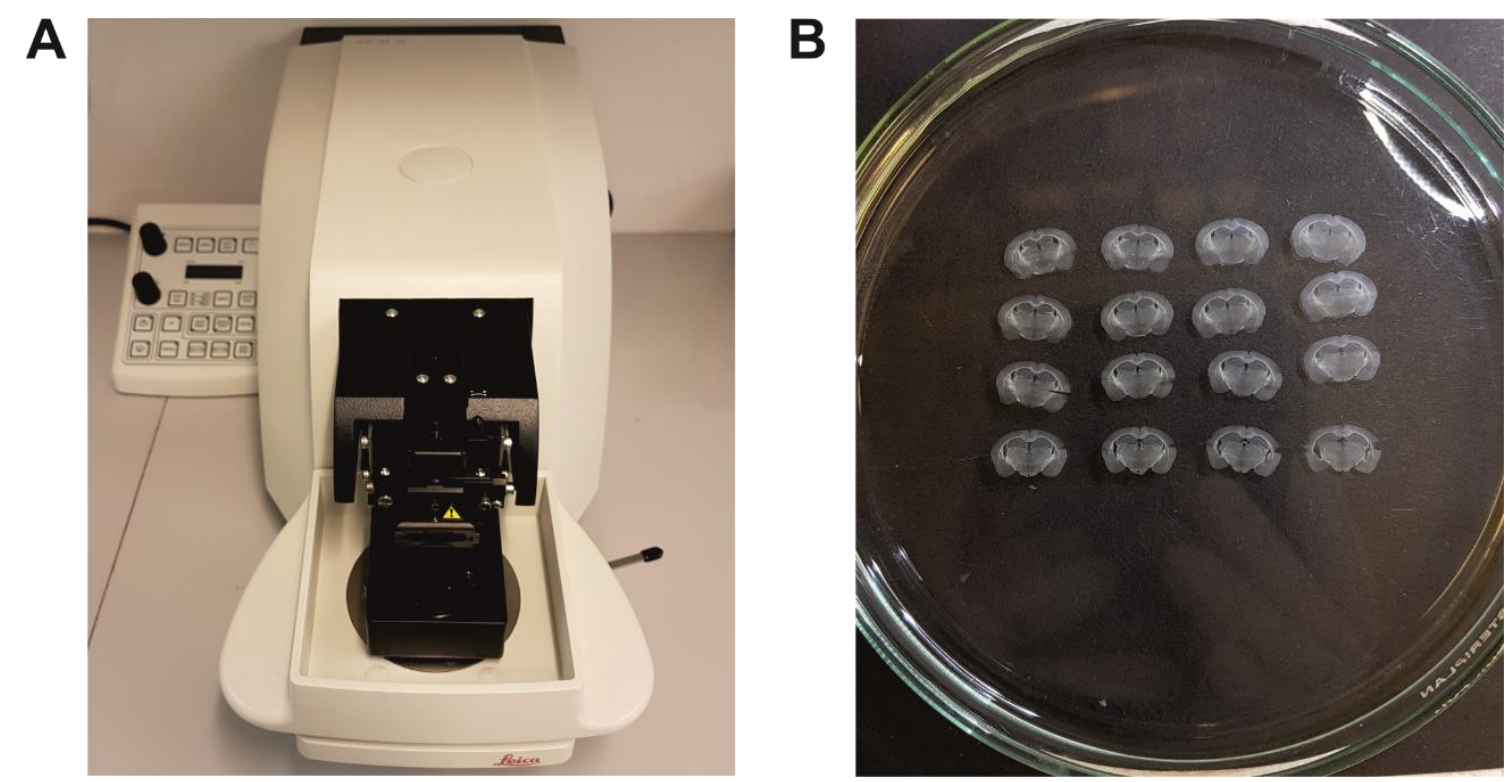

Abbildung 5: Anfertigung von Hirnschnitten. A) Mit dem Vibratom Leica VT1200S wurden $30 \mu \mathrm{m}$ dicke Hirnschnitte hergestellt. B) Die Schnitte wurden zunächst in eine mit PBS gefüllte Petrischale überführt und von dort auf Objektträger übertragen.

\subsubsection{Nissl-Färbung}

Zur Färbung der Hirnschnitte wurde eine Nissl-Färbung nach arbeitsgruppeninternem Protokoll mit Kresylviolett angewendet. Zur Herstellung der Kresylviolettlösung wurden 1,25 g Kresylviolett mit 0,75 ml reiner Essigsäure (Roth) vermengt und anschließend in $250 \mathrm{ml}$ destilliertem Wasser $\left(\mathrm{H}_{2} \mathrm{O}\right)$ unter Wärmezufuhr gelöst. Nach Abkühlung der Lösung wurden noch verbliebende grobe Partikel herausgefiltert. Eine mehrfache Verwendung der entstandenen Kresylviolettlösung war möglich.

Anhand des Färbeprotokolls (Abbildung 6) wurden die getrockneten Hirnschnitte in Färbekammern unter einem Abzug mithilfe einer absteigenden Alkoholreihe und destilliertem $\mathrm{H}_{2} \mathrm{O}$ hydratisiert (15 min in 95\% Ethanol (Th. Geyer), 1 min in 70\% Ethanol, 1 min in 50\% Ethanol, 2 min in $\mathrm{H}_{2} \mathrm{O}, 1$ min in $\mathrm{H}_{2} \mathrm{O}$ ). Danach konnten die Schnitte für 2 min im hydrophilen Kresylviolett gefärbt werden. Überschüssige Farbe wurde für 1 min in destilliertem $\mathrm{H}_{2} \mathrm{O}$ entfernt und die Schnitte schließlich durch Essigsäure differenziert und mithilfe einer aufsteigenden Alkoholreihe erneut dehydriert. Beginnend mit $1 \mathrm{~min}$ in 50\% Ethanol folgten 2 min Ethanol versetzt mit Essigsäure (1 ml reine Essigsäure pro $100 \mathrm{ml} 70 \%$ Ethanol). Die Säure wurde anschließend durch eine zweiminütige Inkubation in $95 \%$ Ethanol und das mehrmalige Eintauchen in einer weiteren Färbekammer mit 95\% Ethanol wieder entfernt. Die endgültige Entwässerung fand anschließend für $1 \mathrm{~min}$ in 
99\% Ethanol statt. Als letztes folgte die Reinigung in Xylol (Roth) für 5 min. Die Objektträger trockneten nun für mindestens 15 min unter einem Abzug und wurden anschließend mit einem Deckmedium (Eukitt Quick-hardening mountain medium) und Deckgläsern bedeckt. Zur Aushärtung des Deckmediums wurden die Objektträger für mindestens $12 \mathrm{~h}$ unter einem Abzug belassen.

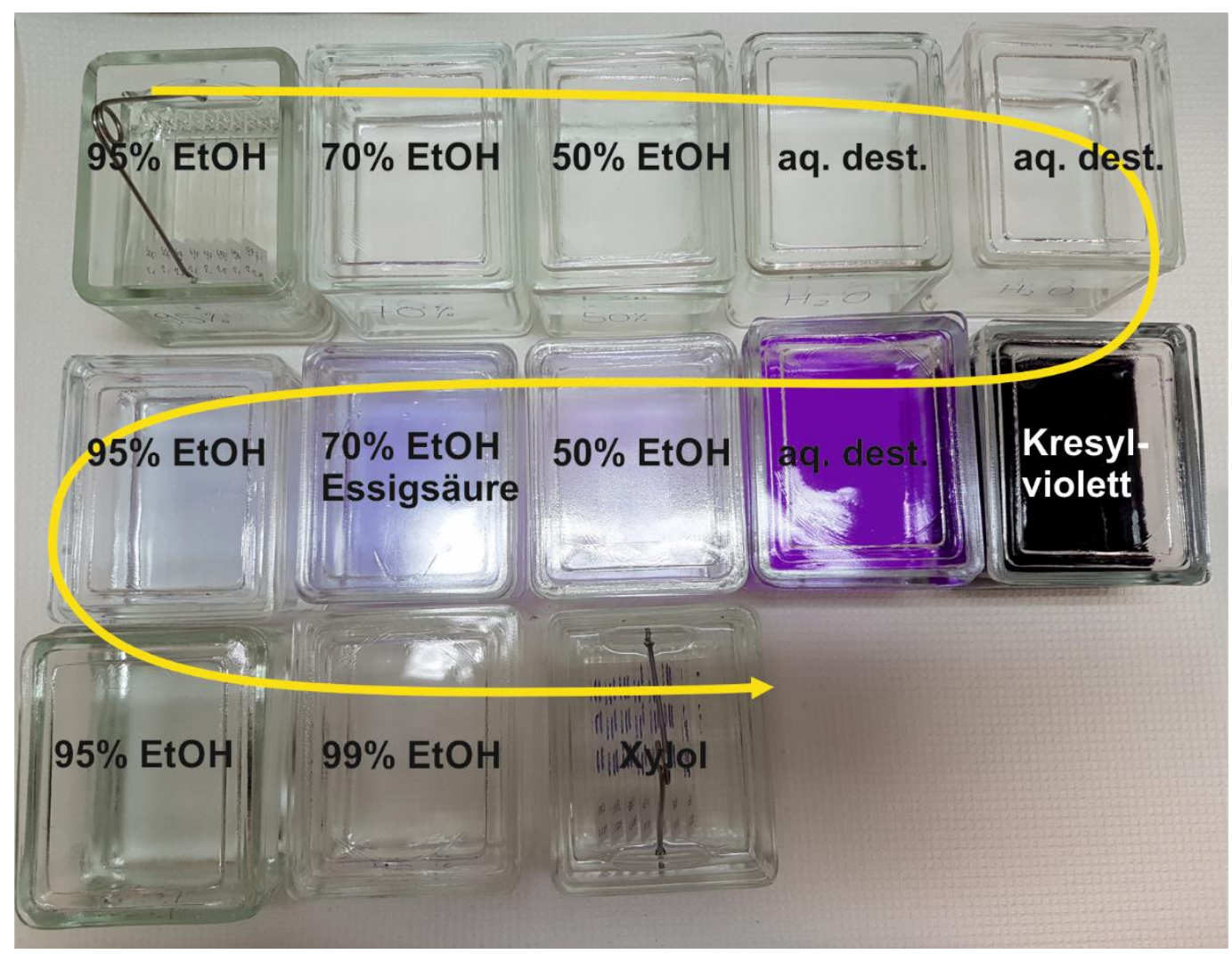

Abbildung 6: Durchführung der Nissl-Färbung. Der Färbevorgang startete mit der Hydratisierung der Schnitte durch eine absteigende Alkoholreihe gefolgt von der eigentlichen Färbung mit Kresylviolett und anschließender Dehydratisierung, Differenzierung und Reinigung. Zu sehen sind außerdem Halter mit Objektträgern an erster und letzter Position der Färbestraße.

\subsubsection{Auswertung der nach Nissl gefärbten Hirnschnitte}

Nach Fertigstellung der Nissl-Färbung wurden aus den Schnitten mithilfe eines digitalen Mikroskops (Nikon Coolscope) und der damit gekoppelten Software NIS-Elements AR (Version 3.22.13, Laboratory Imaging) digitale Bildserien erstellt (Abbildung 7). Zunächst wurden für jede Maus Gesamtaufnahmen mehrerer Hirnschnitte mit zweifacher Vergrößerung angefertigt. Die Region des gesamten Hippokampus und des darüber befindlichen Kortex wurden bei vierfacher Vergrößerung aufgenommen. Die Schichtdicke des stratum pyramidale ließ sich bei 20-facher und die einzelnen Pyramidenzellen bei 40-facher Vergrößerung optimal darstellen. Zur Auswahl einer 
einheitlichen Schnittebene diente ein topografischer Atlas des Maushirns als Orientierung (Paxinos und Franklin 2001). Mithilfe des Atlas wurden Schnitte ausgewählt, deren Seitenventrikel möglichst klein angeschnitten sowie in direkter Beziehung zum Hippokampus lagen und deren medialen habenulae als bereits makroskopisch gut sichtbare Struktur abgebildet waren (Janc et al. 2016).

A

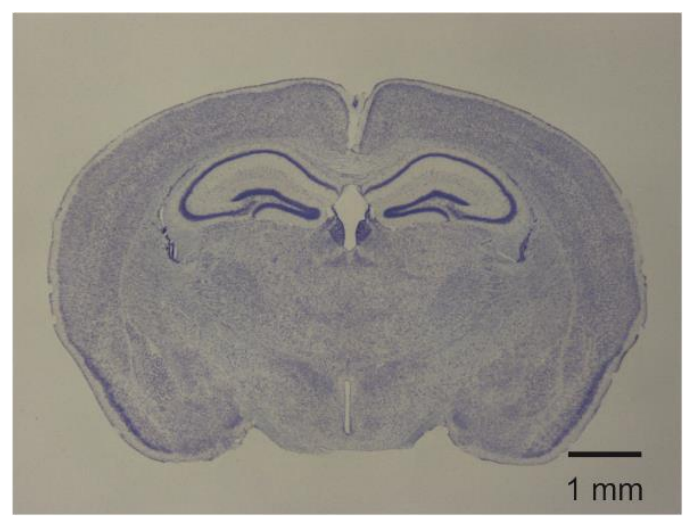

C

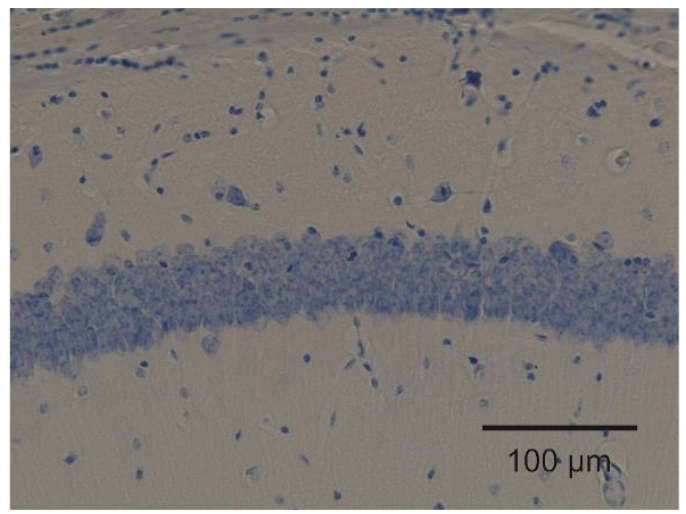

B

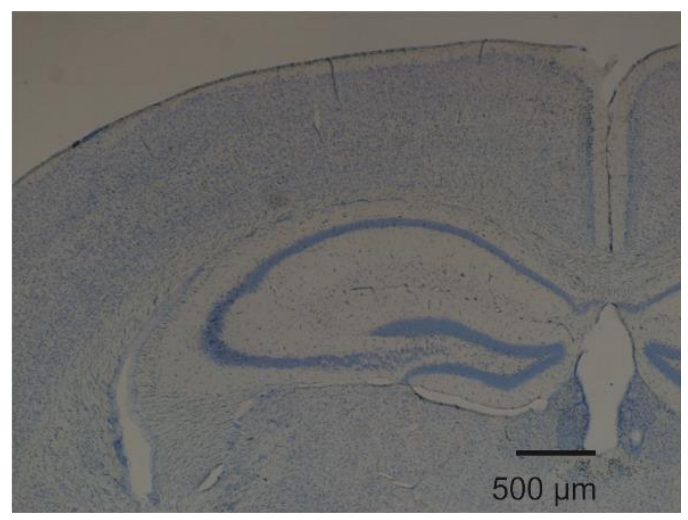

D

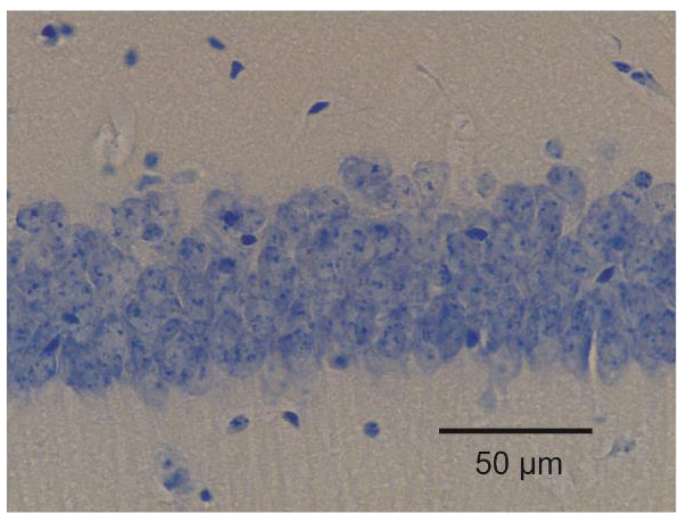

Abbildung 7: Beurteilung morphologischer Gewebeparameter. A) Zur Messung der

Hemisphärenfläche wurde die Gesamtübersicht eines den Auswahlkriterien entsprechenden Hirnschnittes verwendet und pro Maus jeweils ein Mittelwert aus rechter und linker Hemisphärenfläche des

Hirnschnittes gebildet. B) Anhand vierfach vergrößerter Aufnahmen wurden die Hippokampusfläche, die Fasertraktdicke des corpus callosum und die kortikale Schichtdicke bestimmt. Auch zur Ermittlung der Hippokampusfläche sowie der kortikalen Schichtdicke wurde aus je einem Wert der rechten und linken Hemisphäre ein Mittelwert gebildet. Die Dicke des Fasertraktes des corpus callosum wurde einmalig an der Stelle des größten Durchmessers gemessen. C) Die 20-fache Vergrößerung gab Aufschluss über die Schichtdicke des stratum pyramidale verschiedener hippokampaler Regionen. Dabei wurden rechts und links hemisphärisch jeweils drei Messwerte bestimmt und gemittelt. D) Bei 40-facher Vergrößerung wurden die Zellgrößen der Pyramidenneurone der CA1-Region ermittelt. Hierbei verhalfen pro Hemisphäre jeweils fünf exemplarische Zellsomata zum Mittelwert. 
Mithilfe der verwendeten Software konnten nun morphometrische Parameter bestimmt werden. Insgesamt wurden aus jeder der in Kapitel 2.2 genannten Gruppen sechs bis acht Mäuse morphologisch untersucht. Gemessen wurden dabei die Hemisphärenfläche, die Hippokampusfläche, die kortikale Schichtdicke, die Fasertraktdicke des corpus callosum, die Schichtdicke des stratum pyramidale der Regionen CA1, CA3 sowie des stratum granulare des gyrus dentatus und die Größe der Pyramidenzellsomata im CA1-Bereich.

\subsection{Messung der $\mathrm{H}_{2} \mathrm{O}_{2}$-Produktion isolierter Mitochondrien}

\subsubsection{Zusammensetzung der Versuchslösungen}

Für die Messung der $\mathrm{H}_{2} \mathrm{O}_{2}$-Produktion isolierter Mitochondrien wurden verschiedene Lösungen verwendet. Bei der Präparation wurden zunächst einfach konzentrierte PBS und ein Mitochondrien-Isolationspuffer benötigt. Zur Herstellung des MitochondrienIsolationspuffers wurden 20 mM HEPES (pH 7,6), 220 mM Mannitol, 70 mM Sucrose und $1 \mathrm{mM}$ EDTA in destilliertem $\mathrm{H}_{2} \mathrm{O}$ gelöst und der pH-Wert mit $1 \mathrm{M} \mathrm{KOH}$ auf 7,4 eingestellt. Diese Lösung konnte daraufhin in kleineren Rationen bei $-20^{\circ} \mathrm{C}$ als Vorrat gelagert werden. Vor Versuchsbeginn wurden der Lösung zusätzlich 0,5 mM in Ethanol gelöstes Phenylmethylsulfonylfluorid (PMSF) beigefügt und der Isolationspuffer damit vervollständigt. Die verwendete PMSF-Lösung ließ sich bei $4^{\circ} \mathrm{C}$ mehrere Wochen lagern. Die Farblösung zur Proteinbestimmung mittels Bradford Assay wurde aus Farbkonzentrat (Bio-Rad Laboratories) und destilliertem $\mathrm{H}_{2} \mathrm{O}$ im Verhältnis 1:4 an jedem Versuchstag frisch angefertigt. Hierbei handelt es sich um eine Lösung, die den Farbstoff CoomassieBrilliant-Blau beinhaltet. Die für das Bradford Assay benötigten Proteinstandards wurden aus bovinem Serumalbumin (BSA) sowie Isolationspuffer hergestellt und konnten mehrere Wochen bei $4^{\circ} \mathrm{C}$ gelagert und wiederverwendet werden. Die Proteinkonzentrationen der Standardlösungen betrugen $0 \mathrm{mg} / \mathrm{ml}, 0,2 \mathrm{mg} / \mathrm{ml}, 0,5 \mathrm{mg} / \mathrm{ml}$, $0,7 \mathrm{mg} / \mathrm{ml}$ und $0,9 \mathrm{mg} / \mathrm{ml}$.

Das mitochondriale Atmungsmedium O5 (MiRO5) wurde nach einem Protokoll der Oroboros Instruments $\mathrm{GmbH}$ erstellt. Dafür wurden 0,5 $\mathrm{mM}$ des $\mathrm{Ca}^{2+}$-Chelators EGTA, $3 \mathrm{mM}$ des Magnesiumdonors $\mathrm{MgCl}_{2}$ (Scharlau) und $60 \mathrm{mM}$ des $\mathrm{K}^{+}$-Donors K-Laktobionat vermengt. Zusätzlich wurden dem mitochondrialen Atmungsmedium $20 \mathrm{mM}$ des Membranstabilisators und Radikalfängers Taurin, $10 \mathrm{mM}$ des Phosphatmolekül-Donors $\mathrm{KH}_{2} \mathrm{PO}_{4}$ (Merck), $20 \mathrm{mM}$ der Puffersubstanz HEPES, $110 \mathrm{mM}$ 
D-Sucrose (Roth) und $1 \mathrm{~g} / \mathrm{l}$ BSA beigefügt. Abschließend wurde der pH-Wert der Lösung mit $5 \mathrm{M} \mathrm{KOH}$ auf 7,1 eingestellt und somit insgesamt ein ideales, physiologisches Medium für Mitochondrien erzeugt (Gnaiger et al. 2000). Auch diese Lösung ließ sich in kleineren Mengen bei $-20^{\circ} \mathrm{C}$ lagern.

Für die abschließenden Messungen wurden mit destilliertem $\mathrm{H}_{2} \mathrm{O}$ außerdem jeweils Substratlösungen aus Pyruvat (1 M), Malat (0,4 M) und Succinat (1 M) angemischt. Die Pyruvatlösung wurde an jedem Versuchstag frisch hergestellt. Die Malat- sowie die Succinatlösung konnten bei $-20^{\circ} \mathrm{C}$ gelagert werden. Als Farbstoff zur Messung der $\mathrm{H}_{2} \mathrm{O}_{2}-$ Produktion der isolierten Mitochondrien diente Amplex UltraRed (Thermo Fisher Scientific) gelöst in Dimethylsulfoxid (DMSO). Als Katalysator dieser Reaktion wurde Meerrettich-Peroxidase (horseradish peroxidase, HRP) gelöst in MiRO5 verwendet. Sowohl Farbstoff als auch Katalysator konnten bei $-20^{\circ} \mathrm{C}$ aufbewahrt werden.

\subsubsection{Präparation und Isolation der Mitochondrien}

Vor der Präparation wurden alle genannten Lösungen vorbereitet, benötigtes Besteck und Instrumentarium auf Eis kühl gestellt und die Zentrifuge (Hettich, Mikro $220 \mathrm{R}$ ) auf $4^{\circ} \mathrm{C}$ temperiert. Nach tiefer Betäubung der Maus mithilfe von Diethylether und anschließender Dekapitation durch berechtigte Mitglieder der Arbeitsgruppe wurde das Gehirn zügig entnommen. Dafür wurden Kopfhaut und Schädeldecke abgelöst und das Gewebe zur Kühlung mit PBS übergossen, bevor das Gehirn nach Entfernung weiterer kleiner Knochenpartikel vorsichtig extrahiert werden konnte. Anschließend wurde das Gehirn für weitere zwei Minuten in eiskaltem PBS abgekühlt und danach zur Gewinnung von kortikalem Gewebe mit einer spitzen Pinzette fixiert. Nach Abtrennung des Frontalkortex und Teilung der Hemisphären konnte beidseitig eine Probe des Kortex entnommen werden. Die regelmäßige Verwendung von PBS als kühlende Lösung erwies sich als besonders gewebeschonend.

Anschließend wurden die Gewebeproben jeweils mit $700 \mu$ l Mitochondrien-Isolationspuffer in einen Glasmörser des Volumens $2 \mathrm{ml}$ gegeben und unter ständiger Kühlung des Mörsers auf Eis mit 15 - 20 Stößen manuell homogenisiert. Während der Etablierung dieses Arbeitsprotokolls zeigte sich, dass eine manuelle Homogenisierung der elektrischen Homogenisierung in Bezug auf den Funktionserhalt der Mitochondrien zu bevorzugen war. Die anschließende Zentrifugation der Proben erfolgte zunächst bei 800 x g für 15 min. Der Überstand wurde daraufhin bei 800 x g für 30 min zentrifugiert 
und der dabei entstandene Überschuss für 10 min bei 10.000 x g. Im nun erkennbaren Pellet befanden sich die Mitochondrien der jeweiligen Hirngewebeproben. Nach Entfernung des Überstands, wurde das Mitochondrienpellet mit $100 \mu$ l gekühltem Isolationspuffer erneut in Lösung gebracht und weiterhin kühl gehalten.

\subsubsection{Bestimmung der Proteinkonzentration}

Im weiteren Verlauf wurde die Mitochondrienkonzentration der hergestellten Lösungen mit der allgemeinen Proteinkonzentration dieser gleichgesetzt. Zur Bestimmung der Proteinkonzentration wurde das Bradford Assay angewendet. Hierbei handelt es sich um eine photometrische Messmethode auf Basis der Absorptionsspektroskopie. Der Farbstoff Coomassie-Brilliant-Blau in der hierfür verwendeten Farblösung bindet an basische und aromatische Aminosäuren in Proteinen. Diese Bindung verursacht eine Verschiebung des Absorptionsmaximums des Farbstoffes von 470 auf 595 nm sowie einen Farbwechsel der Probenlösungen in Abhängigkeit von der Proteinkonzentration, was photometrisch registriert werden kann (Bradford 1976). In diesem Fall fanden die Messungen am Spektrometer DU 800 (Beckmann Coulter) und der zugehörigen Systemsoftware statt. Zunächst wurde mithilfe der vorbereiteten Proteinstandards mit bekannter Proteinkonzentration eine Standardkurve erzeugt. Dafür wurden jeweils $20 \mu$ l Standardlösung mit $1 \mathrm{ml}$ Farblösung in Kunststoffküvetten (SARSTEDT AG \& Co. KG) vermengt und bei Raumtemperatur 5 min inkubiert. Es folgte die Messung der Absorption der Standardlösungen bei $595 \mathrm{~nm}$. Anhand der resultierenden Standardkurve konnte im Nachhinein die Proteinkonzentration der Probenlösungen bestimmt werden. Um möglichst viel Probenmaterial für nachfolgende Untersuchungen zu erhalten, wurden $10 \mu 1$ der Probenlösung mit $10 \mu \mathrm{l}$ Isolationspuffer vermengt, danach mit $1 \mathrm{ml}$ Farblösung bei Raumtemperatur 5 min inkubiert und anschließend gemessen. Die Verwendung einer geringeren Menge an Probenlösung pro Küvette im Gegensatz zur Standardlösung wurde nach Ermittlung der Proteinkonzentration rechnerisch angepasst.

\subsubsection{Messung der $\mathrm{H}_{2} \mathrm{O}_{2}$-Produktion mit Amplex UltraRed}

Zur Erfassung der mitochondrialen $\mathrm{H}_{2} \mathrm{O}_{2}$-Produktion wurde das Spektrofluorometer SAFAS Flx-Xenius (SAFAS Monaco) in Kombination mit der zugehörigen Steuer- und Analyse-Software SP2000V7 (SAFAS Monaco) verwendet. Mittels Fluoreszenzspektroskopie konnte so die relative $\mathrm{H}_{2} \mathrm{O}_{2}$-Produktion von bis zu zehn Proben gleichzeitig 
gemessen werden (Abbildung 8). Als Küvetten dienten wiederverwendbare Glasküvetten mit lichtdurchlässigem Quarzglasboden des Geräteherstellers.

A

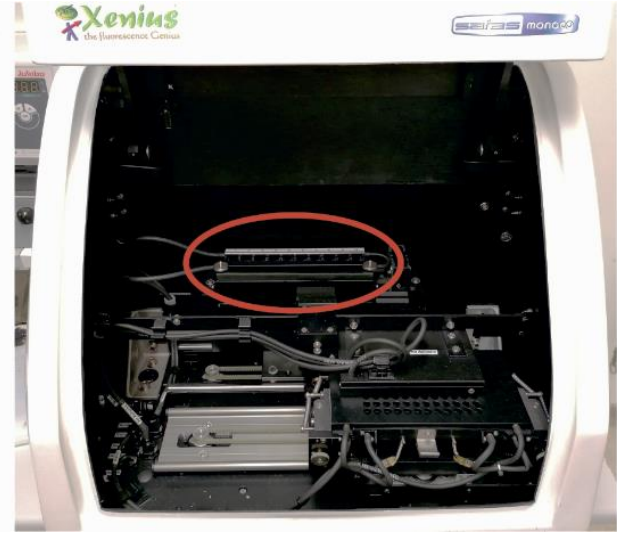

B

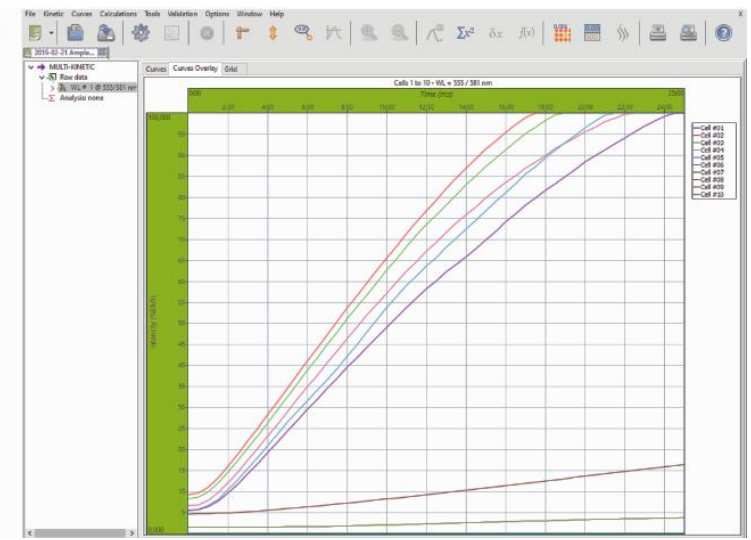

Abbildung 8: Spektrofluorometer SAFAS Flx-Xenius. A) Das Spektrofluorometer SAFAS Flx-Xenius verfügt über einen motorisierten 10-fach-Küvettenhalter (rot markiert), sodass zu den definierten Messzeitpunkten alle $30 \mathrm{~s}$ bis zu zehn Proben unmittelbar nacheinander analysiert werden konnten.

B) Die Ergebnisse dieser gemessenen Proben konnten mittels Software in einer jeweils zusammenfassenden Kinetik dargestellt werden.

Der verwendete Farbstoff Amplex UltraRed leitet sich von 10-Acetyl-3,7-Dihydroxyphenoxazin (Amplex Red) ab. Er hat eine höhere Sensitivität als sein Vorgänger Amplex Red, wird allerdings vom Hersteller bezüglich seiner genauen chemischen Zusammensetzung nicht differenzierter beschrieben. Amplex UltraRed reagiert mit $\mathrm{H}_{2} \mathrm{O}_{2}$ unter Katalyse der HRP in einer stöchiometrischen 1:1 Reaktion zu Amplex UltroxRed, einem stark fluoreszierenden Reaktionsprodukt. Das Reaktionsprodukt Amplex UltroxRed hat ein Anregungsmaximum von $568 \mathrm{~nm}$ sowie ein Emissionsmaximum von $581 \mathrm{~nm}$ und ähnelt dem Farbstoff Resorufin, der bei äquivalenter Reaktion von Amplex Red mit $\mathrm{H}_{2} \mathrm{O}_{2}$ entsteht (Abbildung 9).

Das Messprinzip bestand darin, dass die Proben durch den Küvettenboden über eine Lichtquelle mit nachgeschaltetem, exzitationsseitigem Monochromator mit der Wellenlänge des Anregungsmaximums von Amplex UltroxRed (568 nm) angeregt wurden. Die daraufhin emittierte Strahlung $(581 \mathrm{~nm})$ wurde orthogonal dazu von einem photomultiplier erfasst. Auch dort selektierte ein emissionsseitiger Monochromator die gewünschte Wellenlänge (Abbildung 10). Die registrierte Fluoreszenzintensität stieg proportional zur Entstehung des Reaktionsprodukts Amplex UltroxRed aus Farbstoff und $\mathrm{H}_{2} \mathrm{O}_{2}$ und gab damit Rückschluss auf die Menge des von den Mitochondrien freigesetzten 
$\mathrm{H}_{2} \mathrm{O}_{2}$. Dabei konnte mit diesem Versuchsaufbau keine absolute $\mathrm{H}_{2} \mathrm{O}_{2}$-Konzentration ermittelt werden, sondern nur die relative $\mathrm{H}_{2} \mathrm{O}_{2}$-Produktion, die im Anschluss der Messungen als Vergleich zwischen verschiedenen Proben diente.

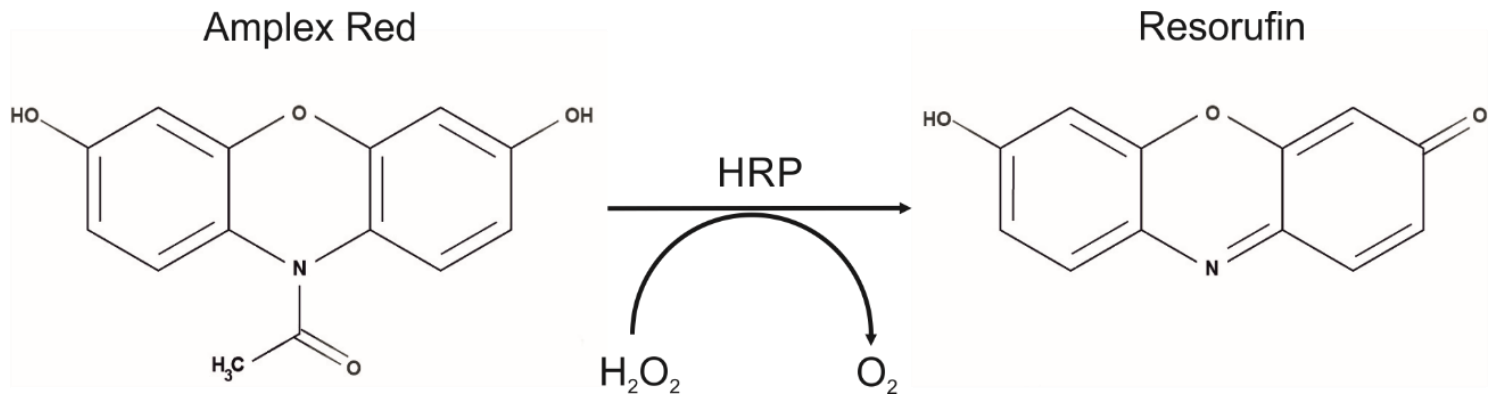

Abbildung 9: Reaktion von Amplex Red zu Resorufin. Unter Katalyse der HRP reagiert Amplex Red mit $\mathrm{H}_{2} \mathrm{O}_{2}$ 1:1 zu dem stark fluoreszierenden Reaktionsprodukt Resorufin. Analog dazu verläuft die Reaktion von Amplex UltraRed zu Amplex UltroxRed.

In jede Küvette wurden $30 \mu \mathrm{g}$ Mitochondrien gegeben und diese Menge bis $500 \mu \mathrm{lmit}$ MiRO5 aufgefüllt. Zusätzlich wurden $5 \mathrm{mM}$ Pyruvat, $2 \mathrm{mM}$ Malat und $10 \mathrm{mM}$ Succinat hinzugefügt und $10 \mu \mathrm{M}$ des Farbstoffs Amplex UltraRed sowie $1 \mathrm{U} / \mathrm{ml}$ des Katalysators HRP ergänzt. Um eine möglichst gleichzeitige Reaktion des Farbstoffes mit dem mitochondrial produzierten $\mathrm{H}_{2} \mathrm{O}_{2}$ hervorzurufen, wurden die Mitochondrien stets als letzte Komponente hinzugegeben. Mittels eines Umwälzwasserbades wurden die Küvetten auf eine konstante Temperatur von $35^{\circ} \mathrm{C}$ erwärmt. Neben den beschriebenen Gewebeproben wurden bei jeder Messung zusätzliche Kontrollproben ohne mitochondriales Gewebe angefertigt. Die Dauer der Messung betrug $30 \mathrm{~min}$, in denen alle $30 \mathrm{~s}$ eine Messung vorgenommen wurde. Das Anregungsmaximum wurde nach Empfehlung des Herstellers auf $555 \mathrm{~nm}$ und das Emissionsmaximum auf $581 \mathrm{~nm}$ eingestellt. Weitere Einstellungsparameter sind der Tabelle $2 \mathrm{zu}$ entnehmen. Nach Abschluss einer Messung wurden die Fluoreszenzintensitäten in das Programm Microsoft Excel exportiert und auf ihren Ausgangswert normiert, um mögliche Pipettierunterschiede zwischen den einzelnen Küvetten auszugleichen. 


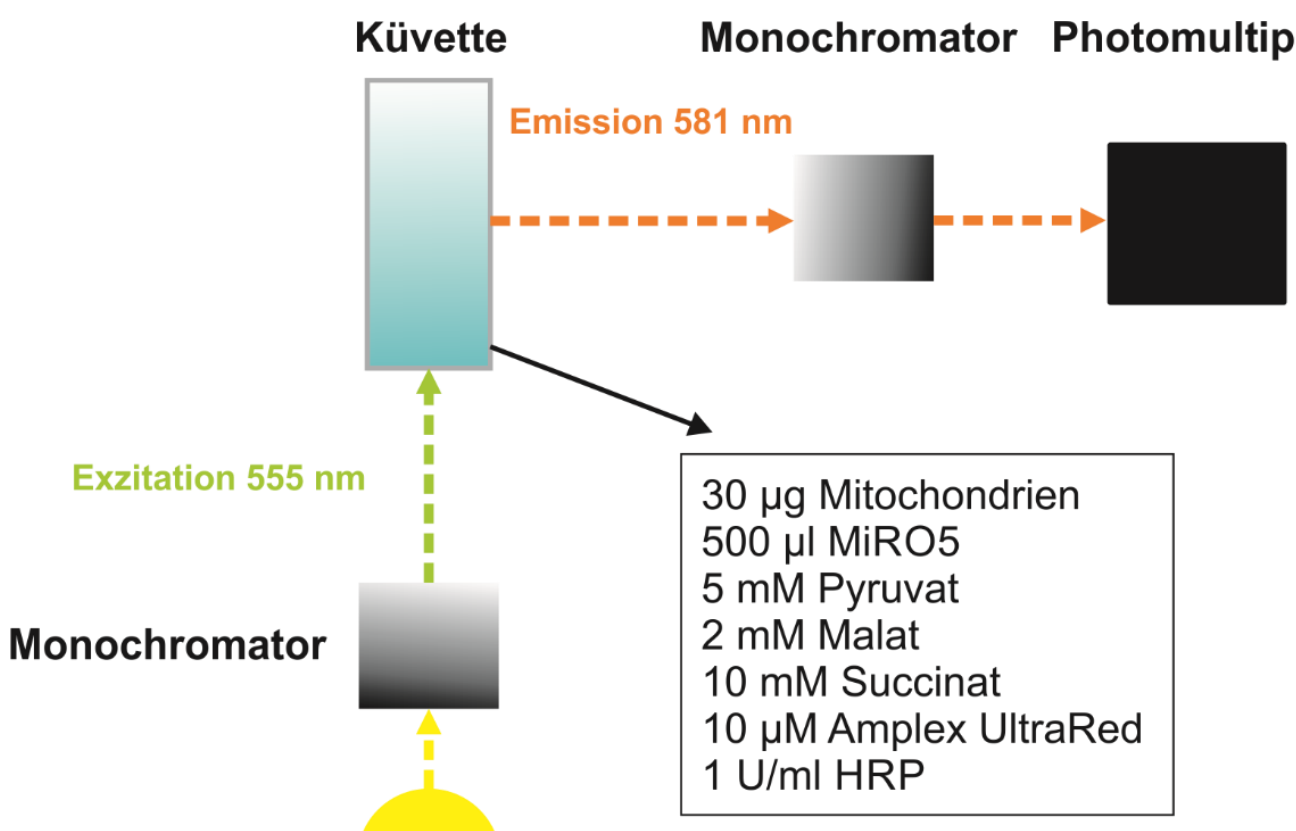

Lichtquelle

Abbildung 10: Schematischer Versuchsaufbau der Fluoreszenzspektroskopie. An der Messposition wurde die jeweilige Küvette durch den Küvettenboden mit Licht der Wellenlänge $555 \mathrm{~nm}$ angeregt. Ein photomultiplier registrierte das von der Probe emittierte Licht der Wellenlänge $581 \mathrm{~nm}$ im rechten Winkel dazu. Ein Anregungs- und ein Emissionsmonochromator dienten der spektralen Isolierung dieser Wellenlängen. Anschließend wurde über den motorisierten Küvettenschlitten die nächste der zehn Küvetten in die Messposition gefahren und der Vorgang entsprechend wiederholt, bis alle Küvetten für den jeweiligen Messzeitpunkt gemessen wurden. Die Küvetten wurden alle $30 \mathrm{~s}$ gemessen und dies zur Erstellung einer Reaktionskinetik für 30 min durchgeführt.

Tabelle 2: Einstellungsparameter Spektroflurometer SAFA Flx-Xenius

\begin{tabular}{|c|c|c|c|}
\hline Unit & Fluo Intensity & Averaging time in $s$ & 1 \\
\hline EXC & $555 \mathrm{~nm}$ & EXC Slit & $10 \mathrm{~nm}$ \\
\hline$E M$ & $581 \mathrm{~nm}$ & EM Slit & $5 \mathrm{~nm}$ \\
\hline Cells & PC auto & Number & 10 \\
\hline Filtering & Full filtering & Voltage & $500 \mathrm{~V}$ \\
\hline Cycles cadence & $30 \mathrm{~s}$ & blank & no \\
\hline Duration at cadence & $30 \mathrm{~min}$ & general blank & none \\
\hline
\end{tabular}

Abgebildet sind die für die Messungen verwendeten Einstellungsparameter im Programm SP2000V7 für die Benutzung des Spektroflurometers SAFAS Flx-Xenius (SAFAS Monaco). Aus Gründen der Übersichtlichkeit wurde hier auf die Übersetzung der Parameter verzichtet. 


\subsection{Statistik}

Die Darstellung der Ergebnisse dieser Arbeit wurde als Mittelwert \pm Standardabweichung vorgenommen. Dabei deutet die in Diagrammen auftretende Kennzeichnung mit einem Stern (*) auf eine signifikante Veränderung $(\mathrm{p} \leq 0,05)$ und die Kennzeichnung mit zwei Sternen $(* *)$ auf einen sehr signifikanten Unterschied $(\mathrm{p} \leq 0,01)$ hin. Die Anzahl (n) stellt die Menge der betrachteten Mäuse oder Mitochondrienproben dar.

Zur statistischen Auswertung wurde die Software SigmaStat 3.5 (Systat Software GmbH) verwendet. Entsprachen die Ergebnisse einer Normalverteilung, wurde zunächst die Einweg-Varianzanalyse (ANOVA) durchgeführt. Wenn sich hierbei Unterschiede zwischen den Versuchsgruppen ergaben, wurden die einzelnen Ergebnisse anschließend jeweils mit den Ergebnissen der normal gefütterten gesunden und erkrankten Mäuse anhand des Holm-Sidak-Tests verglichen. Zeigten die Ergebnisse in seltenen Fällen keine Normalverteilung, wurde die Kruskal-Wallis Varianzanalyse an Rängen durchgeführt und anschließend der Dunn-Test zum Vergleich der relevanten Versuchsgruppen verwendet. 


\section{Ergebnisse}

Zur Evaluierung einer oralen Antioxidantien-Therapie im Mausmodell für das RettSyndrom wurden im Rahmen dieser Dissertation verschiedene Untersuchungen durchgeführt, die Aufschluss über den therapeutischen Effekt der oral verabreichten, antioxidativ wirksamen Substanzen Vitamin E, $\alpha$-Liponsäure und N-Acetylcystein geben sollten. Verglichen wurden in diesem Zusammenhang jeweils Mäuse gleichen Geschlechts und Alters. Dabei fand eine Gegenüberstellung von Wildtypen und hemizygoten Männchen $\left(\mathrm{Mecp}^{-/ \mathrm{y}}\right)$ bzw. heterozygoten Weibchen $\left(\mathrm{Mecp}^{+/-}\right)$statt, von denen jeweils eine Gruppe Normalfutter (NF) und eine andere Gruppe speziell angefertigtes Antioxidantien-Futter (AOF) erhielt. Die Gabe des jeweiligen Futters begann nach dem Absetzen der Mäuse mit dem postnatalen Tag p20. Insgesamt diente die angewendete Methodik der Betrachtung verschiedener Effekte der AntioxidantienTherapie und berücksichtigte multiple Wirkorte wie den Gesamtorganismus, das Nervengewebe und die Mitochondrien der Mäuse.

Untersucht wurden die Parameter Körpergröße, Körpergewicht und Hirngewicht. Außerdem dienten Nissl-gefärbte Hirnschnitte der Betrachtung morphologischer Gewebeparameter wie Hemisphärenfläche, Hippokampusfläche, kortikale Schichtdicke, Fasertraktdicke des corpus callosum, Schichtdicke des stratum pyramidale der Regionen CA1 und CA3 und des stratum granulare im gyrus dentatus sowie CA1-Pyramidenzellsomata. Für die genannten Parameter gab es für beide Geschlechter Untersuchungsgruppen von Mäusen im Alter von 50 Tagen. Zusätzlich wurde eine Versuchsgruppe mit weiblichen Mäusen des Alters 400 Tage generiert, um Langzeitfolgen der oralen AntioxidantienTherapie zu evaluieren. Da Mecp $2^{-/ y}$-Männchen eine geringere Lebenserwartung aufweisen als $M e c p 2^{+/-}$-Weibchen, konnten für das männliche Geschlecht keine Mäuse des Alters 400 Tage beurteilt werden. Als weitere Untersuchung zur Beantwortung der Grundfragestellung dienten fluoreszenzspektroskopische Messungen der mitochondrialen $\mathrm{H}_{2} \mathrm{O}_{2}$-Produktion. Dabei wurden Mitochondrien aus Hirngewebe von 50 Tage alten männlichen Mäusen isoliert und untersucht. Im Rahmen des Ergebnisteils wurde die in Tabelle 1 definierte Farbcodierung zur Einteilung der Versuchsgruppen beibehalten. Die Anzahl (n) der untersuchten Mäuse ist den Abbildungen zu entnehmen. Statistisch signifikante Unterschiede wurden in den Diagrammen mit Verbindungsklammern gekennzeichnet. Sofern nicht explizit angegeben, zeigte der jeweilige Vergleich zwischen den mit NF und AOF gefütterten Wildtypen keine signifikanten Abweichungen. 


\subsection{Körpergewicht, Körpergröße und Hirngewicht}

Zunächst wurden Körpergewicht und -größe aller Mäuse bestimmt, die anschließend auch der Beurteilung morphologischer Gewebeparameter dienten. Nach transkardialer Perfusion durch entsprechend befugte Mitglieder der Arbeitsgruppe konnte das Gehirn der Mäuse entnommen, in PFA gelagert und vor Herstellung histologischer Schnitte gewogen werden. Bekannt ist in diesem Zusammenhang, dass Rett-Patientinnen unter Wachstumsstörungen und Mikrozephalie leiden (Chahrour und Zoghbi 2007). Auch im Modell MeCP2-defizienter Mäuse konnten diese Merkmale bestätigt werden (Chen et al. 2001; Guy et al. 2001). Im Rahmen dieser Dissertation wurden daraufhin zusätzlich antioxidativ therapierte Rett-Mäuse in den Vergleich aufgenommen.

\subsubsection{Männchen (p50)}

Bei Männchen der Altersklasse 50 Tage zeigte der Vergleich in den drei Kategorien Körpergewicht, Körpergröße und Hirngewicht zwischen Wildtypen $(n=6)$ und normal gefütterten $M e c p 2^{-/ y}$-Mäusen $(n=6)$ signifikant geringere Werte bei den $M e c p 2^{-/ y_{-}}$ Männchen $(\mathrm{p}<0,01)$. Auch unter Gabe von AOF blieben diese Unterschiede zwischen Mecp $^{-/ y}$-Mäusen $(\mathrm{n}=7)$ und normal gefütterten Wildtypen bestehen (Abbildung 11). Bei Betrachtung des Quotienten aus Hirn- und Körpergewicht waren keine signifikanten Unterschiede erkennbar. Die Ergebnisse sind in Tabelle 3 aufgeführt.

Tabelle 3: Körpergewicht, Körpergröße und Hirngewicht männlicher Mäuse (p50)

\begin{tabular}{|c|c|c|c|}
\hline Männchen (p50) & Futter & WT & Mecp2-/y \\
\hline \multirow[t]{2}{*}{ Körpergewicht [g] } & NF & $23,5 \pm 1,4$ & $14,8 \pm 3,7$ \\
\hline & $\mathrm{AOF}$ & $24,5 \pm 1,7$ & $14,3 \pm 2,7$ \\
\hline \multirow[t]{2}{*}{ Körpergröße [cm] } & $\mathrm{NF}$ & $8,5 \pm 0,2$ & $7,1 \pm 0,5$ \\
\hline & $\mathrm{AOF}$ & $8,4 \pm 0,2$ & $7,1 \pm 0,4$ \\
\hline \multirow[t]{2}{*}{ Hirngewicht $[\mathrm{g}]$} & NF & $0,51 \pm 0,01$ & $0,41 \pm 0,02$ \\
\hline & $\mathrm{AOF}$ & $0,48 \pm 0,02$ & $0,41 \pm 0,02$ \\
\hline \multirow[t]{2}{*}{ Hirngewicht/Körpergewicht [\%] } & $\mathrm{NF}$ & $2,2 \pm 0,1$ & $2,9 \pm 0,6$ \\
\hline & $\mathrm{AOF}$ & $2,0 \pm 0,1$ & $2,9 \pm 0,5$ \\
\hline
\end{tabular}



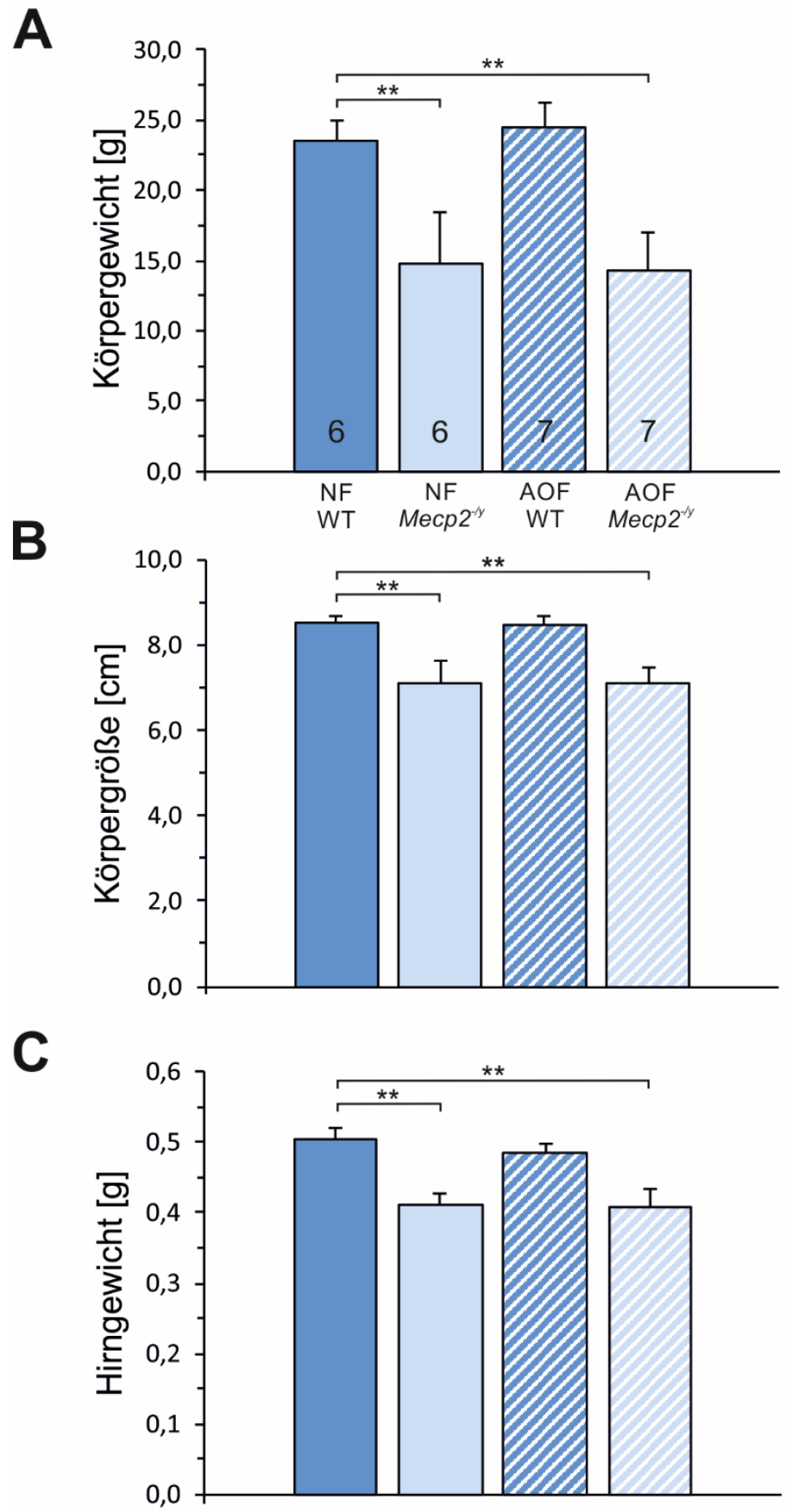

Abbildung 11: Körpergewicht, Körpergröße und Hirngewicht männlicher Mäuse (p50). Darstellung von Körpergewicht in g (A), Körpergröße in cm (B) und Hirngewicht in g (C) männlicher Mäuse (p50). Die Anzahl (n) der betrachteten Versuchsgruppen ist der Basis des Diagramms A zu entnehmen und kann auf Diagramm B und C übertragen werden. Auch sind Fehlerbalken im Sinne der Standardabweichung sowie Signifikanzniveaus mithilfe von Sternchen abgebildet. Dabei beschreibt ein Stern das Signifikanzniveau $\mathrm{p} \leq 0,05$ und zwei Sterne $\mathrm{p} \leq 0,01$. Gleiches gilt für alle weiteren Abbildungen im Rahmen der Ergebnisvorstellung. Es zeigt sich, dass sowohl bei Gabe von NF als auch AOF RettMännchen signifikant leichter und kleiner waren sowie ein geringeres Hirngewicht im Vergleich zu den Wildtyp-Männchen aufwiesen. 


\subsubsection{Kurzzeitbehandlung Weibchen (p50)}

In der Gruppe der Weibchen des Alters 50 Tage zeigten sich zwischen den Vergleichsgruppen keine signifikanten Unterschiede im Körpergewicht. Dahingegen waren Körper-

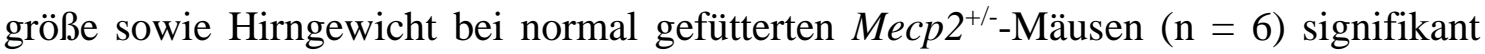
geringer $(\mathrm{p}<0,05)$ als bei den Wildtyp-Weibchen $(\mathrm{n}=7)$. Nach antioxidativer Fütterung $\operatorname{der}$ Mecp $^{+/-}$-Weibchen $(\mathrm{n}=7)$ konnten die Unterschiede zu den normal gefütterten Wildtypen nicht mehr verzeichnet werden (Abbildung 12). Zusätzlich stellte sich die Körpergröße der Rett-Weibchen nach antioxidativer Therapie mit 7,96 \pm 0,52 cm signifikant größer dar als die der normal gefütterten $M e c p 2^{+/-}$-Mäuse $(7,52 \pm 0,15 \mathrm{~cm}, \mathrm{p}<0,05)$. Der Quotient aus Hirn- und Körpergewicht zeigte keine signifikanten Unterschiede zwischen den Versuchsgruppen. In Tabelle 4 sind die Ergebnisse dieser Versuchsgruppe gesammelt aufgeführt.

Tabelle 4: Körpergewicht, Körpergröße und Hirngewicht weiblicher Mäuse (p50)

\begin{tabular}{|l|l|l|l|}
\hline \multicolumn{1}{|c|}{ Weibchen (p50) } & \multicolumn{1}{|c|}{ Futter } & \multicolumn{1}{c|}{ WT } & \multicolumn{1}{c|}{ Mecp2 $^{+/-}$} \\
\hline \hline \multirow{2}{*}{ Körpergewicht [g] } & NF & $18,1 \pm 3$ & $17,4 \pm 1,6$ \\
\cline { 2 - 5 } & AOF & $19,2 \pm 1,3$ & $19,0 \pm 2,6$ \\
\hline \multirow{2}{*}{ Körpergröße [cm] } & & & $7,5 \pm 0,2$ \\
\hline \multirow{2}{*}{ Hirngewicht [g] } & NF & $8,0 \pm 0,5$ & $8,0 \pm 0,5$ \\
\cline { 2 - 5 } & AOF & $8,0 \pm 0,3$ & $0,44 \pm 0,02$ \\
\hline \multirow{2}{*}{ Hirngewicht/Körpergewicht [\%] } & & & $0,47 \pm 0,03$ \\
\hline & $\mathrm{NF}$ & $0,49 \pm 0,04$ & $2,5 \pm 0,1$ \\
\cline { 2 - 5 } & $\mathrm{AOF}$ & $0,51 \pm 0,02$ & $2,5 \pm 0,3$ \\
\hline & $\mathrm{NOF}$ & $2,7 \pm 0,1$ & \\
\hline
\end{tabular}



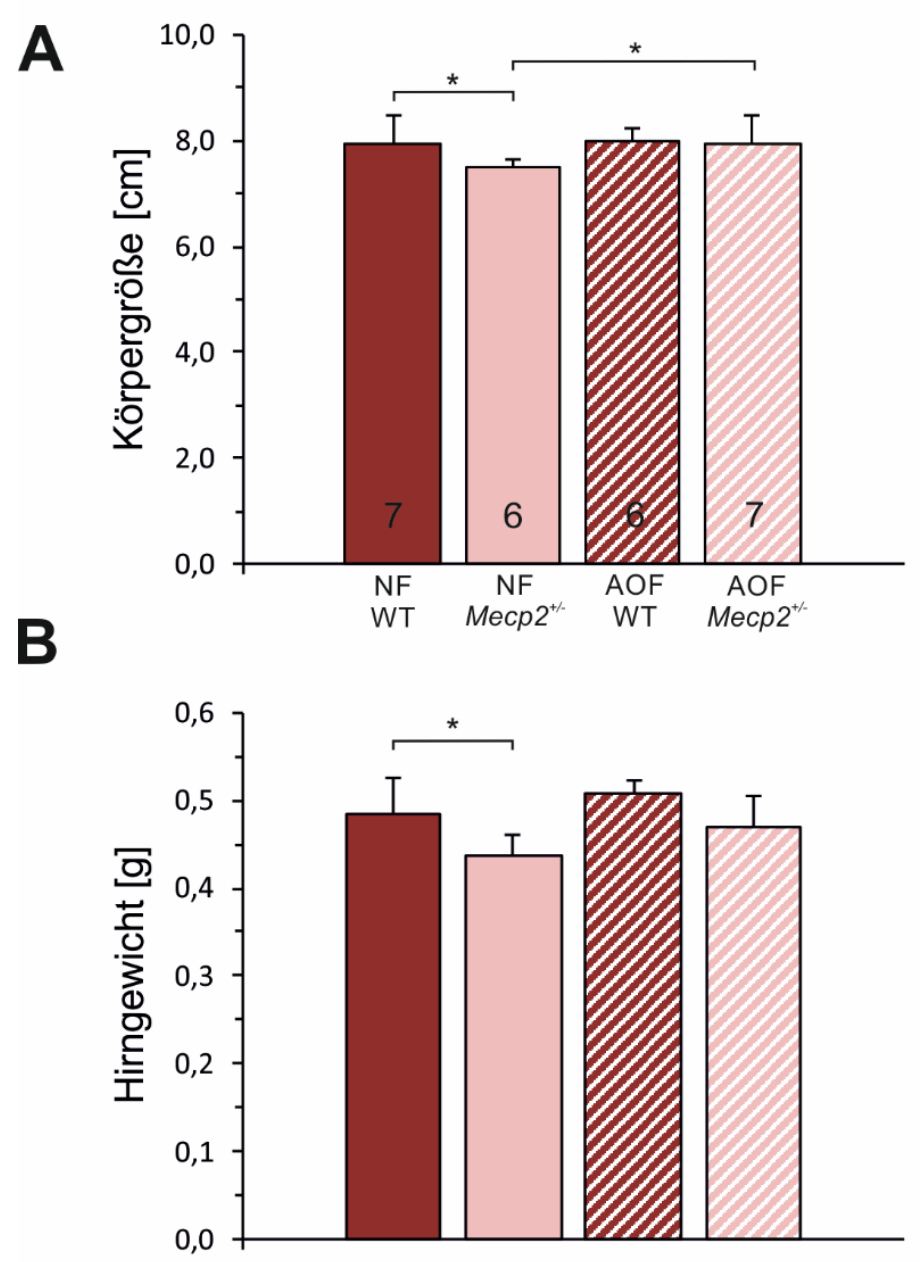

Abbildung 12: Körpergröße und Hirngewicht weiblicher Versuchsgruppen (p50). A) Darstellung der Körpergröße der Weibchen (p50) in cm. Auffällig ist, dass die normal gefütterten Rett-Weibchen signifikant kleiner waren als Wildtyp-Weibchen. Dieser Unterschied war zwischen antioxidativ gefütterten Rett-Weibchen und Wildtypen nicht mehr zu sehen. Zusätzlich waren antioxidativ gefütterte Rett-Weibchen signifikant größer als die Rett-Weibchen, die NF erhielten. B) Veranschaulichung des Hirngewichts der weiblichen Mäuse in g. Hier zeigt sich, ähnlich zur Körpergröße, dass das Hirngewicht normal gefütterter Rett-Weibchen signifikant kleiner als das der Wildtyp-Weibchen war und sich dieser Zustand durch das AOF aufhob. Da das Körpergewicht der Weibchen keine Unterschiede zwischen den Versuchsgruppen zeigte (Tabelle 4), wurde dieser Parameter an dieser Stelle nicht zusätzlich grafisch abgebildet. 


\subsubsection{Langzeitbehandlung Weibchen (p400)}

Weibchen im Alter von 400 Tagen wiesen keine signifikanten Unterschiede der Körpergröße auf. Auch ergab der Vergleich des Körpergewichts zwischen Wildtyp-Weibchen $(\mathrm{n}=7)$ und normal gefütterten Rett-Weibchen $(\mathrm{n}=8)$ keinen signifikanten Unterschied. Allerdings waren die antioxidativ behandelten $\operatorname{Mecp}^{+/-}$-Weibchen $(\mathrm{n}=6)$ erheblich schwerer $(\mathrm{p}<0,05)$ als die Wildtypen. Das Hirngewicht der Mecp2 $2^{+-}-$Weibchen stellte sich sowohl mit NF als auch mit AOF signifikant geringer dar als das der WildtypWeibchen ( $\mathrm{p}<0,01)$ (Abbildung 13). Der Quotient aus Hirn- und Körpergewicht zeigte einen signifikant geringeren Wert $(\mathrm{p}<0,05)$ bei den mit AOF gefütterten $M e c p 2^{+/-}$ Weibchen im Vergleich zu den Wildtypen. Tabelle 5 stellt die Ergebnisse gesammelt dar.

Tabelle 5: Körpergewicht, Körpergröße und Hirngewicht weiblicher Mäuse (p400)

\begin{tabular}{|l|l|l|l|}
\hline \multicolumn{1}{|c|}{ Weibchen (p400) } & \multicolumn{1}{|c|}{ Futter } & \multicolumn{1}{c|}{ WT } & \multicolumn{1}{c|}{ Mecp2 $^{+/-}$} \\
\hline \hline \multirow{2}{*}{ Körpergewicht [g] } & NF & $31,1 \pm 3,4$ & $38,5 \pm 19,5$ \\
\cline { 2 - 5 } & AOF & $33,8 \pm 4,3$ & $54,7 \pm 11,6$ \\
\hline \multirow{2}{*}{ Körpergröße [cm] } & & & \\
\hline \multirow{2}{*}{ Hirngewicht [g] } & NF & $9,0 \pm 0,5$ & $8,6 \pm 0,9$ \\
\cline { 2 - 5 } & AOF & $9,6 \pm 0,4$ & $9,0 \pm 0,2$ \\
\hline \multirow{2}{*}{ Hirngewicht/Körpergewicht [\%] } & & & $0,43 \pm 0,03$ \\
\hline & NF & $0,52 \pm 0,02$ & $0,43 \pm 0,03$ \\
\cline { 2 - 5 } & AOF & $0,52 \pm 0,02$ & $1,4 \pm 0,6$ \\
\cline { 2 - 5 } & AOF & $1,5 \pm 0,2$ & $0,8 \pm 0,3$ \\
\hline
\end{tabular}


A

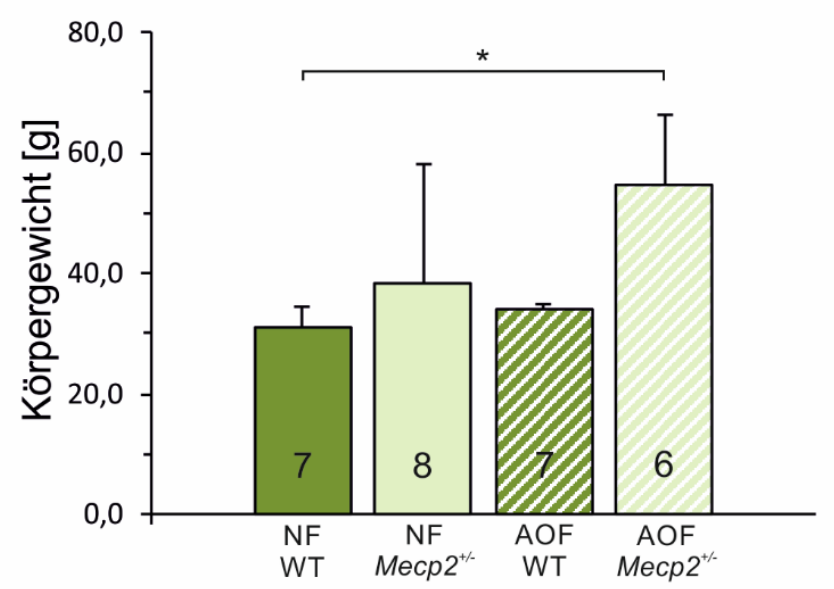

B

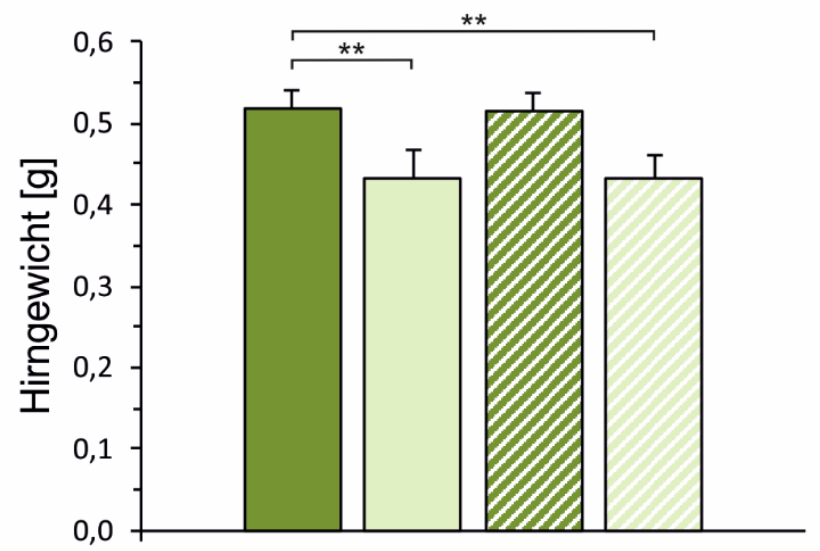

Abbildung 13: Körpergewicht und Hirngewicht weiblicher Versuchsgruppen (p400). A) Darstellung des Körpergewichts der weiblichen Mäuse (p400) in g. Zu sehen ist, dass die antioxidativ behandelten Rett-Weibchen signifikant schwerer waren als die normal gefütterten Wildtyp-Weibchen. Zwischen den normal gefütterten Rett-Weibchen und Wildtyp-Weibchen gab es keine signifikanten Unterschiede im Körpergewicht. B) Abbildung des Hirngewichts in g bei Langzeitbetrachtung weiblicher Mäuse. Sowohl bei Normalfütterung als auch bei antioxidativer Fütterung konnte ein signifikant kleineres Hirngewicht der Rett-Weibchen im Vergleich zu den Wildtyp-Weibchen registriert werden. 


\subsection{Morphologische Gewebeparameter}

Die Herstellung histologischer Schnittbilder erfolgte mittels Vibratom. Dabei wurden Frontalschnitte des fixierten Hirngewebes mit einer Dicke von $30 \mu \mathrm{m}$ im Bereich des Hippokampus angefertigt, auf Objektträger gebracht und getrocknet. Daraufhin konnten die Hirnschnitte mittels Nissl-Färbung durch den Farbstoff Kresylviolett zur Darstellung neuronaler Schichten gefärbt werden. Die gefärbten Hirnschnitte wurden anschließend nach den zuvor definierten Kriterien selektiert und mithilfe eines digitalen Mikroskops eingelesen und vermessen. Bei einfacher Vergrößerung wurden zunächst die Hemisphärenflächen der Hirnschnitte bestimmt. Eine vierfache Vergrößerung diente der Darstellung der Hippokampusfläche, kortikalen Schichtdicke und der Fasertraktdicke des corpus callosum. Die Schichtdicke des stratum pyramidale der hippokampalen Regionen CA1 und CA3 sowie das stratum granulare im gyrus dentatus wurden bei 20-facher Vergrößerung gemessen und die Pyramidenzellsomata bei 40-facher Vergrößerung dargestellt.

Hirnbiopsien von Rett-Patientinnen bewiesen in diesem Zusammenhang schon früh die verminderte Größe von Nervenzellsomata als Begleiterscheinung des RTT (Rett 1966; Bauman et al. 1995). Im Mausmodell konnten neben der Mikrozephalie ebenfalls geringere neuronale Somatagrößen nachgewiesen werden (Chen et al. 2001). Auch die Arbeitsgruppe um Prof. M. Müller bestätigte eine verkleinerte Hippokampusformation und weniger große CA1-Neurone in MeCP2-defizienten männlichen Mäusen (Fischer et al. 2009). Daran anknüpfend diente die Auswertung histologischer Schnittbilder in dieser Dissertation der Beurteilung potenzieller zerebraler Strukturverbesserungen durch die orale Antioxidantien-Therapie (Abbildung 14). 


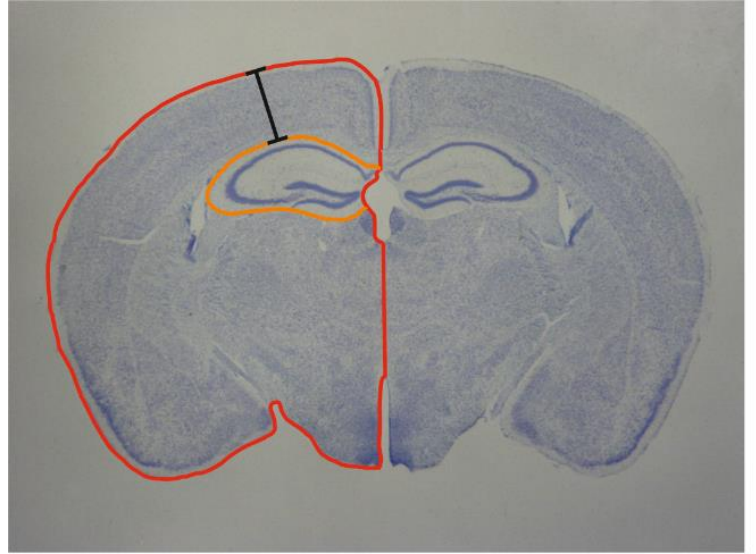

$\overline{1 \mathrm{~mm}}$

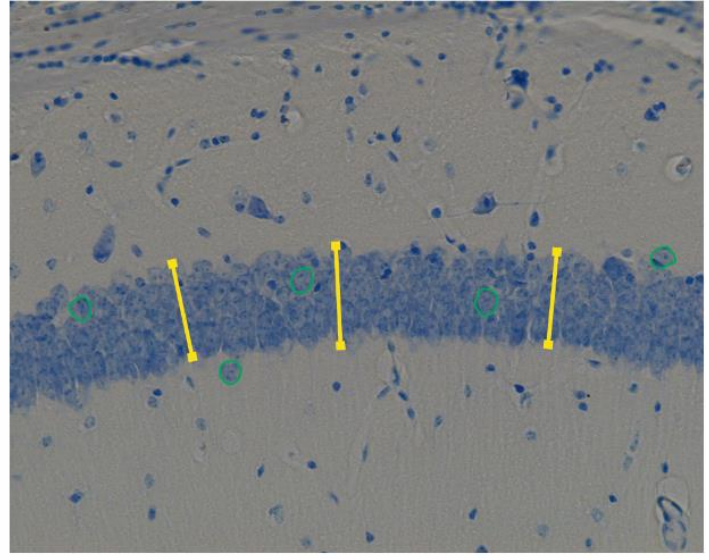

$100 \mu \mathrm{m}$

Abbildung 14: Morphometrische Analyse histologischer Schnittbilder. Um zu bewerten, ob AOF der Mikrozephalie im RTT entgegenwirkt, wurden folgende Gewebeparameter betrachtet: Hemisphärenfläche (rot), Hippokampusfläche (orange), kortikale Schichtdicke (schwarz), stratum pyramidale verschiedener hippokampaler Regionen (gelb) und Pyramidenzellsomata (grün).

\subsubsection{Männchen (p50)}

Bei den Männchen im Alter von 50 Tagen ergaben die Auswertungen der Hemisphärenfläche, der kortikalen Schichtdicke und der Zellgröße der CA1Pyramidenzellsomata jeweils signifikant geringere Werte $(\mathrm{p}<0,01)$ für die normal gefütterten $M e c p 2^{-/ y}$-Mäuse $(n=6)$ im Vergleich zu den Wildtyp-Mäusen $(n=6)$. Dieser Unterschied blieb trotz Antioxidantien-Fütterung in der Kategorie der Hemisphärenfläche bestehen. Anders gestaltete es sich bei der kortikalen Schichtdicke und der Zellgröße der CA1-Nervenzellsomata. Hier führte das AOF zur Zunahme der Schichtdicke des Kortex sowie der Größe der Pyramidenzellsomata und somit zur Aufhebung des Unterschieds zwischen $M e c p 2^{-/ y}$-Mäusen ( $\mathrm{n}=7$ ) und normal gefütterten Wildtypen. Zusätzlich zeigten die antioxidativ behandelten $M e c p 2^{-/ y}$-Mäuse in diesen Parametern signifikant erhöhte $(\mathrm{p}<0,05)$ Werte im Vergleich zu normal gefütterten Mecp2 $2^{-/ y}-$ Mäusen (Abbildung 15). Alle weiteren Parameter (Hippokampusfläche, Fasertraktdicke des corpus callosum, Schichtdicke des stratum pyramidale der Regionen CA1 und CA3 sowie des stratum granulare des gyrus dentatus) wiesen keine Unterschiede zwischen den Versuchsgruppen auf. Die detaillierten Ergebnisse sind in Tabelle 6 aufgeführt. 
Tabelle 6: Morphologische Gewebeparameter männlicher Mäuse (p50)

\begin{tabular}{|c|c|c|c|}
\hline Männchen (p50) & Futter & WT & Mecp $2^{-/ y}$ \\
\hline \multirow[t]{2}{*}{ Hemisphärenfläche $\left[\mathrm{mm}^{2}\right]$} & NF & $27,03 \pm 1,06$ & $23,91 \pm 0,37$ \\
\hline & $\mathrm{AOF}$ & $26,69 \pm 0,68$ & $23,68 \pm 0,86$ \\
\hline \multirow[t]{2}{*}{ Hippokampusfläche $\left[\mathrm{mm}^{2}\right]$} & $\mathrm{NF}$ & $2,72 \pm 0,40$ & $2,61 \pm 0,16$ \\
\hline & $\mathrm{AOF}$ & $2,45 \pm 0,40$ & $2,34 \pm 0,19$ \\
\hline \multirow[t]{2}{*}{ kortikale Schichtdicke $[\mu \mathrm{m}]$} & $\mathrm{NF}$ & $1002,15 \pm 38,88$ & $871,62 \pm 54,94$ \\
\hline & $\mathrm{AOF}$ & $1071,57 \pm 91,65$ & $952,93 \pm 45,33$ \\
\hline \multirow{2}{*}{$\begin{array}{l}\text { Hippokampusfläche/ } \\
\text { Hemisphärenfläche [\%] }\end{array}$} & $\mathrm{NF}$ & $10,0 \pm 0,1$ & $10,9 \pm 0,6$ \\
\hline & $\mathrm{AOF}$ & $9,1 \pm 1,3$ & $9,9 \pm 0,6$ \\
\hline \multirow{2}{*}{$\begin{array}{l}\text { Fasertraktdicke } \\
\text { corpus callosum }[\mu \mathrm{m}]\end{array}$} & $\mathrm{NF}$ & $224,54 \pm 68,65$ & $236,19 \pm 43,71$ \\
\hline & $\mathrm{AOF}$ & $249,68 \pm 66,09$ & $219,67 \pm 25,40$ \\
\hline \multirow{2}{*}{$\begin{array}{l}\text { Schichtdicke stratum pyramidale } \\
\text { CA1 }[\mu \mathrm{m}]\end{array}$} & $\mathrm{NF}$ & $60,70 \pm 3,15$ & $56,18 \pm 6,00$ \\
\hline & $\mathrm{AOF}$ & $58,57 \pm 2,63$ & $56,62 \pm 3,60$ \\
\hline \multirow{2}{*}{$\begin{array}{l}\text { Schichtdicke stratum pyramidale } \\
\text { CA3 }[\mu \mathrm{m}]\end{array}$} & $\mathrm{NF}$ & $71,00 \pm 5,81$ & $67,79 \pm 5,24$ \\
\hline & $\mathrm{AOF}$ & $71,05 \pm 3,68$ & $79,54 \pm 2,47$ \\
\hline \multirow{2}{*}{$\begin{array}{l}\text { Schichtdicke stratum granulare des } \\
\text { gyrus dentatus }[\mu \mathrm{m}]\end{array}$} & $\mathrm{NF}$ & $79,10 \pm 2,19$ & $77,09 \pm 7,52$ \\
\hline & $\mathrm{AOF}$ & $66,82 \pm 3,43$ & $75,96 \pm 5,38$ \\
\hline \multirow{2}{*}{$\begin{array}{l}\text { Größe Pyramidenzellsomata } \\
\text { CA1 }\left[\mu \mathrm{m}^{2}\right]\end{array}$} & $\mathrm{NF}$ & $150,90 \pm 12,32$ & $129,51 \pm 7,20$ \\
\hline & $\mathrm{AOF}$ & $147,91 \pm 12,02$ & $140,94 \pm 4,88$ \\
\hline
\end{tabular}



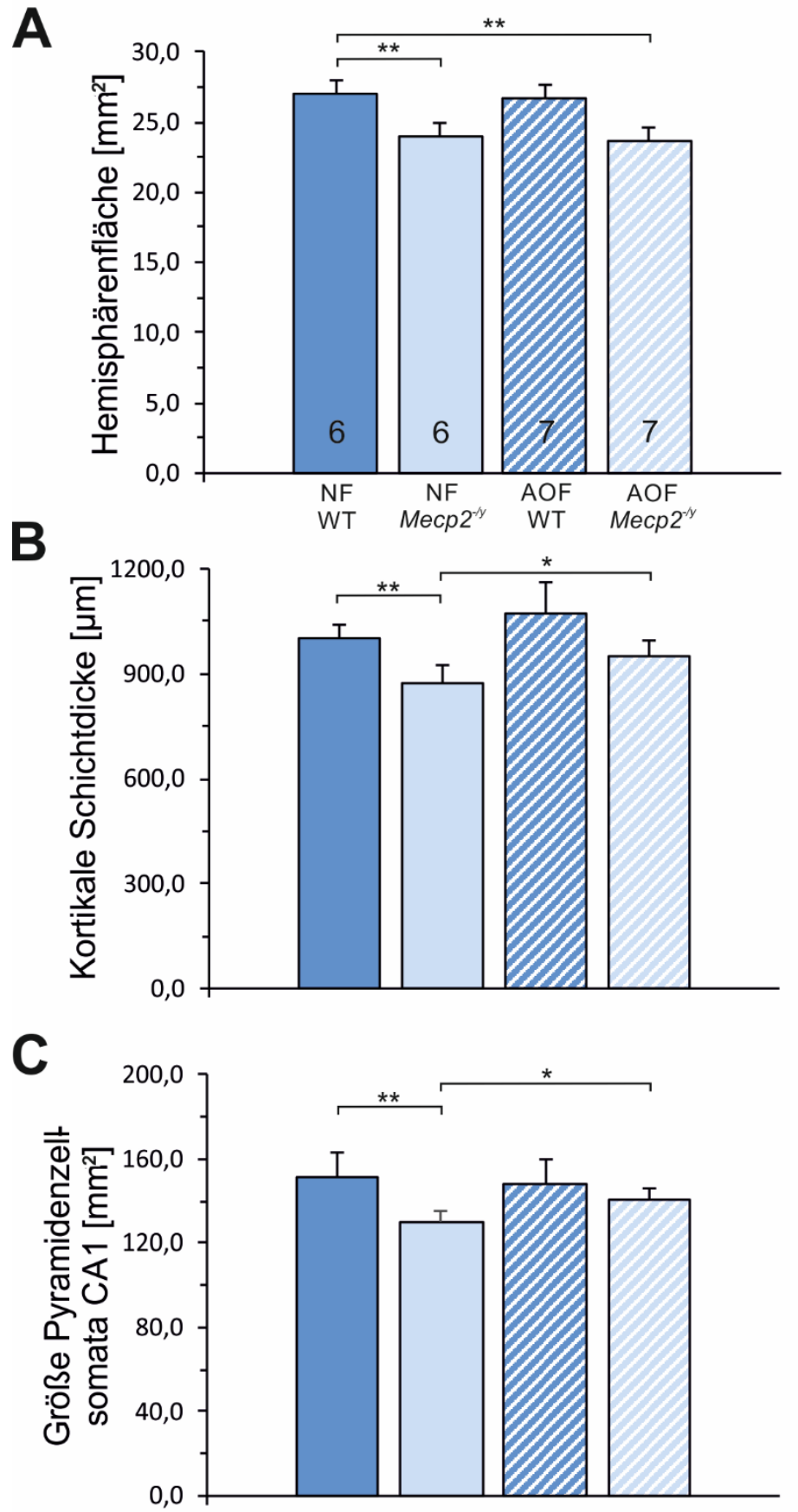

\section{Abbildung 15: Darstellung morphologischer Gewebeparameter männlicher Mäuse (p50).}

A) Hemisphärenfläche männlicher Mäuse (p50) in $\mathrm{mm}^{2}$. Sowohl normal gefütterte als auch antioxidativ gefütterte Rett-Männchen wiesen signifikant kleinere Hemisphärenflächen im Vergleich zum Wildtyp auf. B) Kortikale Schichtdicke in $\mu \mathrm{m}$. C) Größe der CA1-Pyramidenzellsomata in $\mathrm{mm}^{2}$. Während sich die kortikale Schichtdicke und Größe der CA1-Pyramidenzellsomata der normal gefütterten Rett-Männchen signifikant kleiner als die der Wildtyp-Männchen darstellte, war dieser Unterschied nach AntioxidantienTherapie nicht mehr zu erkennen. Zusätzlich zeigten antioxidativ gefütterte Rett-Männchen signifikant größere kortikale Schichtdicken und Zellsomata als normal gefütterte Rett-Männchen. 


\subsubsection{Kurzzeitbehandlung Weibchen (p50)}

Auch bei den 50 Tage alten Weibchen sind die Größe der Hemisphärenfläche sowie die Fläche der Pyramidenzellsomata der CA1-Region bei normal gefütterten heterozygoten Rett-Mäusen $(n=6)$ signifikant kleiner $(\mathrm{p}<0,05)$ als bei Wildtyp-Weibchen $(\mathrm{n}=6)$. Durch die Antioxidantien-Fütterung konnte zwar keine signifikante Verbesserung der beiden Parameter bei $M e c p 2^{+/-}$-Weibchen $(n=7)$ im Vergleich zu normal gefütterten RettWeibchen registriert werden, jedoch ergab sich eine tendenzielle Zunahme beider Parameter, sodass kein Unterschied mehr zu den Wildtypen unter Normalfutter bestand (Abbildung 16). Alle weiteren Untersuchungsbereiche (Hippokampusfläche, kortikale Schichtdicke, Fasertraktdicke des corpus callosum, Schichtdicke des stratum pyramidale der Regionen CA1 und CA3 sowie des stratum granulare des gyrus dentatus) zeigten keine signifikanten Abweichungen zwischen den Versuchsgruppen. Tabelle 7 gibt eine detaillierte Gesamtübersicht über die morphologischen Gewebeparameter weiblicher Mäuse im Alter von 50 Tagen.

\subsubsection{Langzeitbehandlung Weibchen (p400)}

Bei Langzeitbehandlung der Weibchen bis zu einem postnatalen Alter von 400 Tagen ergaben die Auswertungen morphologischer Gewebeparameter zunächst signifikant geringere Werte zwischen normal gefütterten $M e c p 2^{+/-}$-Weibchen $(\mathrm{n}=8)$ im Vergleich zu Wildtypen $(n=7)$ in den Kategorien Hemisphärenfläche, Hippokampusfläche und kortikale Schichtdicke $(\mathrm{p}<0,01)$ sowie bei der Schichtdicke des stratum pyramidale der CA1-Region ( $\mathrm{p}<0,05)$. Für die Parameter Hemisphärenfläche und kortikale Schichtdicke blieben diese Differenzen auch unter Antioxidantien-Therapie bestehen und zeigten keine Verbesserungen (Abbildung 17). Dahingegen führte das AOF zur Aufhebung der signifi-

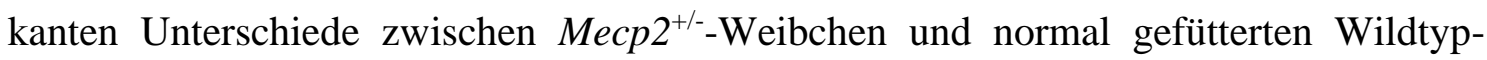
Mäusen bei der Betrachtung der Hippokampusfläche sowie des stratum pyramidale (Abbildung 18). Die anderen vermessenen Parameter (Fasertraktdicke des corpus callosum, Schichtdicke des stratum pyramidale der Region CA3 sowie des stratum granulare des gyrus dentatus, CA1-Pyramidenzellsomata) ließen keine generellen Unterschiede erkennen. Eine Übersicht ist in Tabelle 8 dargestellt. 
Tabelle 7: Morphologische Gewebeparameter weiblicher Mäuse (p50)

\begin{tabular}{|c|c|c|c|}
\hline Weibchen (p50) & Futter & WT & $\operatorname{Mecp} 2^{+/-}$ \\
\hline \multirow[t]{2}{*}{ Hemisphärenfläche $\left[\mathrm{mm}^{2}\right]$} & NF & $26,92 \pm 1,41$ & $25,06 \pm 0,65$ \\
\hline & AOF & $27,64 \pm 0,74$ & $25,94 \pm 1,02$ \\
\hline \multirow[t]{2}{*}{ Hippokampusfläche $\left[\mathrm{mm}^{2}\right]$} & NF & $2,60 \pm 0,34$ & $2,38 \pm 0,31$ \\
\hline & AOF & $2,65 \pm 0,36$ & $2,43 \pm 0,12$ \\
\hline \multirow[t]{2}{*}{ kortikale Schichtdicke $[\mu \mathrm{m}]$} & $\mathrm{NF}$ & $1054,85 \pm 67,33$ & $1023,73 \pm 86,64$ \\
\hline & $\mathrm{AOF}$ & $1070,90 \pm 24,65$ & $1012,75 \pm 28,15$ \\
\hline \multirow{2}{*}{$\begin{array}{l}\text { Hippokampusfläche/ } \\
\text { Hemisphärenfläche [\%] }\end{array}$} & NF & $9,6 \pm 0,9$ & $9,5 \pm 1,3$ \\
\hline & AOF & $9,6 \pm 1,1$ & $9,4 \pm 0,3$ \\
\hline \multirow{2}{*}{$\begin{array}{l}\text { Fasertraktdicke } \\
\text { corpus callosum }[\mu \mathrm{m}]\end{array}$} & NF & $210,99 \pm 41,20$ & $215,29 \pm 26,76$ \\
\hline & AOF & $244,08 \pm 51,17$ & $232,95 \pm 22,20$ \\
\hline \multirow{2}{*}{$\begin{array}{l}\text { Schichtdicke stratum pyramidale } \\
\text { CA1 }[\mu \mathrm{m}]\end{array}$} & $\mathrm{NF}$ & $61,86 \pm 2,89$ & $56,42 \pm 4,62$ \\
\hline & AOF & $65,06 \pm 3,87$ & $58,54 \pm 4,69$ \\
\hline \multirow{2}{*}{$\begin{array}{l}\text { Schichtdicke stratum pyramidale } \\
\text { CA3 }[\mu \mathrm{m}]\end{array}$} & NF & $74,84 \pm 2,15$ & $67,94 \pm 2,91$ \\
\hline & $\mathrm{AOF}$ & $68,50 \pm 4,39$ & $71,00 \pm 6,02$ \\
\hline \multirow{2}{*}{$\begin{array}{l}\text { Schichtdicke stratum granulare des } \\
\text { gyrus dentatus }[\mu \mathrm{m}]\end{array}$} & $\mathrm{NF}$ & $80,66 \pm 2,72$ & $78,31 \pm 4,23$ \\
\hline & AOF & $80,64 \pm 6,12$ & $80,50 \pm 4,73$ \\
\hline \multirow{2}{*}{$\begin{array}{l}\text { Größe Pyramidenzellsomata } \\
\text { CA1 }\left[\mu \mathrm{m}^{2}\right]\end{array}$} & NF & $155,25 \pm 10,41$ & $137,13 \pm 11,18$ \\
\hline & AOF & $150,35 \pm 6,19$ & $148,02 \pm 10,67$ \\
\hline
\end{tabular}




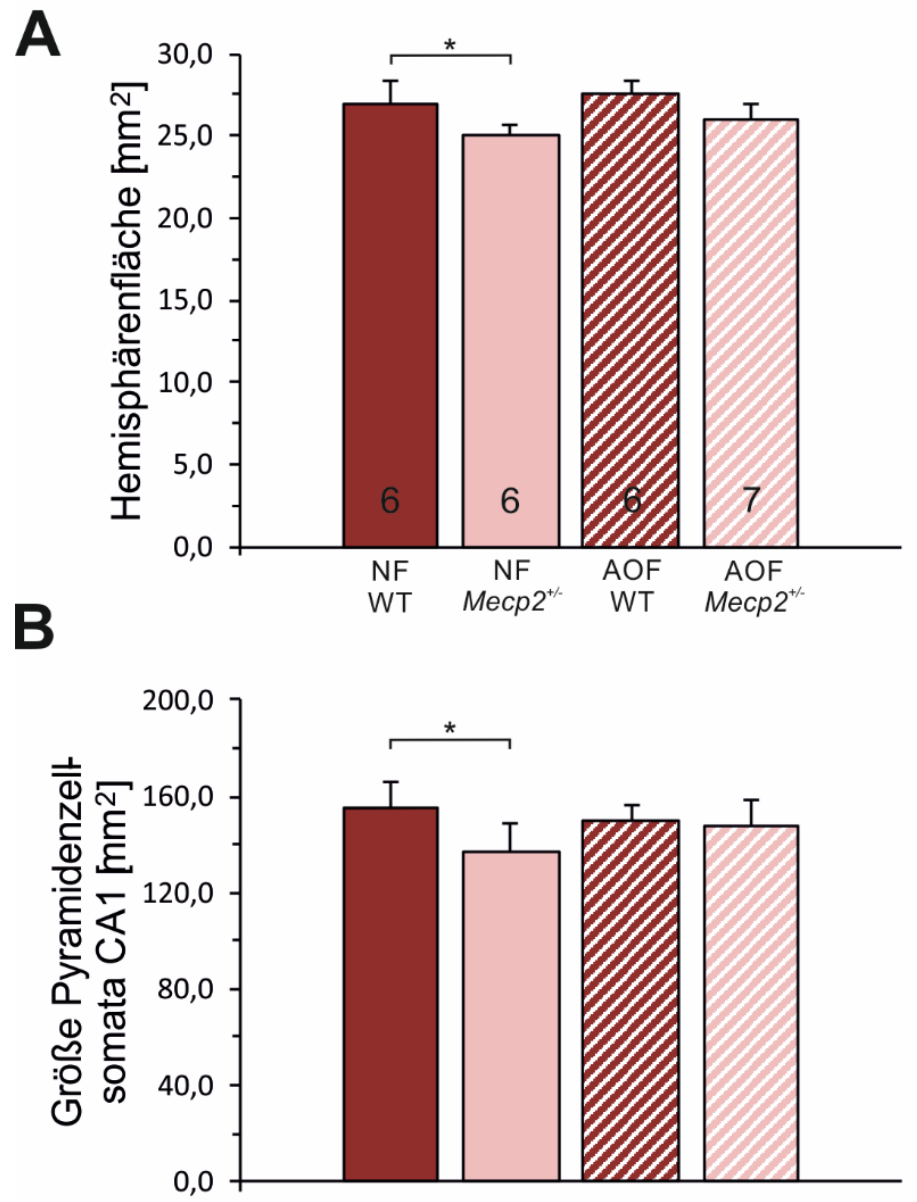

\section{Abbildung 16: Darstellung morphologischer Gewebeparameter weiblicher Mäuse (p50).}

A) Darstellung der Hemisphärenfläche weiblicher Mäuse (p50) in mm². Bei der Kurzzeitbetrachtung weiblicher Mäuse ist zu beobachten, dass normal gefütterte Rett-Weibchen eine signifikant geringere Hemisphärenfläche im Vergleich zu Wildtyp-Weibchen besaßen. Bei Gabe von AOF waren diese Unterschiede nicht zu verzeichnen. B) Größe der CA1-Pyramidenzellsomata in $\mathrm{mm}^{2}$. Auch die Größe der CA1-Pyramidenzellsomate der Rett-Weibchen war bei normaler Fütterung signifikant kleiner als die der Vergleichsgruppe. Unter Antioxidantien-Therapie konnten diese Unterschiede nicht mehr registriert werden. 
Tabelle 8: Morphologische Gewebeparameter weiblicher Mäuse (p400)

\begin{tabular}{|c|c|c|c|}
\hline Weibchen (p400) & Futter & WT & $\operatorname{Mecp}^{+/-}$ \\
\hline \multirow[t]{2}{*}{ Hemisphärenfläche $\left[\mathrm{mm}^{2}\right]$} & NF & $27,16 \pm 0,67$ & $22,97 \pm 1,36$ \\
\hline & $\mathrm{AOF}$ & $26,82 \pm 0,94$ & $23,05 \pm 1,63$ \\
\hline \multirow[t]{2}{*}{ Hippokampusfläche $\left[\mathrm{mm}^{2}\right]$} & NF & $2,73 \pm 0,23$ & $2,26 \pm 0,19$ \\
\hline & $\mathrm{AOF}$ & $2,82 \pm 0,33$ & $2,56 \pm 0,16$ \\
\hline \multirow[t]{2}{*}{ kortikale Schichtdicke $[\mu \mathrm{m}]$} & NF & $962,84 \pm 51,21$ & $846,67 \pm 67,97$ \\
\hline & $\mathrm{AOF}$ & $937,04 \pm 60,53$ & $801,26 \pm 63,52$ \\
\hline \multirow{2}{*}{$\begin{array}{l}\text { Hippokampusfläche/ } \\
\text { Hemisphärenfläche [\%] }\end{array}$} & NF & $10,1 \pm 0,7$ & $9,4 \pm 0,9$ \\
\hline & $\mathrm{AOF}$ & $9,9 \pm 1,1$ & $11,1 \pm 0,3$ \\
\hline \multirow{2}{*}{$\begin{array}{l}\text { Fasertraktdicke } \\
\text { corpus callosum }[\mu \mathrm{m}]\end{array}$} & NF & $291,83 \pm 25,94$ & $263,04 \pm 40,86$ \\
\hline & AOF & $291,85 \pm 52,81$ & $300,27 \pm 28,27$ \\
\hline \multirow{2}{*}{$\begin{array}{l}\text { Schichtdicke stratum pyramidale } \\
\text { CA1 }[\mu \mathrm{m}]\end{array}$} & NF & $55,08 \pm 2,46$ & $50,84 \pm 2,09$ \\
\hline & AOF & $53,02 \pm 2,43$ & $52,65 \pm 0,64$ \\
\hline \multirow{2}{*}{$\begin{array}{l}\text { Schichtdicke stratum pyramidale } \\
\text { CA3 }[\mu \mathrm{m}]\end{array}$} & NF & $66,37 \pm 4,03$ & $59,96 \pm 3,32$ \\
\hline & $\mathrm{AOF}$ & $62,35 \pm 7,25$ & $60,61 \pm 3,69$ \\
\hline \multirow{2}{*}{$\begin{array}{l}\text { Schichtdicke stratum granulare des } \\
\text { gyrus dentatus }[\mu \mathrm{m}]\end{array}$} & NF & $76,31 \pm 4,05$ & $72,90 \pm 3,30$ \\
\hline & $\mathrm{AOF}$ & $74,01 \pm 4,08$ & $74,79 \pm 3,68$ \\
\hline \multirow{2}{*}{$\begin{array}{l}\text { Größe Pyramidenzellsomata } \\
\text { CA1 }\left[\mu \mathrm{m}^{2}\right] \\
\end{array}$} & NF & $137,00 \pm 9,78$ & $120,29 \pm 13,73$ \\
\hline & AOF & $139,51 \pm 7,90$ & $133,95 \pm 6,67$ \\
\hline
\end{tabular}


A
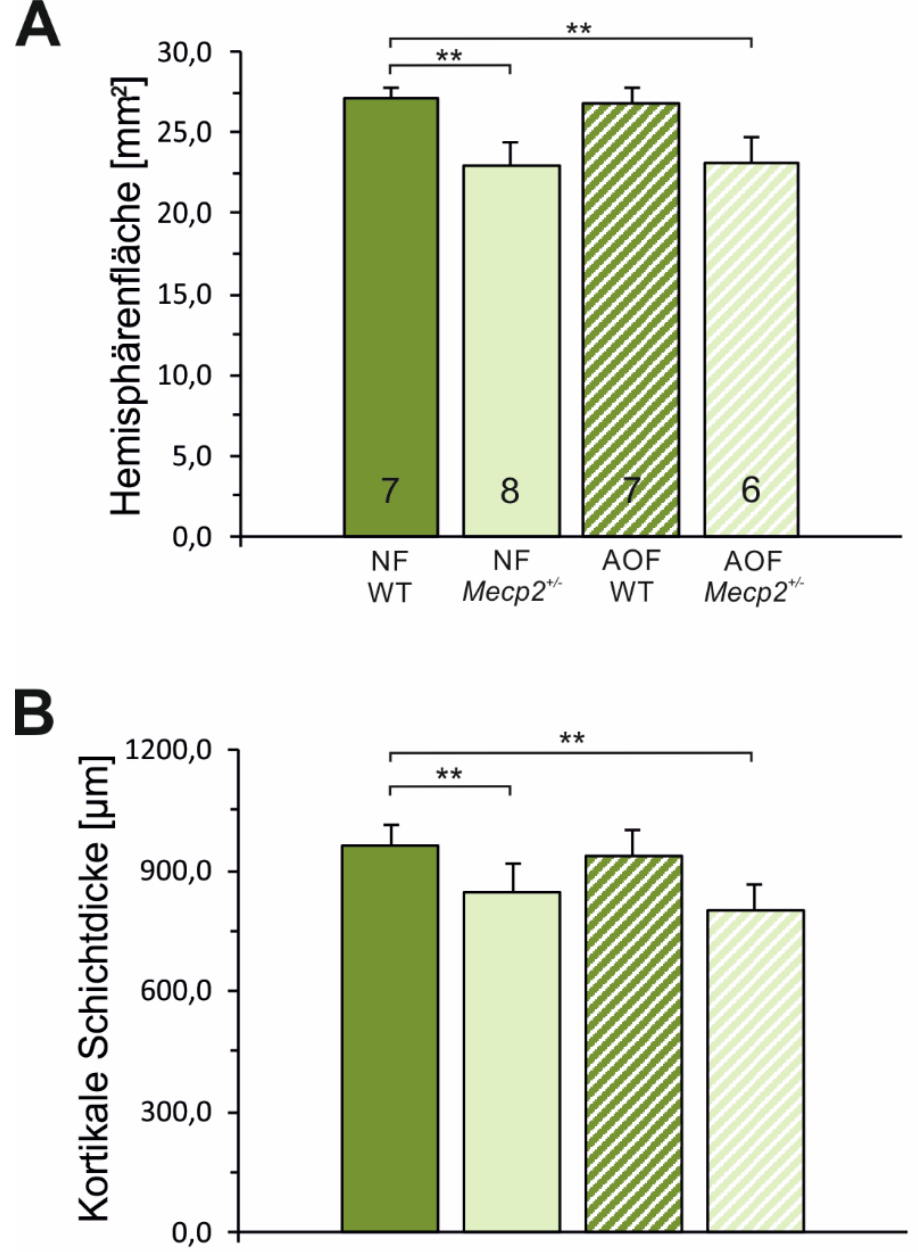

Abbildung 17: Morphologische Gewebeparameter weiblicher Mäuse (p400) - I. A) Darstellung der Hemisphärenfläche der 400 Tage alten Weibchen in $\mathrm{mm}^{2}$. B) Darstellung der kortikalen Schichtdicke in $\mu \mathrm{m}$. Bei Langzeitbehandlung der Weibchen zeigten sich in den Parametern Hemisphärenfläche und kortikale Schichtdicke trotz AOF keine Verbesserungen. Sowohl die normal gefütterten Rett-Weibchen als auch die antioxidativ gefütterten Rett-Weibchen wiesen im Vergleich zu den Wildtyp-Weibchen signifikant kleinere Hemisphären sowie geringere kortikale Schichtdicken auf. 
A

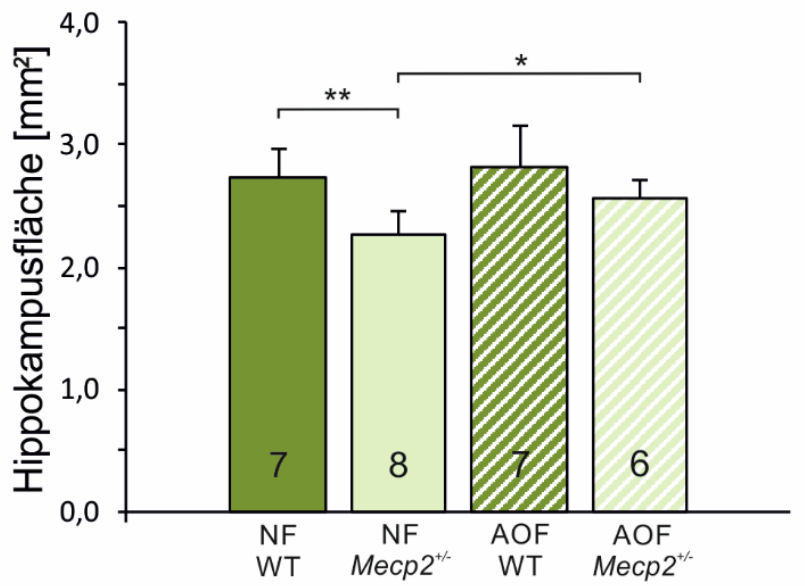

B

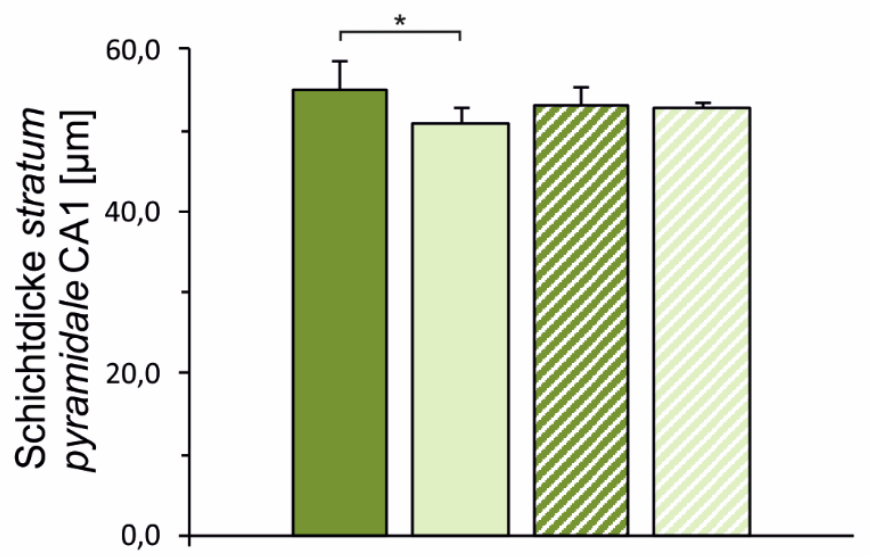

Abbildung 18: Morphologische Gewebeparameter weiblicher Mäuse (p400) - II. A) Darstellung der Hippokampusfläche in $\mathrm{mm}^{2}$. Die Entwicklung im Parameter Hippokampusfläche zeigte bei Langzeitbehandlung mit AOF insgesamt Verbesserungen. Während die normal gefütterten RettWeibchen signifikant kleinere Hippokampusflächen im Vergleich zu den Wildtyp-Weibchen aufwiesen, konnte dieser Unterschied zu den antioxidativ gefütterten Rett-Weibchen nicht registriert werden. Zusätzlich zeigten sich die Hippokampusformationen der AOF-therapierten Rett-Weibchen signifikant größer als die der normal gefütterten Rett-Mäuse. B) Schichtdicke des stratum pyramidale der CA1Region in $\mu \mathrm{m}$ bei weiblichen Mäusen (p400). Auch hier führte das AOF zu Verbesserungen im Sinne einer Vergrößerung der Schichtdicke des stratum pyramidale bei Rett-Weibchen und damit zur Aufhebung des signifikanten Unterschieds zu der Vergleichsgruppe der Wildtyp-Weibchen. 


\section{3 $\quad \mathrm{H}_{2} \mathrm{O}_{2}$-Produktion isolierter Mitochondrien}

Wie in Kapitel 1.5 beschrieben, weisen Rett-Patientinnen eine erhöhte Redoximbalance auf. Diese Annahme basiert auf Untersuchungen, die erhöhte oxidative Stressmarker (De Felice et al. 2009) sowie veränderte Enzymaktivitäten und Serumlevel von Antioxidantien und Radikalfängern in Rett-Patientinnen bestätigten (Formichi et al. 1998; Sierra et al. 2001). Vorangegangene Untersuchungen der Arbeitsgruppe um Prof. M. Müller konnten in diesem Zusammenhang eine gesteigerte $\mathrm{H}_{2} \mathrm{O}_{2}$-Produktion isolierter Mitochondrien bei MeCP2-defizienten Mäusen im Vergleich zu gesunden Mäusen verifizieren. Die gesteigerte ROS-Produktion wurde in diesem Fall als oxidativer Stress durch erhöhte mitochondriale Aktivität gewertet (Can et al. 2019). Auf Grundlage dieser Erkenntnisse wurden in dieser Dissertation zusätzlich antioxidativ behandelte Mäuse im Vergleich zu normal gefütterten Kontrollgruppen betrachtet, um den Effekt der Supplementierung von Antioxidantien auf die Redoxbalance zu bewerten.

Dazu wurde in einer weiteren Versuchsreihe die $\mathrm{H}_{2} \mathrm{O}_{2}$-Produktion isolierter Mitochondrien aus kortikalem Gewebe 50 Tage alter männlicher Mäuse anhand fluoreszenzspektroskopischer Messungen bestimmt. Nach Betäubung und Dekapitation wurde das Gehirn der Mäuse zur Probengewinnung freigelegt. Anschließend wurden Anteile des Kortex entnommen und mithilfe eines Mörsers homogenisiert. Durch mehrschrittige Zentrifugationen konnten daraufhin die Mitochondrien der Gewebeproben isoliert werden. Die Proteinkonzentrationen der gewonnenen Mitochondrienlösungen wurden mittels Bradford Assay bestimmt. Eine definierte Menge der Mitochondrien $(30 \mu \mathrm{g})$ wurde anschließend mit den Substraten Pyruvat, Malat und Succinat sowie dem Farbstoff Amplex UltraRed und dem Katalysator Meerrettich-Peroxidase zusammen mit einer Pufferlösung in Küvetten vermengt. Der Farbstoff konnte unter diesen Bedingungen mit dem mitochondrial produzierten $\mathrm{H}_{2} \mathrm{O}_{2}$ zu dem stark fluoreszierenden Reaktionsprodukt Amplex UltroxRed reagieren, was als relative Fluoreszenzintensität von einem Spektrofluorometer registriert wurde. Die Messungen wurden alle $30 \mathrm{~s}$ über einen Zeitraum von 30 min getätigt und anschließend auf den Ausgangswert normiert. Da die Fluoreszenzintensität einiger Proben bereits vor dem jeweiligen Versuchsende in die Sättigung ging, wurden die Ergebnisse nur bis zur Versuchsminute 20 betrachtet. Intensiver eingegangen wurde auf die Ergebnisse bei Minute 5, 10 und 12. Neben der Entstehung von $\mathrm{H}_{2} \mathrm{O}_{2}$ detektierte dieses Assay keine weiteren ROS. Um Ergebnisverfälschungen durch z. B. 
autooxidative Prozesse des Farbstoffes auszuschließen, wurden zusätzlich Leerproben ohne Mitochondrien betrachtet.

Bei Betrachtung der kortikalen Gewebeproben konnten sowohl nach 5, 10 als auch 12 min signifikant höhere $(\mathrm{p}<0,05)$ Fluoreszenzintensitäten durch mitochondriale $\mathrm{H}_{2} \mathrm{O}_{2}$ Entstehung bei den normal gefütterten $M e c p 2^{-/ y}$-Mäusen $(n=12)$ im Vergleich zu den normal gefütterten Wildtypen $(\mathrm{n}=12)$ beobachtet werden. Auch beim Vergleich der antioxidativ gefütterten $M e c p 2^{-/ y}-$ Männchen $(n=9)$ zu den normal gefütterten Wildtypen blieben die signifikant höheren Fluoreszenzintensitäten bestehen (Abbildung 19). Zusätzlich fiel auf, dass die Mitochondrien antioxidativ gefütterter Wildtyp-Männchen $(n=9)$ signifikant erhöhte $(\mathrm{p}<0,05)$ Fluoreszenzintensitäten im Vergleich zu den normal gefütterten Wildtypen erzeugten und damit das AOF auch bei den Wildtypen zu einer erhöhten $\mathrm{H}_{2} \mathrm{O}_{2}$-Freisetzung führte (Abbildung 20). Eine Übersicht $\mathrm{zu}$ den genauen Fluoreszenzintensitäten ist in Tabelle 9 aufgeführt.

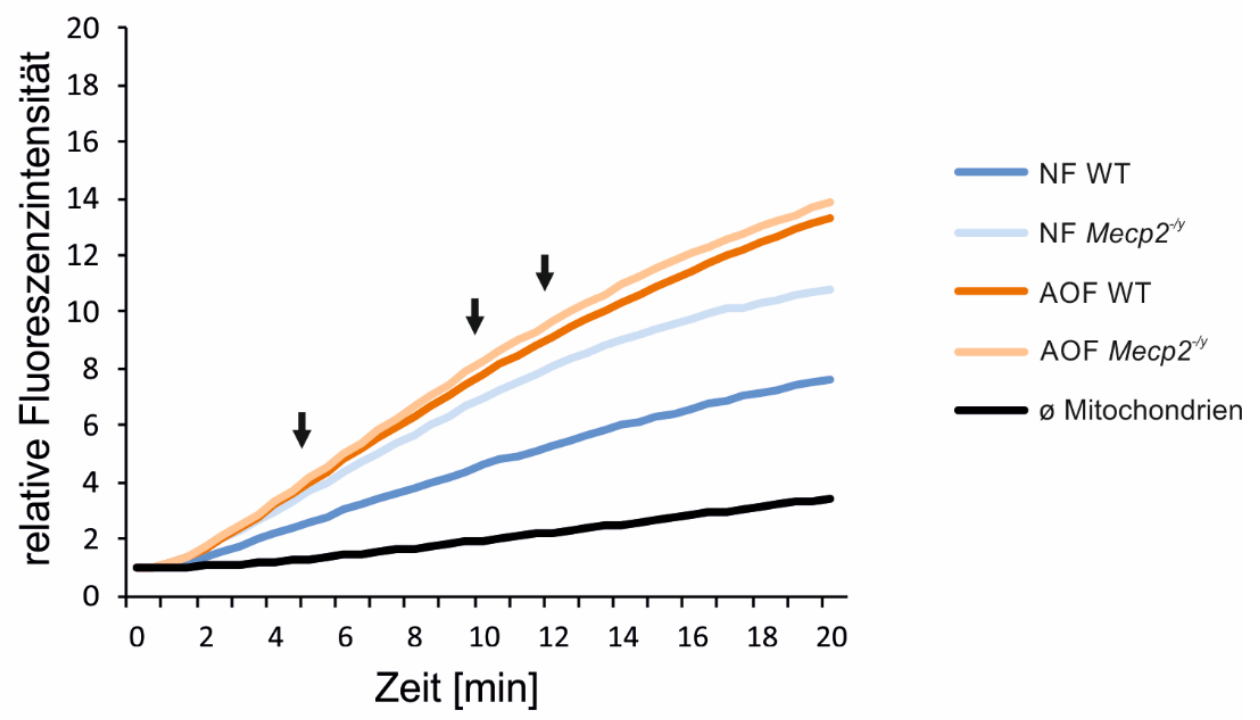

Abbildung 19: $\mathrm{H}_{2} \mathrm{O}_{2}$-Produktion isolierter kortikaler Mitochondrien. Dargestellt ist der zeitliche Verlauf der relativen Fluoreszenzintensität als Ausdruck der $\mathrm{H}_{2} \mathrm{O}_{2}$-Produktion isolierter kortikaler Mitochondrien. Genotyp und Futterschema sind der Farblegende zu entnehmen. Zusätzlich ist die Leerprobe ohne Mitochondrien zur Registrierung autooxidativer Prozesse abgebildet. Die schwarzen Pfeile zeigen auf die Messpunkte, die im Detail nochmals in Abbildung 20 aufgeführt sind. 


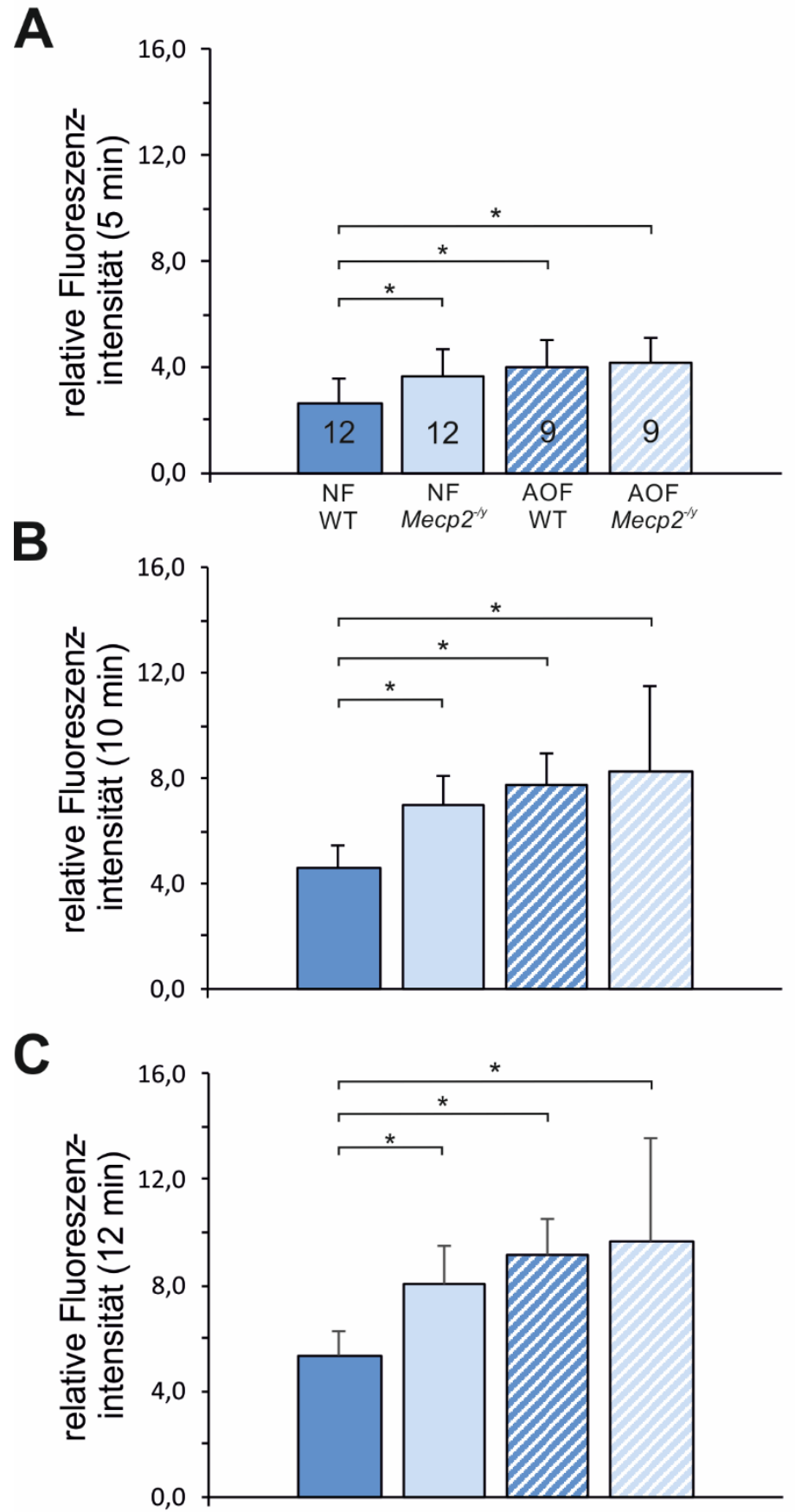

Abbildung 20: Überschießende $\mathrm{H}_{2} \mathrm{O}_{2}$-Produktion isolierter Mitochondrien in Mecp2-/y-Mäusen.

Dargestellt ist die relative Fluoreszenzintensität durch $\mathrm{H}_{2} \mathrm{O}_{2}$-Produktion kortikaler Mitochondrien normiert auf den jeweiligen Ausgangswert jeder Küvette nach 5 (A), 10 (B) und 12 min (C). Zu allen Zeitpunkten erzeugten die isolierten Mitochondrien der normal gefütterten und der antioxidativ behandelten Rett-Männchen signifikant mehr $\mathrm{H}_{2} \mathrm{O}_{2}$ als die Mitochondrien der normal gefütterten Wildtyp-Männchen. Auffällig ist außerdem, dass auch die Kontrollgruppe der antioxidativ behandelten Wildtypen signifikant höhere relative Fluoreszenzintensitäten im Vergleich zu den unbehandelten Wildtypen aufwies. Somit zeigte das AOF in diesem Zusammenhang eine Auswirkung auf den Wildtyp. 
Tabelle 9: Relative Fluoreszenzintensität (Kortex)

\begin{tabular}{|c|c|c|c|}
\hline Kortex - Männchen (p50) & Futter & WT & Mecp2 $^{-/ y}$ \\
\hline \multirow[t]{2}{*}{$5 \mathrm{~min}$} & NF & $2,60 \pm 0,42$ & $3,68 \pm 0,51$ \\
\hline & $\mathrm{AOF}$ & $3,98 \pm 0,49$ & $4,15 \pm 1,34$ \\
\hline \multirow[t]{2}{*}{$10 \mathrm{~min}$} & NF & $4,59 \pm 0,84$ & $6,95 \pm 1,18$ \\
\hline & $\mathrm{AOF}$ & $7,78 \pm 1,14$ & $8,23 \pm 3,25$ \\
\hline \multirow[t]{2}{*}{$12 \mathrm{~min}$} & NF & $5,32 \pm 0,98$ & $8,08 \pm 1,43$ \\
\hline & $\mathrm{AOF}$ & $9,14 \pm 1,37$ & $9,68 \pm 3,92$ \\
\hline
\end{tabular}




\section{Diskussion}

Bisher ist für das RTT keine effektive Therapie verfügbar (Valenti et al. 2014). Vielmehr gibt es zahlreiche Therapieansätze (Chapleau et al. 2013; Katz et al. 2016). Im Rahmen dieser Dissertation wurde der therapeutische Ansatz einer oralen Antioxidantien-Therapie im Rett-Mausmodell evaluiert. Dabei kam eine Kombination der drei antioxidativ wirksamen Substanzen Vitamin E, $\alpha$-Liponsäure und N-Acetylcystein als Futterkomponenten zum Einsatz. Zur Beurteilung des Therapieerfolgs wurden antioxidativ behandelte Mäuse unterschiedlichen Geschlechts und Alters anhand verschiedener Parameter mit normal gefütterten Kontrollgruppen verglichen.

Die Auswahl des verwendeten Therapiemodells beruht auf Erkenntnissen der molekulargenetischen Ursachen sowie auf vorherigen Therapieansätzen im RTT. Sowohl bei der Untersuchung betroffener Patientinnen als auch im Mausmodell ließ sich das mit dem RTT assoziierte MeCP2-Defizit vor allem in neuronalen Gewebestrukturen nachweisen und erklärt den stark neurologisch geprägten Phänotyp der Erkrankung (Guy et al. 2001; Jung et al. 2003). Gleichzeitig steht der MeCP2-Mangel mit mitochondrialen Dysfunktionen in Verbindung (Müller und Can 2014; De Filippis et al. 2015; Can et al. 2019). Demnach führen fehlregulierte mitochondriale Komplexe zur Entkopplung der Atmungskette und somit zur vermehrten Entstehung von ROS (Kriaucionis et al. 2006), die bei ungenügender Kompensation eine Redoximbalance bedingen (Großer et al. 2012; De Filippis et al. 2015). Dabei weist neuronales Gewebe eine besonders starke Vulnerabilität für oxidative Belastungen auf und ist gleichzeitig von einer hohen ROS-Generierung durch eine intensive metabolische Umsatzrate geprägt (López-Erauskin et al. 2011; Valenti et al. 2014). Zusätzlich scheinen enzymatische und nicht-enzymatische Antioxidantien wie die SOD, Vitamin E, Vitamin C und GSH im RTT verringert (Formichi et al. 1998; Sierra et al. 2001). Ein aussichtsreicher Therapieansatz ist somit die Wiederherstellung der Redoxbalance durch Senkung der ROS-Produktion, Stimulation der Expression zelleigener Antioxidantien oder Substitution von Radikalfängern (Müller und Can 2014). Im Mausmodell konnte durch Reexpression des Mecp2-Gens außerdem gezeigt werden, dass die Redoximbalance eine gewisse Reversibilität aufweist (De Felice et al. 2014).

Erste Untersuchungen murinen Gewebes zeigten im Zusammenhang mit der Methodik der Supplementierung von Antioxidantien Verbesserungen der Langzeitpotenzierung hippokampaler Schnitte, die mit Radikalfängern inkubiert wurden (Klann et al. 1998). In 
der Arbeitsgruppe um Prof. M. Müller wurden die Auswirkungen des wasserlöslichen Vitamin-E-Derivats Trolox auf hippokampale Schnitte untersucht. Dabei führte Trolox zur Senkung der oxidativen Belastung des Gewebes, Reduktion der neuronalen Hypererregbarkeit, Verringerung der Hypoxieanfälligkeit sowie zu Verbesserungen der Langund Kurzzeitplastizität (Großer et al. 2012; Janc und Müller 2014). Aufgrund dieser vielversprechenden In-vitro-Ergebnisse schlossen sich entsprechende In-vivo-Experimente an. So testete die Arbeitsgruppe um Prof. M. Müller die systemischen Auswirkungen des Vitamin-E-Derivats Trolox im Mausmodell nach regelmäßiger intraperitonealer Injektion. Zwar traten auch hierbei Verbesserungen der oxidativen Stressmarker, der Hypoxietoleranz und der synaptischen Kurzzeitplastizität auf, jedoch konnten keine positiven Effekte auf Körpergewicht und -größe, Gewebeparameter, Motorik und Atmung festgestellt werden. Vor allem die regelmäßige Handhabung der Mäuse und die invasive Applikationsart der Injektionstherapie mit Trolox wurden in diesem Zusammenhang als stressinduzierend und optimierungsbedürftig eingeschätzt (Janc et al. 2016).

Alternativ kann die orale Gabe von Antioxidantien genannt werden, die als besonders schonend bewertet wird und im Rahmen dieser Dissertation als Therapiekonzept angewendet wurde. In vorherigen Studien ergab die orale Fütterung des antioxidativ wirksamen Stoffes Kurkumin eine Reduktion der ROS-Entstehung im Rett-Mausmodell (Panighini et al. 2013). Erste Untersuchungen an Rett-Patientinnen zeigten ein positiveres Krankheitsgeschehen nach oraler Gabe von ungesättigten $\omega$-3-Fettsäuren (De Felice et al. 2012; Maffei et al. 2014). In einer aktuellen italienischen Studie entwickelten RettPatientinnen nach sechsmonatiger therapeutischer Gabe des Vitamin-E-Derivats EPI-743 einen erhöhten Kopfumfang im Vergleich zu Kontrollgruppen. Darüber hinaus zeigte eine Analyse der Probandinnen mit dem stärksten Wachstumszuwachs Verbesserungen der oxidativen Stressmarker, der Atmung und der Handfunktionen (Enns und Cohen 2017).

Neben der oralen Applikation basierte das Therapiekonzept dieser Dissertation auf der Kombination dreier antioxidativer Wirkstoffe. Ein ähnlicher Antioxidantien-Cocktail wurde zuvor am Krankheitsbild der Adrenoleukodystrophie getestet, das von einer erhöhten ROS-Generierung durch einen gestörten Lipidstoffwechsel geprägt ist (LópezErauskin et al. 2011). Zunächst fand man heraus, dass die Substanzen Vitamin E, $\alpha$-Liponsäure und N-Acetylcystein jeweils einzeln das ROS-Level von Zellkulturen der Adrenoleukodystrophie reduzieren können. In Kombination riefen die drei Substanzen 
schon bei geringerer Dosierung die gleichen Ergebnisse hervor, sodass synergistische Effekte vermutet wurden. Im Mausmodell der Adrenoleukodystrophie konnten durch die Kombinationstherapie schließlich oxidative Stressmarker verringert, axonale Störungen verhindert, Schäden der DNA reduziert sowie die Lokomotorik und der klinische Phänotyp verbessert werden (López-Erauskin et al. 2011). Angelehnt an diese Erfolge wurde eine vergleichbare Therapie nun auf das RTT übertragen.

Indessen muss berücksichtigt werden, dass Antioxidantien-Therapien nach wie vor nicht vollständig erschlossen sind und in klinischen Studien teilweise konträre Ergebnisse hervorbringen. Vor allem die exakte personalisierte Dosierung der antioxidativen Wirkstoffe stellt eine große Herausforderung bei diesem Therapiekonzept dar. Sowohl unterschiedliche Krankheitsstadien als auch die weibliche zufällige X-ChromosomInaktivierung führen zu verschiedenen Ausprägungsformen der Symptomatik und damit auch der Redoximbalance im RTT (Chahrour und Zoghbi 2007). Allgemein haben ROS vielfältige physiologische Funktionen bei der Signaltransduktion und Zellkommunikation (Valko et al. 2007). So haben Studien zur Überexpression der SOD ergeben, dass ROS für die Langzeitpotenzierung in hippokampalen CA1-Neuronen unerlässlich sind (Klann et al. 1998; Thiels et al. 2000). Dementsprechend könnte neben der Unterdosierung auch eine Überdosierung von Antioxidantien durch zu starke Einflussnahme auf die zelluläre Redoxbalance zum Ausbleiben eines Therapieerfolgs führen.

Vitamin E gilt als effizienter Schutz für Membranstrukturen durch Unterdrückung der Lipidperoxidation mittels Neutralisierung von Lipidradikalen (Formichi et al. 1998). Ein Defizit an Vitamin E kann allgemein zu schweren neurologischen Dysfunktionen begleitet von Sprachstörungen, Ataxie und kognitiven Einschränkungen führen und wurde somit bereits früh Forschungsbestandteil im Zusammenhang mit verschiedensten neurologischen Krankheitsbildern (Ouahchi et al. 1995; Brigelius-Flohé und Traber 1999). Dabei gehören Vitamin E und seine Derivate zu den nicht-enzymatischen, kettenbrechenden Antioxidantien, die das Voranschreiten radikalisierender Prozesse unterbinden (Buettner 1993). Bei der oralen Aufnahme durch Futter wird Vitamin E intestinal resorbiert und als hydrophobes Molekül im Plasma durch Lipoproteine transportiert (Uttara et al. 2009). Außerdem kann Vitamin E, wie auch $\alpha$-Liponsäure und N-Acetylcystein, die Blut-Hirn-Schranke passieren (López-Erauskin et al. 2011). Des Weiteren ist die Wirksamkeit von Vitamin E eng mit der Verfügbarkeit von Vitamin C und GSH verknüpft, da die beiden Substanzen hauptsächlich für die Regeneration von 
Vitamin E nach einer Reaktion verantwortlich sind (Formichi et al. 1998). Vitamin E wird demnach nicht verbraucht, was eine gesteigerte Effizienz bedeuten könnte. Andererseits stellt sich die Frage, ob es durch Supplementierung zu einer Akkumulation von Vitamin E kommen kann und welche Auswirkungen eine solche Anhäufung mit sich bringt. Zusätzlich könnte ein Mangel an Vitamin C und GSH eine unzureichende Regenerationsrate von oxidiertem zu reduziertem Vitamin E verursachen, sodass auch diese beiden Substanzen nicht außer Acht gelassen werden sollten.

Anhand dieser Überlegungen lassen sich die synergistischen Effekte durch Ergänzung von $\alpha$-Liponsäure und $\mathrm{N}$-Acetylcystein erklären. So ist $\alpha$-Liponsäure neben der direkten Eliminierung von Superoxidanionen und Hydroxylradikalen in der Lage, die oxidierten Formen von Vitamin $\mathrm{C}$ und GSH zu regenerieren und fördert dadurch indirekt die Regeneration von Vitamin E (Packer et al. 1995). Neueren Erkenntnissen zufolge kann $\alpha$-Liponsäure sogar Vitamin E selbst recyceln (López-Erauskin et al. 2011). Im Zusammenhang mit dem Krankheitsbild der Trisomie 21 ergab die Gabe von $\alpha$-Liponsäure verbesserte mitochondriale Funktionen und reduzierten oxidativen Stress (Valenti et al. 2014). Der Wirkstoff N-Acetylcystein wird als Vorläufer von Cystein für die Synthese von GSH benötigt und wirkt sich damit ebenfalls indirekt auf die Wirksamkeit von Vitamin E aus (Aldini et al. 2018). GSH wird außerdem für die Eliminierung von $\mathrm{H}_{2} \mathrm{O}_{2}$ durch die Glutathionperoxidase benötigt (Bai und Cederbaum 2001). Grundsätzlich weist N-Acetylcystein eine eher schlechte Bioverfügbarkeit auf und wird daher häufig in sehr hohen Dosen verabreicht (Nance et al. 2017). Dementsprechend positiv zu bewerten ist die Möglichkeit der geringeren Dosierung durch die Kombination mit den beiden anderen Wirkstoffen. Außerdem scheint N-Acetylcystein neben der Wirksamkeit auf neuronales Gewebe auch Einfluss auf Gliazellen zu haben (Nance et al. 2017). Während lange Zeit davon ausgegangen wurde, dass die Pathogenese des RTT vor allem neuronalen Ursprungs ist, ist mittlerweile bekannt, dass auch Gliazellen betroffen sind (Valenti et al. 2014). Auch im Zusammenhang mit anderen Erkrankungen, wie dem Autismus, stellt die Gabe von N-Acetylcystein einen erfolgversprechenden therapeutischen Ansatz dar (Valenti et al. 2014). 


\subsection{Einfluss der Antioxidantien-Therapie auf Körpergröße, Körpergewicht und Hirngewicht}

Bei der Betrachtung der Parameter Körpergröße, Körpergewicht und Hirngewicht in der Gruppe der Männchen (p50) konnten trotz AOF keine Verbesserungen registriert werden. Die Rett-Mäuse waren im Vergleich zu den Wildtypen sowohl bei normaler Fütterung als auch bei Antioxidantien-Therapie signifikant kleiner, leichter und wiesen ein geringeres Hirngewicht auf, sodass in diesem Zusammenhang nicht von einem Therapieerfolg gesprochen werden kann. Dabei ist jedoch zu berücksichtigen, dass nur relativ kleine Kohorten von 6 - 7 Mäusen pro Versuchsgruppe in den Vergleich aufgenommen wurden. Ähnliche Beobachtungen wurden auch in vergangenen Studien der Arbeitsgruppe um Prof. M. Müller gemacht, in denen die Injektionstherapie mit Trolox an männlichen RettMäusen keine Wachstumszunahme der Mäuse hervorbrachte (Janc et al. 2016).

Anders gestalteten sich die Ergebnisse bei den weiblichen Versuchsgruppen. So zeigte sich bei Rett-Weibchen (p50) durch die Antioxidantien-Therapie eine signifikante Zunahme der Körpergröße und des Hirngewichts, sodass hier von einem Therapieerfolg gesprochen werden kann. Auf der anderen Seite macht der generell fehlende Unterschied im Körpergewicht zwischen den unbehandelten weiblichen Mäusen deutlich, dass die phänotypische Differenz wesentlich schwächer ausfällt als bei den männlichen Tieren.

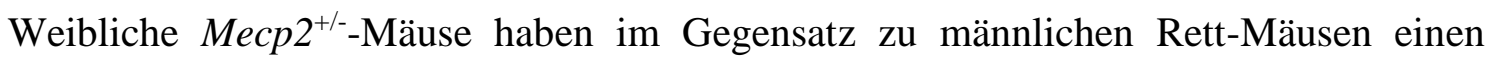
milderen, langsameren und deutlich variableren Krankheitsverlauf, der zum Teil auf die zufällige X-Chromosom-Inaktivierung und den heterozygoten Phänotyp zurückzuführen ist (Shahbazian et al. 2002). Es ist also denkbar, dass ein Therapieversuch an weiblichen Mäusen schneller zu Erfolgen führt als an männlichen Mäusen. Außerdem gilt das weibliche Sexualhormon Östrogen ebenfalls als Radikalfänger, sodass hier ein weiterer Unterschied zum männlichen Organismus gesehen werden muss (Uttara et al. 2009). Da es sich bei den klinisch beschriebenen Fällen des RTT meist um weibliche Patientinnen handelt, ist es unerlässlich, auch weibliche $M e c p 2^{+/-}$-Mäuse in den Untersuchungen zu berïcksichtigen, auch wenn die Ergebnisse aufgrund des variablen Phänotyps als weniger eindeutig eingestuft werden sollten.

Dies könnte eine Begründung dafür sein, dass sich bei Langzeitbetrachtung der Weibchen (p400) konträre Ergebnisse zur Kurzzeitbetrachtung darstellten. In der Körpergröße ließen sich hier, anders als bei den Weibchen im Alter von 50 Tagen, keine Unterschiede zwischen den Vergleichsgruppen feststellen. Das Hirngewicht der Rett-Weibchen (p400) 
gestaltete sich im Vergleich zu den Wildtypen sowohl ohne als auch mit AOF signifikant geringer, sodass in diesem Parameter kein Erfolg durch die Antioxidantien-Therapie erzielt werden konnte. Eine weitere Besonderheit stellte das Körpergewicht der weiblichen Mäuse (p400) dar. So gab es keine Unterschiede zwischen den normal gefütterten Wildtypen und $M e c p 2^{+/-}$-Weibchen, allerdings waren die antioxidativ behandelten Rett-Weibchen signifikant schwerer als die Wildtypen. Der Unterschied betrug $42 \%$, sodass in diesem Zusammenhang bereits von einer adipösen Veränderung gesprochen werden kann. Diese Beobachtungen lassen sich offenbar nicht ausschließlich auf neurologische Prozesse zurückführen und zeigen, dass ein MeCP2-Defizit und die daran anknüpfende Antioxidantien-Therapie den gesamten Organismus beeinflussen. Gleichzeitig ist an dieser Stelle zu erwähnen, dass das im Rahmen dieser Dissertation verwendete Mausmodell grundsätzlich adipöse Neigungen aufweist (Calfa et al. 2011).

\subsection{Antioxidantien-Therapie verbessert morphologische Gewebeparameter}

Die Bewertung morphologischer Gewebeparameter neuronalen Gewebes beruht auf vorherigen Erkenntnissen der Rett-Forschung. Vergangene Untersuchungen betroffener Patientinnen ergaben einen verminderten Kopfumfang (Bauman et al. 1995), eine geringere Hirngröße (Belichenko et al. 2008) sowie reduzierte Größe neuronaler Zellsomata (Rett 1966; Bauman et al. 1995). Im Mausmodell konnten diese Erkenntnisse ebenfalls bestätigt werden (Chen et al. 2001). Trotzdem muss bei der Beurteilung morphologischer Gewebeparameter stets berücksichtigt werden, dass es sich beim RTT nicht um eine neurodegenerative Erkrankung handelt, sondern um eine neuronale Entwicklungsstörung (Chahrour und Zoghbi 2007). Im Fokus stehen demnach die neuronale Entwicklung sowie das zerebrale Wachstum.

Im Zusammenhang mit der Untersuchung von Hirnschnitten männlicher Mäuse (p50) wurde in der Arbeitsgruppe um Prof. M. Müller zuvor festgestellt, dass die Hemisphärenfläche, die Fläche des Hippokampus, die kortikale Schichtdicke und die Zellsomata der CA1-Neurone von Rett-Männchen im Vergleich zu Wildtyp-Männchen signifikant geringer ausfallen (Fischer et al. 2009; Janc et al. 2016). Die Schichtdicke des stratum pyramidale der CA1-Region zeigte in vergangenen Untersuchungen keine signifikanten Abweichungen zwischen Wildtypen und Mecp2-/y -Mäusen (Janc et al. 2016). Diese Ergebnisse wurden im Rahmen dieser Dissertation größtenteils bestätigt. Nur die Fläche 
des Hippokampus ergab, anders als in den Voruntersuchungen, keinen signifikanten Unterschied zwischen den Versuchsgruppen. Die in der Vergangenheit von der Arbeitsgruppe getestete Injektionstherapie mit Trolox erzielte keinerlei Verbesserungen der Gewebeparameter (Janc et al. 2016). Anders gestaltete sich die Entwicklung unter der vorliegenden oralen Antioxidantien-Therapie aus der Kombination von Vitamin E, $\alpha$-Liponsäure und N-Acetylcystein. So wiesen die antioxidativ therapierten RettMännchen ein vermehrtes Wachstum von Kortex und CA1-Neuronen auf. Die signifikanten Unterschiede zwischen Wildtypen und Rett-Männchen konnten in den Parametern der kortikalen Schichtdicke und der Größe der CA1-Zellsomata durch das AOF aufgehoben werden, sodass hier ein Therapieerfolg zu verzeichnen ist. Einzig die Größe der Hemisphärenfläche konnte durch die antioxidativ wirksamen Substanzen nicht verbessert werden. Zusätzlich wurden die Fasertraktdicke des corpus callosum, die Schichtdicke des stratum pyramidale der hippokampalen Region CA3 sowie das stratum granulare im gyrus dentatus erstmalig betrachtet. In diesen Kategorien konnten allerdings keine Unterschiede zwischen den Untersuchungsgruppen festgestellt werden.

Auch bei Weibchen der Altersklasse 50 Tage verursachte die zu evaluierende orale Antioxidantien-Therapie insgesamt einen positiven Trend. Während die Untersuchung der Fläche der Hemisphäre sowie der Größe der CA1-Pyramidenzellsomata zwischen den unbehandelten Mäusen signifikant kleinere Werte bei den Rett-Weibchen hervorbrachte, waren in diesen beiden Parametern zwischen antioxidativ behandelten Rett-Weibchen und normal gefütterten Wildtypen keine signifikanten Differenzen mehr festzustellen. Die Antioxidantien-Therapie führte bei den Rett-Weibchen also zu einer Vergrößerung der Hemisphärenfläche und zu einem gesteigerten Wachstum der CA1-Neurone. Die fehlenden Abweichungen in allen anderen Kategorien weisen erneut darauf hin, dass die phänotypische Ausprägung des RTT bei Weibchen geringer ausfällt als bei männlichen Mäusen.

Die Langzeittherapie mit AOF von Weibchen bis zum Alter von 400 Tagen ergab eine Verbesserung der Hippokampusfläche und des stratum pyramidale der CA1-Region. Keinen positiven Effekt hatte die Antioxidantien-Therapie auf die Hemisphärenfläche und die kortikale Schichtdicke. Hier blieben trotzt antioxidativer Behandlung signifikante Unterschiede zum Wildtyp bestehen. Alle weiteren Parameter zeigten auch im Langzeitmodell keine signifikanten Abweichungen zwischen den Versuchsgruppen. Betrachtet man diese Ergebnisse, stellt sich die Frage, warum sich die Verbesserungen in den beiden 
untersuchten Altersklassen der Weibchen in unterschiedlichen Parametern darstellen und keine Überschneidungen aufweisen. Erklärungsversuche könnten einerseits die geringe Anzahl an Mäusen pro Versuchsgruppe oder andererseits Alterationen bei der Bestimmung der Parameter sein. So werden die Schnitte zwar nach eindeutigen morphologischen Kriterien ausgewählt, die Auswahl und Vermessung unterliegt aber trotzdem natürlichen Abweichungen. Ungeachtet dieser Feststellungen hatte die AntioxidantienTherapie in keiner der drei Untersuchungsgruppen einen unerwünschten Effekt auf die Entwicklung der morphologischen Gewebeparameter, da keine weitere Verschlechterung in einem der analysierten Parameter durch das AOF nachzuweisen war.

\subsection{Ausmaß der mitochondrialen $\mathrm{H}_{2} \mathrm{O}_{2}$-Produktion unter Antioxidantien-Therapie}

Zur fluoreszenzmikroskopischen Messung der $\mathrm{H}_{2} \mathrm{O}_{2}$-Produktion isolierter Mitochondrien mithilfe des Farbstoffs Amplex UltraRed wurden kortikale Gewebeproben 50 Tage alter männlicher Mäuse verwendet. Geht man davon aus, dass eine erhöhte $\mathrm{H}_{2} \mathrm{O}_{2}$-Freisetzung eine erhöhte oxidative Last bedeutet, diente die Messmethode der Beurteilung des Redoxstatus und der oxidativen Belastung neuronaler Gewebeproben. In diesem Zusammenhang ist bekannt, dass Rett-Patientinnen erhöhte oxidative Stressmarker (De Felice et al. 2009) und verringerte Aktivitäten antioxidativ wirksamer Enzyme und Moleküle aufweisen (Formichi et al. 1998; Sierra et al. 2001). Die daraus resultierende Redoximbalance scheint, wie bereits beschrieben, eine große Rolle in der Pathogenese des RTT zu spielen.

Erste vergleichbare Untersuchungen der Arbeitsgruppe um Prof. M. Müller wurden zunächst mit dem Farbstoff $2^{`}, 7^{\prime}$-Dichlordihydrofluorescein-Diacetat ( $\left.\mathrm{H}_{2} \mathrm{DCFDA}\right)$ durchgeführt und ergaben erhöhte Oxidationsraten des Farbstoffes bei Gewebeproben MeCP2-defizienter Mäuse (Can et al. 2019). Da der Farbstoff $\mathrm{H}_{2}$ DCFDA neben $\mathrm{H}_{2} \mathrm{O}_{2}$ auch mit anderen Radikalen reagiert und zu spontanen Oxidationen neigt (Zhou et al. 1997), wurden vergleichbare Experimente auch mit dem deutlich zuverlässigeren Farbstoff Amplex UltraRed durchgeführt (Can et al. 2019). Dieser Farbstoff ist ein farbloses, nicht fluoreszierendes Derivat von Dihydroresorufin und reagiert spezifisch mit $\mathrm{H}_{2} \mathrm{O}_{2} \mathrm{zu}$ dem stark fluoreszierenden Resorufin. Im Vergleich zu anderen Farbstoffen hat Amplex UltraRed eine besonders hohe Sensitivität sowie Spezifität und kann $\mathrm{H}_{2} \mathrm{O}_{2}$ bereits in sehr geringen Mengen detektieren. Weiterführende Arbeiten der Arbeitsgruppe um Prof. M. 
Müller bestätigten für dieses Assay die zuverlässige Nachweisbarkeit von bereits $20 \mathrm{nM}$ $\mathrm{H}_{2} \mathrm{O}_{2}$ (Abdebayo et al. 2020). Auch werden die chemische Stabilität, Lagerfähigkeit und Fotostabilität als sehr gut bewertet (Zhou et al. 1997). So zeigten die vergangenen fluoreszenzspektroskopischen Messungen der Arbeitsgruppe mit dem Farbstoff Amplex UltraRed, in die auch im Rahmen dieser Dissertation erhobene Daten zur mitochondrialen $\mathrm{H}_{2} \mathrm{O}_{2}$-Produktion eingeflossen sind, dass kortikale und hippokampale Gewebeproben männlicher Rett-Mäuse im Vergleich zu Wildtypen eine signifikant höhere mitochondriale $\mathrm{H}_{2} \mathrm{O}_{2}$-Produktionsrate aufweisen (Can et al. 2019).

Die im Rahmen der vorliegenden Dissertation erworbenen Erkenntnisse zur $\mathrm{H}_{2} \mathrm{O}_{2}$ Produktion kortikaler Mitochondrien zeigten, dass die Proben unbehandelter Mecp $2^{-/ y_{-}}$ Männchen signifikant höhere Fluoreszenzintensitäten erzeugten und damit eine signifikant höhere $\mathrm{H}_{2} \mathrm{O}_{2}$-Produktionsrate aufwiesen als Vergleichsproben von WildtypMännchen. Auch unter antioxidativer Therapie veränderten sich die beschriebenen Gegebenheiten nicht. Allerdings entwickelten die Gewebeproben der Wildtypen unter AOF signifikant höhere $\mathrm{H}_{2} \mathrm{O}_{2}$-Produktionsraten im Vergleich $\mathrm{zu}$ den unbehandelten Wildtyp-Männchen. Die Antioxidantien-Therapie hatte also einen unbeabsichtigten Einfluss auf den Wildtyp und zeigte keine Verbesserungen in den Rett-Männchen. Diese Beobachtungen lassen sich derzeit nicht eindeutig erklären. Es bleibt außerdem offen, ob diese Entwicklungen einen negativen Effekt auf den Gesamtorganismus der Wildtypen mit sich bringen.

Auf der einen Seite ist es denkbar, dass die Mitochondrien durch das AOF generell eine höhere Funktions- und Widerstandsfähigkeit entwickeln. Dies sollte sich eindeutig im Rahmen detaillierter respirometrischer Analysen nachweisen lassen. Derartige Untersuchungen finden aktuell in der Arbeitsgruppe um Prof. M. Müller statt. Unter diesen Umständen wäre es z. B. möglich, dass die Mitochondrien der antioxidativ behandelten Rett-Mäuse im Isolierungsprozess eine höhere Überlebensrate aufweisen. Somit hätten die Suspensionen isolierter Mitochondrien einen höheren Reinheitsgrad an funktionsfähigen Mitochondrien, die insgesamt mehr $\mathrm{H}_{2} \mathrm{O}_{2}$ produzieren könnten. Dieser Effekt könnte ebenso für die antioxidativ behandelte Kontrollgruppe der Wildtypen gelten. Generell scheint es zur Validierung der Messmethode demnach ratsam, zukünftig die Reinheit der mitochondrialen Suspensionen zu überprüfen. Aufgrund der geringen Menge an gewinnbaren Mitochondrien und des hohen zeitlichen Aufwands, den eine solche Bestimmung mit sich bringt, kann diese Methode allerdings nicht für die genaue 
Ermittlung der Mitochondrienkonzentration vor Beginn einer jeden $\mathrm{H}_{2} \mathrm{O}_{2}$-Messung eingesetzt werden.

Des Weiteren soll an dieser Stelle nochmals angemerkt werden, dass Amplex UltraRed ausschließlich $\mathrm{H}_{2} \mathrm{O}_{2}$ detektieren kann und das verwendete Assay keine Rückschlüsse darauf erlaubt, wie die Zellen mit dem $\mathrm{H}_{2} \mathrm{O}_{2}$ umgehen und dieses detoxifizieren. Es wäre allerdings vorstellbar, dass durch das AOF eine effizientere Dismutation stattfindet und somit mehr $\mathrm{H}_{2} \mathrm{O}_{2}$ entsteht, dafür aber weniger Superoxidanionen verbleiben, die als deutlich reaktionsfreudiger und damit schädlicher gelten (Valko et al. 2007). Auf der anderen Seite könnte auch eine Übertherapie der Wildtypen stattgefunden haben. Die Redoxbalance ist ein empfindliches Gleichgewicht. Vergangene Studien an hippokampalen Schnitten ergaben sowohl bei einem Unter- als auch Überangebot an Antioxidantien Verschlechterungen der synaptischen Langzeitplastizität (Thiels et al. 2000). Zusätzlich bleibt unklar, in welcher Konzentration die supplementierten Antioxidantien die untersuchten neuronalen Gewebe erreichen und welche individuellen Unterschiede sich bei der Verstoffwechselung ergeben.

\subsection{Limitationen des Studiendesigns und Ausblick}

Anhand der Ergebnisse lassen sich abschließend die Limitationen des Studiendesigns anführen. Wie bereits mehrfach angesprochen, ist die individuell abgestimmte Dosierung der Futtertherapie ein Faktor, der nur schwer bestimmt werden kann. Eine regelmäßige Kontrolle der supplementierten Wirkstoffe in Serum und Liquor bei gleichzeitiger Bestimmung des individuellen Redoxstatus wäre ein denkbarer Ansatz zur Ermittlung des individuellen Bedarfs an Antioxidantien. Allerdings schließt ein physiologisches Serumlevel der Wirkstoffe metabolische Alterationen im neuronalen Gewebe nicht aus (Formichi et al. 1998). Zusätzlich wären solche Maßnahmen mit einer sehr hohen Belastung der Mäuse durch häufige Handhabung verbunden.

Gleichzeitig ist die orale Applikation der drei Wirkstoffe über das Futter abhängig von der individuellen Futteraufnahme und daher mit entsprechenden Schwankungen verbunden. So erfolgte die Dosierung auf der Grundlage von Durchschnittswerten der täglichen Nahrungsaufnahme einer gesunden Maus, die etwa 4 g pro Tag beträgt (Wolfensohn und Lloyd 2013). Betrachtet man nun das verwendete Mausmodell, so sind MeCP2-defiziente Männchen geprägt von typischer Rett-Symptomatik wie Ataxie, Verkrampfungen der Pfoten, Zahn- und Kieferfehlstellungen sowie Atemstörungen (Guy et 
al. 2001). Bei Weibchen fällt der Phänotyp häufig etwas milder aus (Shahbazian et al. 2002). Trotzdem könnten diese Begleiterscheinungen zumindest bei den männlichen Mäusen zu einer Erschwerung der Nahrungsaufnahme durch mangelhafte Koordination, Ausdauer und Kaufunktion führen. Passend zu dieser Annahme zeigen Rett-Patientinnen teilweise einen eher schlechten Ernährungszustand (Sierra et al. 2001). Schluckbeschwerden und Kauprobleme äußern sich häufig in Verdauungsstörungen und Unterernährung der Patientinnen (Weaving et al. 2005; Chahrour und Zoghbi 2007).

Des Weiteren ist in vergangenen Studien beschrieben worden, dass biochemische Anzeichen der Entwicklungsstörung im RTT den neurologischen Symptomen vorausgehen (De Felice et al. 2014). Demnach wäre zu diskutieren, ob eine AntioxidantienTherapie bereits $\mathrm{zu}$ einem früheren Zeitpunkt zur Verbesserung der Neurogenese einsetzen sollte. Da die Jungtiere des Mausmodells bis zum 20. Tag gesäugt werden, nehmen sie erst nach diesen drei Wochen ausschließlich feste Nahrung und damit die antioxidativen Wirkstoffe selbständig zu sich.

Außerdem gibt es in der Arbeitsgruppe um Prof. M. Müller seit kurzem eine neue Mauslinie, die mithilfe des Redoxindikators roGFP1 eine dynamische Überprüfung des Redoxstatus von Gewebeproben zulässt (Wagener et al. 2016). Nach Kreuzung mit RettMäusen könnten durch dieses Modell detailliertere Informationen zum Krankheitsverlauf des RTT und zu Auswirkungen von Antioxidantien-Therapien generiert werden (Müller 2019).

Die Erprobungsstudie über die Anwendung der oralen Antioxidantien-Therapie im RettMausmodell ist über diese Dissertation hinaus weitaus breiter angelegt. In diesem Zusammenhang wird eine Vielzahl diverser phänotypischer, systemischer, biochemischer und neurohistologischer Parameter beurteilt. Die in dieser Dissertation durchgeführten Analysen repräsentieren somit nur begrenzte Teilaspekte, die nach Beendigung der Studie in eine abschließende Beurteilung einfließen werden. Über die generelle und umfassende Wirksamkeit der AOF-Therapie kann daher zum jetzigen Zeitpunkt noch keine abschließende Bewertung erfolgen. 


\section{$5 \quad$ Zusammenfassung}

Diese Dissertation galt der Evaluierung einer oralen Antioxidantien-Therapie im Mausmodell für das Rett-Syndrom. Dabei handelt es sich um eine neurologische Entwicklungsstörung, geprägt von mitochondrialen Fehlfunktionen und einer nicht kompensierbaren Überproduktion von reaktiven Sauerstoffspezies. Die Folge ist eine Redoximbalance. Gleichzeitig sind Aktivität und Serumlevel von Antioxidantien im RettSyndrom verringert. Ein weit verbreiteter Therapieansatz im Rett-Syndrom ist demnach die Wiederherstellung und Stabilisierung der Redoxbalance.

Anknüpfend an Voruntersuchungen der Arbeitsgruppe um Prof. M. Müller, die positive Effekte des Vitamin-E-Derivats Trolox hervorbrachten, wurde im Rahmen dieser Dissertation die orale Supplementierung der antioxidativ wirksamen Substanzen Vitamin E, $\alpha$-Liponsäure und N-Acetylcystein an männlichen und weiblichen Mäusen unterschiedlichen Alters erprobt. Im Vordergrund standen dabei die Bestimmung von Körpergröße, Körpergewicht und Hirngewicht, die morphologische Analyse Nisslgefärbter Hirnschnitte sowie die fluoreszenzmikroskopische Messung der $\mathrm{H}_{2} \mathrm{O}_{2}$ Produktion isolierter kortikaler Mitochondrien mithilfe des Farbstoffes Amplex UltraRed.

Bei Betrachtung der Parameter Körpergröße, Körpergewicht und Hirngewicht ergab die Antioxidantien-Therapie bei Männchen der Altersklasse 50 Tage keine signifikanten Verbesserungen. Dahingegen bewirkte das Antioxidantien-Futter bei Rett-Weibchen der Altersklasse 50 Tage eine Zunahme der Körpergröße sowie des Hirngewichts auf das Niveau der Wildtyp-Weibchen und unterstreicht damit den milderen Phänotyp im weiblichen Mausmodell. Bei Weibchen der Altersklasse 400 Tage ist vor allem die Entwicklung eines adipösen Phänotyps der antioxidativ behandelten Rett-Mäuse auffällig, der sich zum jetzigen Zeitpunkt nicht eindeutig erklären lässt.

Aufgrund vergangener Analysen neuronaler Gewebeproben, die ergaben, dass RettPatientinnen geringere Hirngrößen, reduzierte Hippokampusflächen und kleinere Neurone in der hippokampalen CA1-Region aufweisen, wurden ähnliche Messungen auch im Rahmen dieser Dissertation durchgeführt. Dabei konnte die AntioxidantienTherapie Unterschiede zwischen Wildtyp und Rett-Maus in den Parametern kortikale Schichtdicke und Zellgröße bei Männchen (p50), in den Parametern Hemisphärenfläche und Zellgröße bei Weibchen (p50) und in den Kategorien Hippokampusfläche und Schichtdicke des stratum pyramidale der CA1-Region bei Weibchen (p400) im Sinne 
einer Wachstumszunahme bei den antioxidativ therapierten Rett-Mäusen erfolgreich aufheben. Die Antioxidantien-Supplementierung kann in Bezug auf die Entwicklung morphologischer Hirngewebeparameter somit als Therapieerfolg bewertet werden.

Anders gestalteten sich die Ergebnisse bei der Ermittlung der mitochondrialen $\mathrm{H}_{2} \mathrm{O}_{2}$ Produktion, die bei Rett-Mäusen generell deutlich erhöht ist. Hier ergaben sich unerwartete Auswirkungen der antioxidativen Behandlung auf den Wildtyp. Mitochondrien aus kortikalen Gewebeproben von antioxidativ behandelten WildtypMännchen (p50) produzierten signifikant höhere $\mathrm{H}_{2} \mathrm{O}_{2}$-Mengen als die der unbehandelten Vergleichsgruppen. Welche genauen Auswirkungen dies auf die zelluläre Redoxbalance in den behandelten Wildtyp-Männchen hat, bleibt dabei offen. Trotzdem wird an dieser Stelle die hohe Komplexität einer ausgeglichenen Redoxbalance durch eine exakte individuelle Dosierung von Antioxidantien deutlich.

Zukünftig sollte demnach weiterhin die passende individuelle Dosierung von Antioxidantien im Fokus stehen. Überdies könnte eine neue Mauslinie der Arbeitsgruppe um Prof. M. Müller, die eine dynamische Überprüfung des Redoxstatus mithilfe des Redoxindikators roGFP1 zulässt, nach Kreuzung mit Rett-Mäusen für detailliertere Aussagen zu Auswirkungen von Antioxidantien auf das Rett-Mausmodell sorgen. Gleichzeitig sollte die allgemeine Wirkungsweise von antioxidativen Substanzen bei alleiniger und kombinierter Verabreichung weiterhin Bestandteil der Forschung bleiben, um die Entstehung und den Erhalt eines Redoxgleichgewichts besser zu verstehen. Zur abschließenden umfassenden Beurteilung der angewendeten Antioxidantien-Therapie sind außerdem noch ausstehende Resultate weiterer biochemischer, systemischer und phänotypischer Analysen abzuwarten. 


\section{$6 \quad$ Literaturverzeichnis}

Abdebayo OL, Dewenter I, Rinne L, Golubiani G, Solomonia R, Müller M (2020): Intensified mitochondrial hydrogen peroxide release occurs in all brain regions, affects male as well as female Rett mice, and constitutes a life-long burden. Arch Biochem Biophys $\underline{696}, 108666$

Aldini G, Altomare A, Baron G, Vistoli G, Carini M, Borsani L, Sergio F (2018): NAcetylcysteine as an antioxidant and disulphide breaking agent: the reasons why. Free Radic Res $\underline{52}$, 751-762

Amir RE, Van den Veyver IB, Wan M, Tran CQ, Francke U, Zoghbi HY (1999): Rett syndrome is caused by mutations in X-linked $M E C P 2$, encoding methyl-CpG-binding protein 2. Nat Genet $\underline{23}, 185-188$

Anderson A, Wong K, Jacoby P, Downs J, Leonard H (2014): Twenty years of surveillance in Rett syndrome: what does this tell us? Orphanet J Rare Dis $\underline{9}, 87$

Archer HL, Evans JC, Millar DS, Thompson PW, Kerr AM, Leonard H, Christodoulou J, Ravine D, Lazarou L, Grove L (2006): NTNG1 mutations are a rare cause of Rett syndrome. Am J Med Genet A $\underline{140}$, 691-694

Ariani F, Hayek G, Rondinella D, Artuso R, Mencarelli MA, Spanhol-Rosseto A, Pollazzon M, Buoni S, Spiga O, Ricciardi S et al. (2008): FOXG1 is responsible for the congenital variant of Rett syndrome. Am J Hum Genet $\underline{83}$, 89-93

Armstrong D, Dunn JK, Antalffy B, Trivedi R (1995): Selective dendritic alterations in the cortex of Rett syndrome. J Neuropathol Exp Neurol 54, 195-201

Asaka Y, Jugloff DG, Zhang L, Eubanks JH, Fitzsimonds RM (2006): Hippocampal synaptic plasticity is impaired in the Mecp2-null mouse model of Rett syndrome. Neurobiol Dis $\underline{21}, 217-227$

Avshalumov MV, Rice ME (2002): NMDA receptor activation mediates hydrogen peroxide-induced pathophysiology in rat hippocampal slices. J Neurophysiol $\underline{87}$, 28962903

Bai J, Cederbaum AI (2001): Mitochondrial catalase and oxidative injury. Biol Signals Recept 10, 189-199 
Balaban RS, Nemoto S, Finkel T (2005): Mitochondria, oxidants, and aging. Cell $\underline{120}$, 483-495

Bauman ML, Kemper TL, Arin DM (1995): Pervasive neuroanatomic abnormalities of the brain in three cases of Rett's syndrome. Neurology $\underline{45}, 1581-1586$

Bebensee DF, Can K, Müller M (2017): Increased mitochondrial mass and cytosolic redox imbalance in hippocampal astrocytes of a mouse model of Rett syndrome: Subcellular changes revealed by ratiometric imaging of JC-1 and roGFP1 fluorescence. Oxid Med Cell Longev 2017, 3064016

Behl C, Moosmann B (2002): Oxidative nerve cell death in Alzheimer's disease and stroke: antioxidants as neuroprotective compounds. Biol Chem $\underline{383}, 521-536$

Belichenko NP, Belichenko PV, Li HH, Mobley WC, Francke U (2008): Comparative study of brain morphology in Mecp 2 mutant mouse models of Rett syndrome. J Comp Neurol 508, 184-195

Belichenko PV, Wright EE, Belichenko NP, Masliah E, Li HH, Mobley WC, Francke U (2009): Widespread changes in dendritic and axonal morphology in Mecp2-mutant mouse models of Rett syndrome: evidence for disruption of neuronal networks. J Comp Neurol $\underline{514}, 240-258$

Bertani I, Rusconi L, Bolognese F, Forlani G, Conca B, De Monte L, Badaracco G, Landsberger N, Kilstrup-Nielsen C (2006): Functional consequences of mutations in CDKL5, an X-linked gene involved in infantile spasms and mental retardation. $\mathrm{J}$ Biol Chem 281, 32048-32056

Boveris A, Chance B (1973): The mitochondrial generation of hydrogen peroxide: General properties and effect of hyperbaric oxygen. Biochem $\mathrm{J} \underline{134}, 707-716$

Boveris A, Cadenas E, Stoppani AO (1976): Role of ubiquinone in the mitochondrial generation of hydrogen peroxide. Biochem $\mathrm{J} \underline{156}, 435-444$

Bradford MM (1976): A rapid and sensitive method for the quantitation of microgram quantities of protein utilizing the principle of protein-dye binding. Anal Biochem $\underline{72}, 248$ 254

Brand MD (2010): The sites and topology of mitochondrial superoxide production. Exp Gerontol $\underline{45}, 466-472$ 
Brigelius-Flohé R, Traber MG (1999): Vitamin E: function and metabolism. Faseb J $\underline{13}$, 1145-1155

Buettner GR (1993): The pecking order of free radicals and antioxidants: lipid peroxidation, $\alpha$-tocopherol, and ascorbate. Arch Biochem Biophys $\underline{300}$, 535-543

Burton G, Ingold K (1981): Autoxidation of biological molecules. 1. Antioxidant activity of vitamin $\mathrm{E}$ and related chain-breaking phenolic antioxidants in vitro. J Am Chem Soc $\underline{103}, 6472-6477$

Buschdorf JP, Strätling WH (2004): A WW domain binding region in methyl-CpGbinding protein MeCP2: impact on Rett syndrome. J Mol Med 2, 135-143

Buyse IM, Fang P, Hoon KT, Amir RE, Zoghbi HY, Roa BB (2000): Diagnostic testing for Rett syndrome by DHPLC and direct sequencing analysis of the MECP2 gene: identification of several novel mutations and polymorphisms. Am J Hum Genet $\underline{67}, 1428$ 1436

Calfa G, Percy AK, Pozzo-Miller L (2011): Experimental models of Rett syndrome based on MeCP2 dysfunction. Exp Biol Med 236, 3-19

Can K, Menzfeld C, Rinne L, Rehling P, Kügler S, Golubiani G, Dudek J, Müller M (2019): Neuronal redox-imbalance in Rett syndrome affects mitochondria as well as cytosol, and is accompanied by intensified mitochondrial $\mathrm{O}_{2}$ consumption and ROS release. Front Physiol 10, 479

Chae HZ, Kim HJ, Kang SW, Rhee SG (1999): Characterization of three isoforms of mammalian peroxiredoxin that reduce peroxides in the presence of thioredoxin. Diabetes Res Clin Pract $\underline{45}$, 101-112

Chahrour M, Zoghbi HY (2007): The story of Rett syndrome: from clinic to neurobiology. Neuron $\underline{56}, 422-437$

Chahrour M, Jung SY, Shaw C, Zhou X, Wong ST, Qin J, Zoghbi HY (2008): MeCP2, a key contributor to neurological disease, activates and represses transcription. Science $\underline{320}, 1224-1229$

Chan DC (2006): Mitochondria: dynamic organelles in disease, aging, and development. Cell $\underline{125}, 1241-1252$

Chan PH (1996): Role of oxidants in ischemic brain damage. Stroke 27, 1124-1129 
Chapleau CA, Lane J, Pozzo-Miller L, Percy AK (2013): Evaluation of current pharmacological treatment options in the management of Rett syndrome: from the present to future therapeutic alternatives. Curr Clin Pharmacol $\underline{8}$, 358-369

Chen RZ, Akbarian S, Tudor M, Jaenisch R (2001): Deficiency of methyl-CpG binding protein-2 in CNS neurons results in a Rett-like phenotype in mice. Nat Genet 27, 327-331

Christen HJ, Hanefeld F (1995): Male Rett variant. Neuropediatrics 느, 81-82

Coker SB, Melnyk AR (1991): Rett syndrome and mitochondrial enzyme deficiencies. J Child Neurol $\underline{6}, 164-166$

Cornford ME, Philippart M, Jacobs B, Scheibel AB, Vinters HV (1994): Neuropathology of Rett syndrome: case report with neuronal and mitochondrial abnormalities in the brain. J Child Neurol $\underline{9}, 424-431$

Dahl HH (1998): Getting to the nucleus of mitochondrial disorders: identification of respiratory chain-enzyme genes causing Leigh syndrome. Am J Hum Genet $\underline{63}$, 15941597

De Felice C, Signorini C, Leoncini S, Pecorelli A, Durand T, Valacchi G, Ciccoli L, Hayek J (2012): The role of oxidative stress in Rett syndrome: an overview. Ann N Y Acad Sci 1259, 121-135

De Felice C, Ciccoli L, Leoncini S, Signorini C, Rossi M, Vannuccini L, Guazzi G, Latini G, Comporti M, Valacchi G et al. (2009): Systemic oxidative stress in classic Rett syndrome. Free Radic Biol Med 47, 440-448

De Felice C, Signorini C, Durand T, Ciccoli L, Leoncini S, D'Esposito M, Filosa S, Oger C, Guy A, Bultel-Ponce V et al. (2012): Partial rescue of Rett syndrome by $\omega-3$ polyunsaturated fatty acids (PUFAs) oil. Genes Nutr $\underline{7}, 447-458$

De Felice C, Della Ragione F, Signorini C, Leoncini S, Pecorelli A, Ciccoli L, Scalabri F, Marracino F, Madonna M, Belmonte $G$ et al. (2014): Oxidative brain damage in Mecp2-mutant murine models of Rett syndrome. Neurobiol Dis $\underline{68}$, 66-77

De Filippis B, Valenti D, de Bari L, De Rasmo D, Musto M, Fabbri A, Ricceri L, Fiorentini C, Laviola G, Vacca RA (2015): Mitochondrial free radical overproduction due to respiratory chain impairment in the brain of a mouse model of Rett syndrome: protective effect of CNF1. Free Radic Biol Med $\underline{83}$, 167-177 
Dean RT, Fu S, Stocker R, Davies MJ (1997): Biochemistry and pathology of radicalmediated protein oxidation. Biochem J $\underline{324}$, 1-18

Dotti MT, Manneschi L, Malandrini A, De Stefano N, Caznerale F, Federico A (1993): Mitochondrial dysfunction in Rett syndrome. An ultrastructural and biochemical study. Brain Dev 15, 103-106

Eeg-Olofsson O, Al-Zuhair AG, Teebi AS, Al-Essa MM (1988): Abnormal mitochondria in the Rett syndrome. Brain Dev 10, 260-262

Eeg-Olofsson O, Al-Zuhair AG, Teebi AS, Daoud AS, Zaki M, Besisso MS, Al-Essa MM (1990): Rett syndrome: a mitochondrial disease? J Child Neurol $\underline{5}, 210-214$

Enns GM, Cohen BH (2017): Clinical trials in mitochondrial disease: an update con EPI743 and RPI03. J Inborn Errors Metab Screen 5, 1-7

Erecinska M, Silver IA (1989): ATP and brain function. J Cereb Blood Flow Metab $\underline{9}$, 219

Fehr S, Wilson M, Downs J, Williams S, Murgia A, Sartori S, Vecchi M, Ho G, Polli R, Psoni S et al. (2013): The CDKL5 disorder is an independent clinical entity associated with early-onset encephalopathy. Eur J Hum Genet 21, 266-273

Fischer M, Reuter J, Gerich FJ, Hildebrandt B, Hägele S, Katschinski D, Müller M (2009): Enhanced hypoxia susceptibility in hippocampal slices from a mouse model of Rett syndrome. J Neurophysiol 101, 1016-1032

Formichi P, Battisti C, Dotti MT, Hayek G, Zappella M, Federico A (1998): Vitamin E serum levels in Rett syndrome. J Neurol Sci 156, 227-230

Foster KA, Galeffi F, Gerich FJ, Turner DA, Müller M (2006): Optical and pharmacological tools to investigate the role of mitochondria during oxidative stress and neurodegeneration. Prog Neurobiol $\underline{79}, 136-171$

Gibson JH, Slobedman B, K NH, Williamson SL, Minchenko D, El-Osta A, Stern JL, Christodoulou J (2010): Downstream targets of methyl CpG binding protein 2 and their abnormal expression in the frontal cortex of the human Rett syndrome brain. BMC Neurosci $\underline{11}, 53$ 
Gilgun-Sherki Y, Melamed E, Offen D (2004): The role of oxidative stress in the pathogenesis of multiple sclerosis: the need for effective antioxidant therapy. J Neurol $\underline{251}, 261-268$

Girard M, Couvert P, Carrié A, Tardieu M, Chelly J, Beldjord C, Bienvenu T (2001): Parental origin of de novo MECP2 mutations in Rett syndrome. Eur J Hum Genet $\underline{9}, 231$ 236

Gnaiger E, Kuznetsov AV, Schneeberger S, Seiler R, Brandacher G, Steurer W, Margreiter R: Mitochondria in the cold, In: Heldmaier G, Bach MF and Klaus S (Hrsg.): Life in the Cold. Springer, Berlin 2000, 431-442

Großer E, Hirt U, Janc OA, Menzfeld C, Fischer M, Kempkes B, Vogelgesang S, Manzke TU, Opitz L, Salinas-Riester G et al. (2012): Oxidative burden and mitochondrial dysfunction in a mouse model of Rett syndrome. Neurobiol Dis $\underline{48}, 102-114$

Guy J, Hendrich B, Holmes M, Martin JE, Bird A (2001): A mouse Mecp2-null mutation causes neurological symptoms that mimic Rett syndrome. Nat Genet 27, 322-326

Guy J, Gan J, Selfridge J, Cobb S, Bird A (2007): Reversal of neurological defects in a mouse model of Rett syndrome. Science $\underline{315}, 1143-1147$

Hagberg B (1985): Rett syndrome: Swedish approach to analysis of prevalence and cause. Brain Dev $\underline{7}, 276-280$

Hagberg B (1995): Rett syndrome: clinical peculiarities and biological mysteries. Acta Paediatr $\underline{84}$, 971-976

Hagberg B, Witt-Engerström I (1986): Rett syndrome: a suggested staging system for describing impairment profile with increasing age towards adolescence. Am J Med Genet Suppl $1,47-59$

Hagberg B, Aicardi J, Dias K, Ramos O (1983): A progressive syndrome of autism, dementia, ataxia, and loss of purposeful hand use in girls: Rett's syndrome: report of 35 cases. Ann Neurol 14, 471-479

Hagberg B, Goutières F, Hanefeld F, Rett A, Wilson J (1985): Rett syndrome: criteria for inclusion and exclusion. Brain Dev $\underline{7}, 372-373$

Hagberg BA, Skjeldal OH (1994): Rett variants: a suggested model for inclusion criteria. Pediatr Neurol 11, 5-11 
Huppke P, Laccone F, Krämer N, Engel W, Hanefeld F (2000): Rett syndrome: analysis of $M E C P 2$ and clinical characterization of 31 patients. Hum Mol Genet $\underline{9}, 1369-1375$

Jan MM, Dooley JM, Gordon KE (1999): Male Rett syndrome variant: application of diagnostic criteria. Pediatr Neurol 20, 238-240

Janc OA, Müller M (2014): The free radical scavenger Trolox dampens neuronal hyperexcitability, reinstates synaptic plasticity, and improves hypoxia tolerance in a mouse model of Rett syndrome. Front Cell Neurosci $\underline{8}, 56$

Janc OA, Hüser MA, Dietrich K, Kempkes B, Menzfeld C, Hülsmann S, Müller M (2016): Systemic radical scavenger treatment of a mouse model of Rett syndrome: merits and limitations of the vitamin E derivative Trolox. Front Cell Neurosci 10, 266

Jentarra GM, Olfers SL, Rice SG, Srivastava N, Homanics GE, Blue M, Naidu S, Narayanan V (2010): Abnormalities of cell packing density and dendritic complexity in the MeCP2 A140V mouse model of Rett syndrome/X-linked mental retardation. BMC Neurosci $\underline{11}, 19$

Jian L, Nagarajan L, De Klerk N, Ravine D, Bower C, Anderson A, Williamson S, Christodoulou J, Leonard H (2006): Predictors of seizure onset in Rett syndrome. J Pediatr $\underline{149}$, 542-547

Jones PL, Veenstra GJ, Wade PA, Vermaak D, Kass SU, Landsberger N, Strouboulis J, Wolffe AP (1998): Methylated DNA and MeCP2 recruit histone deacetylase to repress transcription. Nat Genet $\underline{19}, 187-191$

Julu PO, Kerr AM, Apartopoulos F, Al-Rawas S, Engerström IW, Engerström L, Jamal GA, Hansen S (2001): Characterisation of breathing and associated central autonomic dysfunction in the Rett disorder. Arch Dis Child 포, 29-37

Jung BP, Jugloff DG, Zhang G, Logan R, Brown S, Eubanks JH (2003): The expression of methyl $\mathrm{CpG}$ binding factor MeCP2 correlates with cellular differentiation in the developing rat brain and in cultured cells. J Neurobiol 55, 86-96

Katz DM, Bird A, Coenraads M, Gray SJ, Menon DU, Philpot BD, Tarquinio DC (2016): Rett Syndrome: Crossing the Threshold to Clinical Translation. Trends Neurosci 39, 100113

Klann E, Roberson ED, Knapp LT, Sweatt JD (1998): A role for superoxide in protein kinase $\mathrm{C}$ activation and induction of long-term potentiation. J Biol Chem $\underline{273}$, 4516-4522 
Kong J, Xu Z (1998): Massive mitochondrial degeneration in motor neurons triggers the onset of amyotrophic lateral sclerosis in mice expressing a mutant SOD1. J Neurosci 18 , 3241-3250

Kriaucionis S, Paterson A, Curtis J, Guy J, Macleod N, Bird A (2006): Gene expression analysis exposes mitochondrial abnormalities in a mouse model of Rett syndrome. Mol Cell Biol 26, 5033-5042

Kron M, Müller M (2010): Impaired hippocampal $\mathrm{Ca}^{2+}$ homeostasis and concomitant $\mathrm{K}^{+}$ channel dysfunction in a mouse model of Rett syndrome during anoxia. Neuroscience $\underline{171}, 300-315$

Kushnareva Y, Murphy AN, Andreyev A (2002): Complex I-mediated reactive oxygen species generation: modulation by cytochrome $\mathrm{c}$ and $\mathrm{NAD}(\mathrm{P})^{+}$oxidation-reduction state. Biochem J $\underline{368}, 545-553$

Lawson-Yuen A, Liu D, Han L, Jiang ZI, Tsai GE, Basu AC, Picker J, Feng J, Coyle JT (2007): Ube3a mRNA and protein expression are not decreased in Mecp2 R168X mutant mice. Brain Res 1180, 1-6

Lenaz G (1998): Role of mitochondria in oxidative stress and ageing. Biochim Biophys Acta 1366, 53-67

Lenaz G, Bovina C, Formiggini G, Parenti Castelli G (1999): Mitochondria, oxidative stress, and antioxidant defences. Acta Biochim Pol $\underline{46}, 1-21$

Lenaz G, Baracca A, Fato R, Genova ML, Solaini G (2006): New insights into structure and function of mitochondria and their role in aging and disease. Antioxid Redox Signal $\underline{8}, 417-437$

Lewis JD, Meehan RR, Henzel WJ, Maurer-Fogy I, Jeppesen P, Klein F, Bird A (1992): Purification, sequence, and cellular localization of a novel chromosomal protein that binds to methylated DNA. Cell $\underline{69}, 905-914$

López-Erauskin J, Fourcade S, Galino J, Ruiz M, Schlüter A, Naudi A, Jove M, PorteroOtin M, Pamplona R, Ferrer I et al. (2011): Antioxidants halt axonal degeneration in a mouse model of X-adrenoleukodystrophy. Ann Neurol 70, 84-92

Lyon MF (1961): Gene action in the X-chromosome of the mouse (Mus musculus L.). Nature 190, 372-373 
Maffei S, De Felice C, Cannarile P, Leoncini S, Signorini C, Pecorelli A, Montomoli B, Lunghetti S, Ciccoli L, Durand $\mathrm{T}$ et al. (2014): Effects of omega-3 PUFAs supplementation on myocardial function and oxidative stress markers in typical Rett syndrome. Mediators Inflamm 2014, 983178

Masuyama T, Matsuo M, Jing JJ, Tabara Y, Kitsuki K, Yamagata H, Kan Y, Miki T, Ishii K, Kondo I (2005): Classic Rett syndrome in a boy with R133C mutation of MECP2. Brain Dev 27, 439-442

Matsuishi T, Urabe F, Percy AK, Komori H, Yamashita Y, Schultz RS, Ohtani Y, Kuriya N, Kato H (1994): Abnormal carbohydrate metabolism in cerebrospinal fluid in Rett syndrome. J Child Neurol $\underline{9}, 26-30$

Monk M, Boubelik M, Lehnert S (1987): Temporal and regional changes in DNA methylation in the embryonic, extraembryonic and germ cell lineages during mouse embryo development. Development 99, 371-382

Moreira PI, Zhu X, Wang X, Lee HG, Nunomura A, Petersen RB, Perry G, Smith MA (2010): Mitochondria: a therapeutic target in neurodegeneration. Biochim Biophys Acta $\underline{1802}, 212-220$

Müller M (2019): Disturbed redox homeostasis and oxidative stress: Potential players in the developmental regression in Rett syndrome. Neurosci Biobehav Rev $\underline{98}, 154-163$

Müller M, Can K (2014): Aberrant redox homoeostasis and mitochondrial dysfunction in Rett syndrome. Biochem Soc Trans $\underline{42}, 959-964$

Nan X, Ng HH, Johnson CA, Laherty CD, Turner BM, Eisenman RN, Bird A (1998): Transcriptional repression by the methyl-CpG-binding protein $\mathrm{MeCP} 2$ involves a histone deacetylase complex. Nature $\underline{393}, 386-389$

Nance E, Kambhampati SP, Smith ES, Zhang Z, Zhang F, Singh S, Johnston MV, Kannan RM, Blue ME, Kannan S (2017): Dendrimer-mediated delivery of N-acetyl cysteine to microglia in a mouse model of Rett syndrome. J Neuroinflammation $\underline{14}, 252$

Ouahchi K, Arita M, Kayden H, Hentati F, Ben Hamida M, Sokol R, Arai H, Inoue K, Mandel JL, Koenig M (1995): Ataxia with isolated vitamin E deficiency is caused by mutations in the $\alpha$-tocopherol transfer protein. Nat Genet $\underline{9}, 141-145$

Packer L, Witt EH, Tritschler HJ (1995): Alpha-Lipoic acid as a biological antioxidant. Free Radic Biol Med 19, 227-250 
Panighini A, Duranti E, Santini F, Maffei M, Pizzorusso T, Funel N, Taddei S, Bernardini N, Ippolito C, Virdis A et al. (2013): Vascular dysfunction in a mouse model of Rett syndrome and effects of curcumin treatment. PLoS One $\underline{8}$, e64863

Paxinos G, Franklin KBJ: The Mouse Brain in Stereotoxic Coordinates. Academic Press, San Diego 2001

Pecorelli A, Leoni G, Cervellati F, Canali R, Signorini C, Leoncini S, Cortelazzo A, De Felice C, Ciccoli L, Hayek J et al. (2013): Genes related to mitochondrial functions, protein degradation, and chromatin folding are differentially expressed in lymphomonocytes of Rett syndrome patients. Mediators Inflamm 2013, 137629

Pellmar TC (1995): Use of brain slices in the study of free-radical actions. J Neurosci Methods $\underline{59}$, 93-98

Reeve AK, Krishnan KJ, Turnbull DM (2008): Age related mitochondrial degenerative disorders in humans. Biotechnol J $\underline{3}, 750-756$

Rett A (1966): Über ein eigenartiges hirnatrophisches Syndrom bei Hyperammonämie im Kindesalter. Wien Med Wochenschr 116, 723-726

Ruch A, Kurczynski TW, Velasco ME (1989): Mitochondrial alterations in Rett syndrome. Pediatr Neurol $\underline{5}, 320-323$

Samaco RC, Fryer JD, Ren J, Fyffe S, Chao HT, Sun Y, Greer JJ, Zoghbi HY, Neul JL (2008): A partial loss of function allele of methyl-CpG-binding protein 2 predicts a human neurodevelopmental syndrome. Hum Mol Genet 17, 1718-1727

Saywell V, Viola A, Confort-Gouny S, Le Fur Y, Villard L, Cozzone PJ (2006): Brain magnetic resonance study of Mecp2 deletion effects on anatomy and metabolism. Biochem Biophys Res Commun $\underline{340}$, 776-783

Scala E, Ariani F, Mari F, Caselli R, Pescucci C, Longo I, Meloni I, Giachino D, Bruttini M, Hayek $G$ et al. (2005): CDKL5/STK9 is mutated in Rett syndrome variant with infantile spasms. J Med Genet $\underline{42}$, 103-107

Schulz JB, Beal MF (1994): Mitochondrial dysfunction in movement disorders. Curr Opin Neurol 프, 333-339 
Schwartzman J, Bernardino A, Nishimura A, Gomes RR, Zatz M (2001): Rett syndrome in a boy with a $47, \mathrm{XXY}$ karyotype confirmed by a rare mutation in the MECP2 gene. Neuropediatrics $\underline{32}, 162-164$

Shahbazian M, Young J, Yuva-Paylor L, Spencer C, Antalffy B, Noebels J, Armstrong D, Paylor R, Zoghbi H (2002): Mice with truncated MeCP2 recapitulate many Rett syndrome features and display hyperacetylation of histone H3. Neuron $\underline{35}$, 243-254

Sierra C, Vilaseca MA, Brandi N, Artuch R, Mira A, Nieto M, Pineda M (2001): Oxidative stress in Rett syndrome. Brain Dev 23, S236-239

Sofic E, Riederer P, Killian W, Rett A (1987): Reduced concentrations of ascorbic acid and glutathione in a single case of Rett syndrome: a postmortem brain study. Brain Dev $\underline{9}, 529-531$

Steffenburg U, Hagberg G, Hagberg B (2001): Epilepsy in a representative series of Rett syndrome. Acta Paediatr 90, 34-39

Suter B, Treadwell-Deering D, Zoghbi HY, Glaze DG, Neul JL (2014): Brief report: $M E C P 2$ mutations in people without Rett syndrome. J Autism Dev Disord 44, 703-711

Tabrizi SJ, Workman J, Hart PE, Mangiarini L, Mahal A, Bates G, Cooper JM, Schapira AH (2000): Mitochondrial dysfunction and free radical damage in the Huntington R6/2 transgenic mouse. Ann Neurol $\underline{47}, 80-86$

Tao J, Van Esch H, Hagedorn-Greiwe M, Hoffmann K, Moser B, Raynaud M, Sperner J, Fryns JP, Schwinger E, Gécz J et al. (2004): Mutations in the X-linked cyclin-dependent kinase-like 5 (CDKL5/STK9) gene are associated with severe neurodevelopmental retardation. Am J Hum Genet $\underline{75}$, 1149-1154

Thiels E, Urban NN, Gonzalez-Burgos GR, Kanterewicz BI, Barrionuevo G, Chu CT, Oury TD, Klann E (2000): Impairment of long-term potentiation and associative memory in mice that overexpress extracellular superoxide dismutase. J Neurosci $\underline{20}, 7631-7639$

Trappe R, Laccone F, Cobilanschi J, Meins M, Huppke P, Hanefeld F, Engel W (2001): $M E C P 2$ mutations in sporadic cases of Rett syndrome are almost exclusively of paternal origin. Am J Hum Genet $\underline{68}$, 1093-1101

Turrens JF (1997): Superoxide production by the mitochondrial respiratory chain. Biosci Rep 17, 3-8 
Turrens JF (2003): Mitochondrial formation of reactive oxygen species. J Physiol 552, 335-344

Turrens JF, Boveris A (1980): Generation of superoxide anion by the NADH dehydrogenase of bovine heart mitochondria. Biochem J 191, 421-427

Uttara B, Singh AV, Zamboni P, Mahajan RT (2009): Oxidative stress and neurodegenerative diseases: a review of upstream and downstream antioxidant therapeutic options. Curr Neuropharmacol $\underline{7}, 65-74$

Valenti D, De Bari L, De Filippis B, Henrion-Caude A, Vacca RA (2014): Mitochondrial dysfunction as a central actor in intellectual disability-related diseases: an overview of Down syndrome, autism, Fragile X and Rett syndrome. Neurosci Biobehav Rev $\underline{46}$, 202217

Valko M, Leibfritz D, Moncol J, Cronin MT, Mazur M, Telser J (2007): Free radicals and antioxidants in normal physiological functions and human disease. Int $\mathbf{J}$ Biochem Cell Biol $\underline{39}, 44-84$

Villard L (2007): MECP2 mutations in males. J Med Genet $\underline{44}$, 417-423

Wagener KC, Kolbrink B, Dietrich K, Kizina KM, Terwitte LS, Kempkes B, Bao G, Müller M (2016): Redox-indicator mice stably expressing genetically-encoded neuronal roGFP: Versatile tools to decipher subcellular redox dynamics in neuropathophysiology. Antioxid Redox Signal 25, 41-58

Wan M, Lee SS, Zhang X, Houwink-Manville I, Song HR, Amir RE, Budden S, Naidu S, Pereira JL, Lo IF et al. (1999): Rett syndrome and beyond: recurrent spontaneous and familial MECP2 mutations at CpG hotspots. Am J Hum Genet $\underline{65}$, 1520-1529

Weaving LS, Ellaway CJ, Gécz J, Christodoulou J (2005): Rett syndrome: clinical review and genetic update. J Med Genet $\underline{42}, 1-7$

Weaving LS, Christodoulou J, Williamson SL, Friend KL, McKenzie OL, Archer H, Evans J, Clarke A, Pelka GJ, Tam PP et al. (2004): Mutations of CDKL5 cause a severe neurodevelopmental disorder with infantile spasms and mental retardation. Am J Hum Genet $\underline{75}$, 1079-1093

Wegener E, Brendel C, Fischer A, Hülsmann S, Gärtner J, Huppke P (2014): Characterization of the MeCP2 R168X knockin mouse model for Rett syndrome. PLoS One $\underline{9}$, e115444 
Weisiger RA, Fridovich I (1973): Mitochondrial superoxide dismutase site of synthesis and intramitochondrial localization. J Biol Chem $\underline{248}$, 4793-4796

Wolfensohn S, Lloyd M: Handbook of Laboratory Animal Management and Welfare. Wiley-Blackwell, Oxford 2013

Young JI, Zoghbi HY (2004): X-chromosome inactivation patterns are unbalanced and affect the phenotypic outcome in a mouse model of Rett syndrome. Am J Hum Genet $\underline{74}$, 511-520

Young JI, Hong EP, Castle JC, Crespo-Barreto J, Bowman AB, Rose MF, Kang D, Richman R, Johnson JM, Berget S et al. (2005): Regulation of RNA splicing by the methylation-dependent transcriptional repressor methyl-CpG binding protein 2. Proc Natl Acad Sci U S A 102, 17551-17558

Zhang L, He J, Jugloff DG, Eubanks JH (2008): The MeCP2-null mouse hippocampus displays altered basal inhibitory rhythms and is prone to hyperexcitability. Hippocampus $\underline{18}, 294-309$

Zhou M, Diwu Z, Panchuk-Voloshina N, Haugland RP (1997): A stable nonfluorescent derivative of resorufin for the fluorometric determination of trace hydrogen peroxide: applications in detecting the activity of phagocyte NADPH oxidase and other oxidases. Anal Biochem 253, 162-168

Zoghbi HY, Percy AK, Schultz RJ, Fill C (1990): Patterns of X chromosome inactivation in the Rett syndrome. Brain Dev 12, 131-135 


\section{Danksagung}

Mein besonderer Dank gilt an dieser Stelle meinem Doktorvater, Prof. Dr. Michael Müller, für die großartige Unterstützung und engagierte Betreuung. Sowohl bei theoretischen als auch praktischen Herausforderungen stand er mir stets mit wertvollen Anregungen zur Seite und ermöglichte mir auf diese Weise einen besonderen Zugang zur Bearbeitung wissenschaftlicher Fragestellungen.

Ganz besonders möchte ich mich auch bei Belinda Kempkes, der technischen Assistentin der Arbeitsgruppe, für ihre fachliche Unterstützung bei praktischen Versuchen und ihre herzliche sowie kollegiale Art bedanken.

Zusätzlich möchte ich mich bei meinem Zweitbetreuer, Prof. Dr. Thomas Dresbach, für die Begutachtung meiner Dissertation und die konstruktiven Diskussionen im Rahmen der Vorstellungen der Fortschrittsberichte bedanken.

Außerdem danke ich meinem Co-Doktoranden Gocha Golubiani, mit dem ich durch regen fachlichen Austausch die Messmethode der mitochondrialen $\mathrm{H}_{2} \mathrm{O}_{2}$-Produktion optimieren konnte.

Vielen Dank auch an die gesamte Arbeitsgruppe Müller und Arbeitsgruppe Hülsmann für das hervorragende Arbeitsklima und die bedingungslose Hilfsbereitschaft.

Aaron Lang und Yannick Rinne möchte ich abschließend für das konstruktive und kritische Lektorat dieser Arbeit danken. 